Políticas para servidores web baseados em sessões visando qualidade e diferenciação de serviços

\author{
Alessandra Kelli Barbato
}



SERVIÇO DE PÓS-GRADUAÇÃO DO ICMC-USP

Data de Depósito : 08/05/2008

Assinatura :

\title{
Políticas para servidores web baseados em sessões visando qualidade e diferenciação de serviços*
}

\author{
Alessandra Kelli Barbato \\ Orientadora: Profㄹ․ Dr $\underline{\underline{a}}$. Regina Helena Carlucci Santana
}

Dissertação apresentada ao Instituto de Ciências Matemáticas e de Computação - ICMC-USP, como parte dos requisitos para obtenção do título de Mestre em Ciências de Computação e Matemática Computacional.

USP - São Carlos

Maio de 2008

* Agradecimentos ao CNPq pelo apoio parcial dado a este trabalho. 



\section{Resumo}

Este trabalho propõe políticas para servidores Web baseados em sessões, visando ao oferecimento de garantias de qualidade de serviço (Quality of Service - QoS) a seus usuários. Para o fornecimento de QoS, dois tipos de políticas são consideradas: as responsáveis pela diferenciação de serviços e as responsáveis pelo controle de admissão. Alguns algoritmos de escalonamento foram desenvolvidos com o objetivo de oferecer melhores serviços para as sessões prioritárias: o algoritmo de escalonamento baseado em sessão (SBSA) e o algoritmo de escalonamento baseado em sessão com diferenciação de serviços (SBSA-DS). Quanto ao controle de admissão, foram consideradas duas novas políticas, as quais utilizam diferentes parâmetros para a tomada de decisão e têm como objetivo garantir a finalização do maior número de sessões prioritárias. A partir dos resultados obtidos nos experimentos realizados por meio de simulação, constatou-se que o emprego dos algoritmos e das políticas desenvolvidos melhora o atendimento das sessões para as quais deve ser oferecido um serviço preferencial. Portanto, em servidores Web preocupados com a garantia de QoS para seus usuários, os quais interagem com o sistema por meio de sessões, o uso dessas novas técnicas se mostra adequado. 



\section{Abstract}

This work considers policies for Web servers based on sessions, aiming at the guarantees of Quality of Service (QoS) to the systems users. Two types of policies are considered: the responsible for the differentiation of services and the responsible for the admission control. Some scheduling algorithms had been developed to offer better services for the priority sessions: the Session Based Scheduling Algorithm (SBSA) and the Session Based Scheduling Algorithm with Differentiation of Services (SBSA-DS). In relation to the admission control, two new policies had been considered, which use different parameters to help the decisions and have as objective guarantee the finalization of as many priority sessions as possible. From the obtained results of the experiments realized by mean of simulation, it is evidenced that the use of the developed algorithms and policies improves the attendance of the sessions that deserve preferential service. Therefore, in Web servers worried in the guarantee the QoS for their users, which interact with the system by sessions, the use of these new techniques reveals adequate. 



\section{Sumário}

Lista de Figuras . . . . . . . . . . . . . . . . . . ix

Lista de Tabelas . . . . . . . . . . . . . . . . . . . . xi

Lista de Abreviaturas e Siglas . . . . . . . . . . . . . . . . . . xiii

1 Introdução 1

1.1 Contextualização . . . . . . . . . . . . . . . . . . . 1

1.2 Motivação . . . . . . . . . . . . . . . . . . . . . 3

1.3 Objetivos ............................ 5

1.4 Estrutura da Monografia . . . . . . . . . . . . . . . . 5

2 Estrutura da Internet $\quad 7$

2.1 Considerações Iniciais . . . . . . . . . . . . . . . . . . . . . . 7

2.2 A Pilha de Protocolos da Internet . . . . . . . . . . . . . . . . 8

2.2 .1 Camada de Aplicação . . . . . . . . . . . . . . . . . . . . 8

2.2 .2 Camada de Transporte . . . . . . . . . . . . . . . . . . . . . . 9

2.2 .3 Camada de Rede . . . . . . . . . . . . . . . . . . . . . . . . 10

2.2 .4 Camada de Enlace . . . . . . . . . . . . . . . . . . . . 10

2.2 .5 Camada Física . . . . . . . . . . . . . . . . . . . . . . 11

2.3 A World Wide Web. . . . . . . . . . . . . . . . . . . . 11

2.3.1 Protocolo HTTP . . . . . . . . . . . . . . . . . . . . . 12

2.3.2 Conexões não persistentes e conexões persistentes . . . . . . . . 13

2.3 .3 Mensagens HTTP . . . . . . . . . . . . . . . . . . . . . . 15

2.4 Sessões em Servidores Web . . . . . . . . . . . . . . . . . . . . 18

2.4 .1 Caracterizando Sessões . . . . . . . . . . . . . . . . . . . . . 18

2.5 Considerações Finais . . . . . . . . . . . . . . . . . . . 20

3 Qualidade de Serviço na Internet $\quad 21$

3.1 Considerações Iniciais . . . . . . . . . . . . . . . . . . . . . . . . 21

3.2 Serviços Integrados . . . . . . . . . . . . . . . . . . . . . . 22

3.2 .1 Protocolo RSVP . . . . . . . . . . . . . . . . . 23

3.3 Serviços Diferenciados . . . . . . . . . . . . . . . . . . . 24

3.4 QoS em Nível de Aplicação . . . . . . . . . . . . . . . . . . . . . . . . 25 
3.4.1 Modelos de Servidores Web com Suporte a QoS . . . . . . . . . . 26

3.5 Considerações Finais . . . . . . . . . . . . . . . . . . . . 28

4 Modelagem e Simulação de um Servidor Web com Diferenciação de Serviços e baseado em Sessões $\quad 29$

4.1 Considerações Iniciais . . . . . . . . . . . . . . . . . . . . . . . . . . . . . . 29

4.2 Modelo do Servidor Web com Diferenciação de Serviços . . . . . . . . . . . 30

4.3 Validação e Parametrização do Modelo . . . . . . . . . . . . . . . . . . . 31

4.4 Modificações no Modelo de Simulação do SWDS . . . . . . . . . . . . . . . 32

4.4 .1 Controle das Sessões . . . . . . . . . . . . . . . . . . . . . . . 32

4.4 .2 Módulo Classificador . . . . . . . . . . . . . . . . . . . . . . 34

4.4.3 Gerenciamento do Estado das Sessões . . . . . . . . . . . . . . . . 34

4.5 Algoritmos de Balanceamento de Carga . . . . . . . . . . . . . . . . . 35

4.5.1 Algoritmo de Balanceamento Round Robin - RR . . . . . . . . . . 36

4.5.2 Algoritmo de Balanceamento Shortest Queue First - SQF . . . . . . 37

4.5.3 Considerações sobre os Resultados Obtidos . . . . . . . . . . . . . 38

4.6 Considerações Finais . . . . . . . . . . . . . . . . . . . . . . . . . . . . . . 39

5 Algoritmos de Escalonamento Baseados em Sessão 41

5.1 Considerações Iniciais . . . . . . . . . . . . . . . . . . . . . . . . . 41

5.2 Trabalhos Relacionados . . . . . . . . . . . . . . . . . . . . . . . . . . . 42

5.2 .1 Políticas de Escalonamento . . . . . . . . . . . . . . . . . 42

5.2 .2 Políticas de Particionamento . . . . . . . . . . . . . . . . . . . 44

5.3 Algoritmo de Escalonamento Baseado em Sessão (Session-Based Scheduling

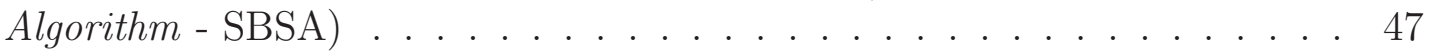

5.3 .1 Métrica de Desempenho . . . . . . . . . . . . . . . . . . 48

5.3.2 Resultados Experimentais . . . . . . . . . . . . . . . . . . 48

5.4 Algoritmo de Escalonamento Baseado em Sessão com Serviços Diferenciados (Session-Based Scheduling Algorithm with Differentiated Services SBSA-DS $\ldots \ldots \ldots \ldots \ldots \ldots \ldots$

5.4 .1 Resultados Experimentais . . . . . . . . . . . . . . . 54

5.5 Considerações Finais . . . . . . . . . . . . . . . . . . . . . . . . . . . 59

6 Políticas de Controle de Admissão $\quad 61$

6.1 Considerações Iniciais . . . . . . . . . . . . . . . . . . . . . . . 61

6.2 Controle de Admissão em Servidores Web . . . . . . . . . . . . . . . . 62

6.3 Trabalhos Relacionados . . . . . . . . . . . . . . . . . . . . . 63

6.4 Definição de uma Política para o Controle de Admissão . . . . . . . . . . . 65

6.5 Mecanismos e Políticas de Controle . . . . . . . . . . . . . . . . . 67

6.6 Resultados Experimentais . . . . . . . . . . . . . . . . . . . . . . . . 69

6.6.1 Mecanismo que limita o tamanho da fila . . . . . . . . . . . 71

6.6.2 Mecanismo que limita a utilização média do cluster . . . . . . . . . 73

6.6.3 Oferecendo garantias de QoS . . . . . . . . . . . . . . . . 74

6.7 Considerações Finais . . . . . . . . . . . . . . . . . . . . . . . . . 78 
7 Conclusões $\quad 81$

7.1 Considerações Iniciais . . . . . . . . . . . . . . . . . . . . . . . . 81

7.2 Principais Resultados e Contribuições . . . . . . . . . . . . . . . . . 82

7.3 Trabalhos Futuros . . . . . . . . . . . . . . . . . . 86

$\begin{array}{ll}\text { Referências Bibliográficas } & 87\end{array}$ 



\section{Lista de Figuras}

1.1 Quatro princípios do fornecimento de QoS (Kurose \& Ross, 2003). . . . . . 3

2.1 A Pilha de Protocolos da Internet. . . . . . . . . . . . . . . . . . 9

2.2 Estrutura de um URL. . . . . . . . . . . . . . . . . . . . . 12

2.3 Exemplo de Requisição HTTP. . . . . . . . . . . . . . . . . . . . . . . 16

2.4 Exemplo de Resposta HTTP. . . . . . . . . . . . . . . . . . . . . . . 17

3.1 Modelo de um servidor Web distribuído (Chen \& Mohapatra, 1999). . . . . 26

3.2 Modelo de um servidor Web com QoS (Kanodia \& Knightly, 2000). . . . . 27

3.3 Modelos de servidores Web (Ye et al., 2005). . . . . . . . . . . . . 27

4.1 Servidor Web com Diferenciação de Serviços (SWDS) (Teixeira, 2004). . 30

5.1 Tempo médio em fila das sessões finalizadas (SBSA - variando os valores

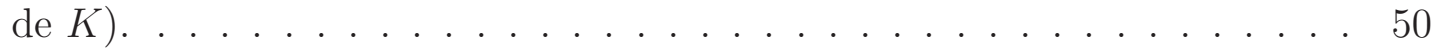

5.2 Tempo médio de residência das requisições pertencentes às sessões finaliza-

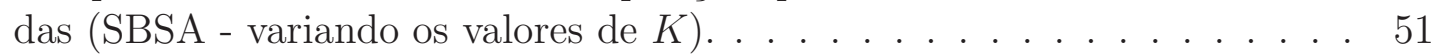

5.3 Tempo médio em fila das sessões finalizadas (SBSA - valor de $K$ elevado). . 52

5.4 Tempo médio em fila das sessões finalizadas (FIFO x SBSA x SBSA-DS). . 56

5.5 Tempo médio de residência das requisições pertencentes às sessões finalizadas $($ SBSA-DS - pesos $\{1,2,3\}) \ldots \ldots \ldots \ldots$

5.6 Tempo médio de residência das requisições pertencentes às sessões finalizadas $($ SBSA-DS - pesos $\{1,4,9\}) \ldots \ldots \ldots \ldots$

6.1 Classificação das Políticas de Controle de Admissão (Barbato et al., 2005). 66

6.2 Avaliação do sistema - Algoritmo de escalonamento FIFO sem controle de admissão. . . . . . . . . . . . . . . . . . 75

6.3 Avaliação do sistema - Algoritmo de escalonamento FIFO e política CA-Híb. 76

6.4 Avaliação do sistema - Algoritmo de escalonamento SBSA-DS e política CA-Híb. . . . . . . . . . . . . . . . . . 77 



\section{Lista de Tabelas}

2.1 Métodos definidos pelo protocolo HTTP. . . . . . . . . . . . . . . . 16

2.2 Classes de código de status das respostas HTTP. . . . . . . . . . . . . . . 17

4.1 Parâmetros do modelo SWDS (Teixeira, 2004). . . . . . . . . . . . . . 32

4.2 Avaliação do algoritmo de balanceamento RR. . . . . . . . . . . . . . . 36

4.3 Avaliação do algoritmo de balanceamento SQF. . . . . . . . . . . . . . 37

4.4 Efeitos dos fatores em relação ao tempo médio de residência no sistema. . . 39

5.1 Médias e desvio padrão do tempo em fila das sessões finalizadas. . . . . . . 49

5.2 Quantidade de sessões finalizadas. . . . . . . . . . . . . . . . . . . 52

5.3 Médias e desvio padrão do tempo em fila das sessões finalizadas. . . . . . . 55

6.1 Avaliação das políticas de CA - Mecanismo que limita o tamanho da fila. . 71

6.2 Porcentagem de sessões finalizadas - Mecanismo que limita o tamanho da fila. . . . . . . . . . . . . . . . . . . . . . 72

6.3 Avaliação das políticas de CA - Mecanismo que limita a utilização média do cluster. . . . . . . . . . . . . . . . . . . 73

6.4 Porcentagem de sessões finalizadas - Mecanismo que limita a utilização média do cluster. . . . . . . . . . . . . . . . . . . . . 74 



\section{Lista de Abreviaturas e Siglas}

ATM Asynchronous Transfer Mode

DoS Denial of Service

DS Differentiated Services

FCFS First-Come First-Served

FIFO First-In First-Out

FTP File Transfer Protocol

HTML Hypertext Markup Language

HTTP Hypertext Transfer Protocol

IETF Internet Engineering Task Force

IP Internet Protocol

NAT Network Address Translation

QoS Quality of Service

QoWS Quality of Web Services

RFC Request for Comments

RSV Reserva de Recursos

RSVAdap Reserva Adaptativa de Recursos

RSVP Resource Reservation Protocol

RTT Round-Trip Time

SLA Service Level Agreement

SMTP Simple Mail Transfer Protocol

SQF Shortest Queue First

SWDS Servidor Web com Diferenciação de Serviços

TCP Transfer Control Protocol

UDP User Datagram Protocol

URL Uniform Resource Locators

W3C World Wide Web Consortium

WFQ Weighted Fair Queueing

WWW World Wide Web 



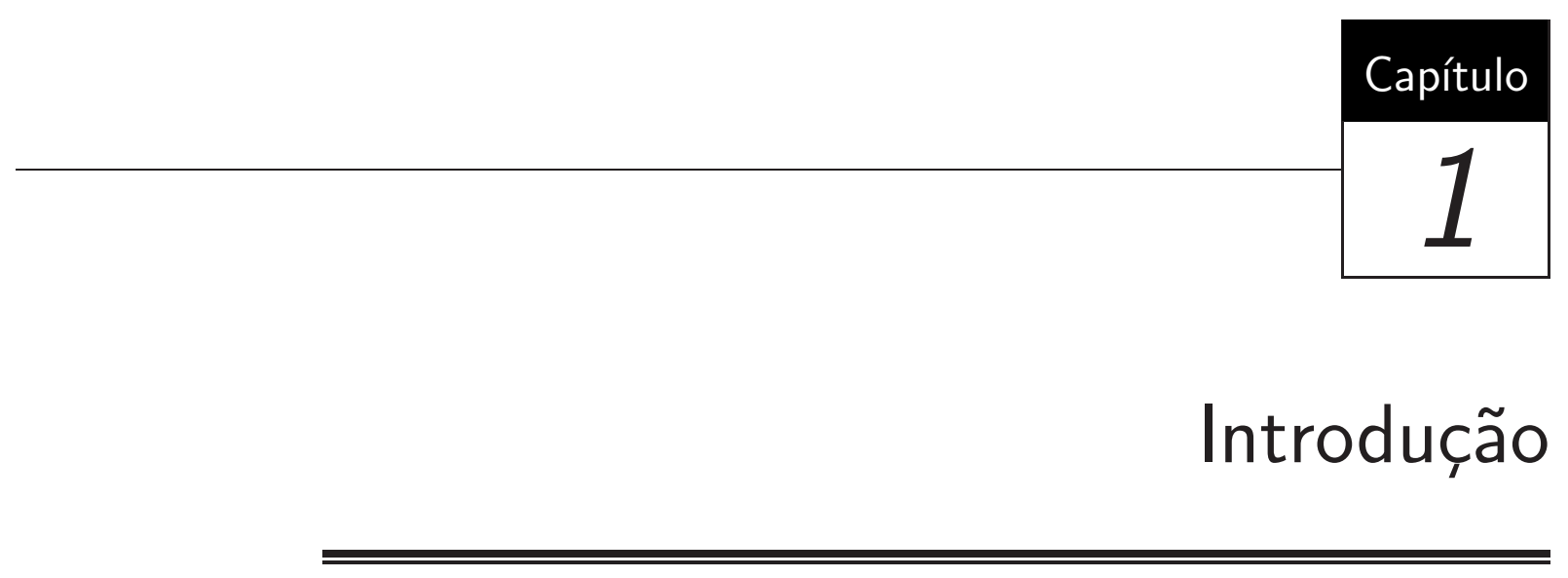

\subsection{Contextualização}

A Internet é hoje um dos mais importantes meios de comunicação, sendo amplamente utilizada após o surgimento da World Wide Web (WWW). Entretanto, em sua concepção original, a Internet não foi projetada para o uso atualmente observado, nem para dar suporte à quantidade de carga que lhe é imposta.

O serviço oferecido na Internet se baseia em um modelo de melhor esforço, ou seja, a rede procura, de todas as maneiras, transportar os dados que lhe são confiados no menor tempo possível, de preferência sem erros ou inconsistências. Contudo, não são dadas às aplicações garantias de que isso realmente ocorrerá (Comer, 2000).

Uma das consequiências da adoção do modelo de melhor esforço na Internet é o fato de que todo o tráfego é tratado de maneira uniforme, sem nenhum tipo de diferenciação ou priorização (Teixeira, 2004). No entanto, verifica-se que nem todos os tipos de tráfego e transações são equivalentes ou têm a mesma prioridade para os usuários (Dovrolis \& Ramanathan, 1999).

Em um site de comércio eletrônico, por exemplo, é desejável que as requisições referentes ao processo de finalização de uma compra recebam prioridade e confiabilidade maiores que as demais requisições. Porém, atualmente, o tráfego na rede é tratado, em geral, de maneira igualitária, sem que seja considerada sua prioridade relativa aos usuários 
e às aplicações. A mesma situação se dá em nível de aplicação, em que as solicitações que chegam aos servidores Web recebem um tratamento uniforme, sem distinção.

Estão disponíveis diversas especificações, sob coordenação da IETF (Internet Engineering Task Force ${ }^{1}$ ), para superar o serviço de melhor esforço e prover alguma Qualidade de Serviço (Quality of Service - QoS) em nível de rede, destacando-se as arquiteturas de Serviços Integrados (Braden et al., 1994) e de Serviços Diferenciados (Blake et al., 1998).

Serviço Diferenciado tem sido proposto como uma solução eficiente para prover melhores serviços, não só em nível de rede como também em servidores Web. A diferenciação de serviços em servidores Web é importante uma vez que a qualidade de serviço diferenciado não terá sucesso se forem empregados apenas mecanismos em nível de rede, pois, em última instância, são os servidores Web os responsáveis pelo atendimento das solicitações dos usuários (Teixeira et al., 2005). Nos casos onde não se utilizam técnicas para o oferecimento de QoS em nível de aplicação, as requisições que chegam ao servidor Web podem enfrentar um sistema sobrecarregado, por exemplo, e todos os esforços desprendidos em nível de rede podem ter sido em vão.

Nesse contexto, Cardellini et al. (2001) introduziram o conceito de Qualidade em Serviços Web (Quality of Web Services - QoWS), inspirado nos princípios de garantia de QoS em nível de rede definidos por Kurose \& Ross (2000). Esses princípios em nível de rede são apresentados a seguir e ilustrados na Figura 1.1:

Princípio 1: Classificação (Marcação). Necessária para distinção entre diferentes classes de serviço.

Princípio 2: Isolamento. Proteção de uma classe em relação às demais. Uma alternativa é a alocação de uma porção do recurso a cada classe; porém, pode produzir o uso ineficiente do recurso caso a classe não utilize toda a sua porção alocada.

Princípio 3: Alta Utilização dos Recursos. Embora fornecendo isolamento, é necessário que os recursos sejam utilizados da forma mais eficiente possível.

Princípio 4: Controle de Admissão. Declarada a necessidade de sua classe, a requisição pode ser bloqueada pela rede caso essa necessidade não possa ser satisfeita.

\footnotetext{
${ }^{1}$ http://www.ietf.org
} 


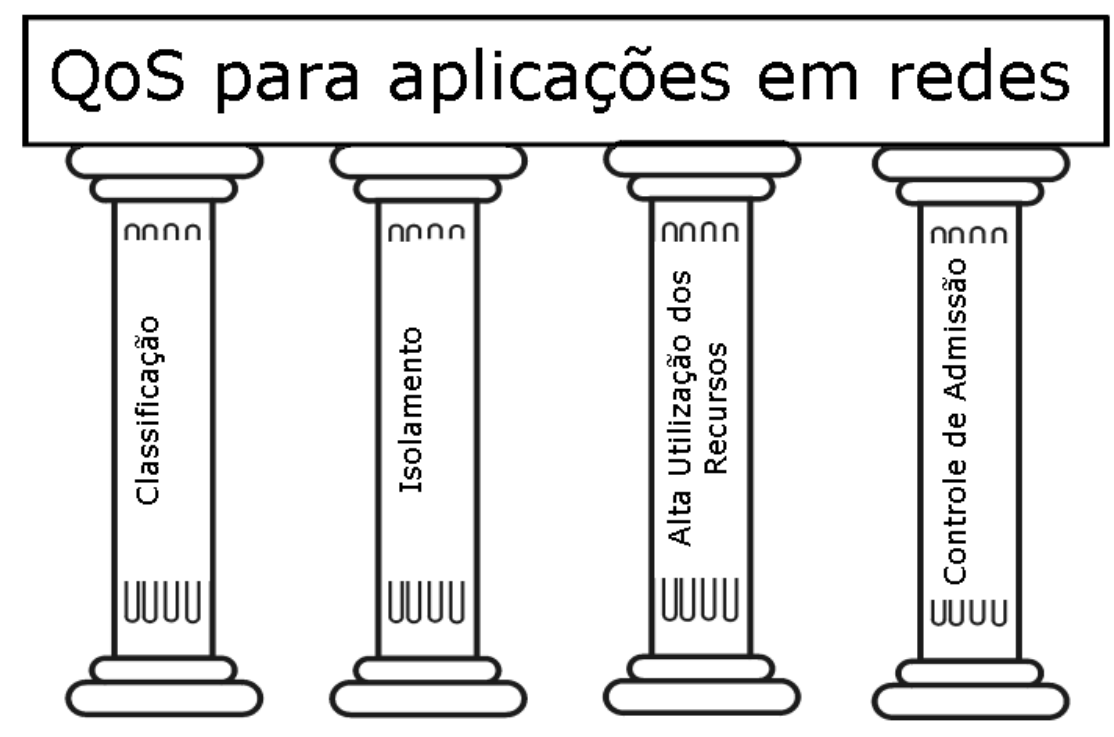

Figura 1.1: Quatro princípios do fornecimento de QoS (Kurose \& Ross, 2003).

\subsection{Motivação}

Cardellini et al. (2001) e Andreolini et al. (2004) demonstram em seus trabalhos que o sistema de servidor Web, mesmo para diferentes cargas e condições, está habilitado em alcançar os acordos de nível de serviços (Service Level Agreements - SLA) firmados com os clientes, somente quando todos os princípios de QoWS são satisfeitos. Caso o sistema use uma política que não satisfaça algum princípio de QoWS, os resultados podem estar dentro de níveis aceitáveis, porém não são oferecidas garantias de SLAs para um cenário altamente variável, tal como ocorre em sistemas de servidores Web.

Cardellini et al. (2001) afirmam que o Isolamento é um dos mais importantes princípios derivados da teoria de QoS. Esse isolamento pode ser alcançado por meio de políticas de escalonamento e/ou por meio de políticas de particionamento de recursos (Andreolini et al., 2004). Essas políticas visam oferecer a diferenciação de serviços baseando-se nas classes das tarefas.

O Controle de Admissão, por meio de suas políticas, previne a sobrecarga do sistema e permite que os SLAs sejam respeitados, baseando-se nas informações de carga do sistema e nos acordos firmados com os clientes.

Tanto as políticas para a diferenciação de serviços, quanto as políticas de controle de admissão, são fundamentais para que o servidor Web possa oferecer qualidade de serviço a seus clientes. Na literatura existem vários trabalhos explorando esses tipos de políticas 
que consideram, na grande maioria dos casos, as requisições individualmente (Welsh \& Culler, 2003; Andreolini et al., 2004; Elnikety et al., 2004; Serra et al., 2005; Teixeira et al., 2005; Ye et al., 2005; Estrella et al., 2006; Traldi et al., 2006). No entanto, em vários servidores Web, principalmente de comércio eletrônico, a maioria das requisições é baseada em sessão (Chen \& Mohapatra, 2002; Cherkasova \& Phaal, 2002). Uma sessão consiste em uma seqüência de requisições, relacionadas, pertencentes a um mesmo cliente (Arlitt, 2000; Chen \& Mohapatra, 2002; Cherkasova \& Phaal, 2002).

Em servidores Web que fazem uso de sessões e oferecem QoS, a garantia de melhor serviço é proporcionada somente se toda a sessão receber atendimento preferencial, ou seja, um determinado usuário do sistema receberá melhor atendimento caso todas as suas requisições tiverem serviço diferenciado e forem finalizadas com sucesso.

As políticas de escalonamento e/ou de particionamento para servidores Web com suporte a QoS encontradas na literatura se preocupam com a diferenciação de serviços. No entanto, essas políticas tratam as requisições individualmente, sem considerar as sessões às quais tais requisições pertencem. O mesmo acontece com as políticas de controle de admissão utilizadas por esses tipos de servidores Web. Por outro lado, têm-se alguns trabalhos na literatura que se preocupam com as sessões, como os trabalhos de Chen \& Mohapatra (2002) e Cherkasova \& Phaal (2002), por exemplo, onde são apresentados controles de admissão baseados em sessão, porém, os servidores Web considerados não visam à diferenciação de serviços.

Além da provisão de qualidade de serviço por meio de políticas, um outro ponto a ser ressaltado em relação aos servidores Web com QoS é quanto à arquitetura. Atualmente, devido ao aumento da quantidade de serviços e de informações disponibilizados na Web, tem-se exigido que os servidores Web apresentem um desempenho de forma escalável, ou seja, que mantenham o desempenho constante com o aumento incremental de sua capacidade, de modo a suportar essa quantidade de carga que lhe é imposta. Essa escalabilidade pode ser alcançada por meio do uso de uma arquitetura distribuída do servidor Web, que tem se tornado uma abordagem cada vez mais importante para a infraestrutura da Internet (Sit et al., 2004). Por meio das arquiteturas distribuídas, além da escalabilidade, o servidor pode prover outras vantagens que um sistema distribuído pode oferecer, tais como a confiabilidade e o aumento do desempenho, características essenciais para que os servidores Web ofereçam melhores serviços. 


\subsection{Objetivos}

O objetivo geral deste trabalho é avaliar o desempenho de servidores Web distribuídos que oferecem serviços diferenciados e reconhecem sessões. O servidor a ser avaliado considera políticas de escalonamento e políticas de controle de admissão baseadas em sessão.

Dentre os objetivos específicos, destacam-se:

- Alteração de um modelo e de seu respectivo programa de simulação de um servidor Web distribuído (Teixeira, 2004), utilizado para a avaliação de desempenho, visando incorporar o controle de sessões.

- Desenvolvimento de políticas de escalonamento para a diferenciação de serviços que considerem sessões.

- Desenvolvimento de políticas para o controle de admissão baseadas em sessões.

- Avaliação da relevância em considerar sessões no desenvolvimento das políticas para servidores Web com serviços diferenciados.

Este trabalho contribui para um melhor entendimento dos aspectos relacionados ao fornecimento de qualidade de serviço diferenciada nos servidores Web que apresentam carga de trabalho baseada em sessão. As políticas propostas são avaliadas por meio de simulação de um servidor Web distribuído com suporte a diferenciação de serviços e com carga de trabalho baseada em sessão. A partir dos resultados obtidos dos experimentos e da experiência adquirida, novos rumos para a pesquisa na área são identificados, dando origem a novos projetos.

\subsection{Estrutura da Monografia}

O foco do Capítulo 2 é a infra-estrutura da Internet, sendo apresentados seus protocolos, especialmente os protocolos TCP e HTTP, além de seus principais serviços, como é o caso da Web. No final desse capítulo, discute-se a importância de considerar sessões em servidores Web e como essas podem ser caracterizadas.

O Capítulo 3 desta dissertação aborda o tópico de qualidade de serviço na Internet tanto em nível de rede, destacando-se os Serviços Integrados e Diferenciados, quanto em 
nível de aplicação, isto é, a diferenciação de serviços em servidores Web, sendo apresentados alguns modelos propostos na literatura.

No Capítulo 4 é apresentado o modelo de Servidor Web com Diferenciação de Serviços (SWDS), utilizado neste trabalho para a avaliação de desempenho das políticas desenvolvidas. Os principais componentes do modelo são descritos, assim como a sua parametrização e a forma de validação. As modificações realizadas no modelo de simulação original do SWDS, necessárias para o controle de sessões, são discutidas. No final do capítulo são comparados os resultados de experimentos realizados com alguns algoritmos de balanceamento de carga, considerando diferentes condições e carga de trabalho para o sistema.

O Capítulo 5 inicia com a apresentação de alguns algoritmos, encontrados na literatura, que não fazem uso de sessões e são responsáveis por realizar a diferenciação de serviços em servidores Web. Dois novos algoritmos de escalonamento baseados em sessão são propostos e descritos, sendo apresentados os principais resultados obtidos.

No Capítulo 6, abordam-se as políticas de controle de admissão. São apresentadas algumas políticas de controle de admissão encontradas na literatura e uma classificação hierárquica de como podem ser definidas essas políticas de modo a prevenir a sobrecarga dos servidores e a oferecer qualidade de serviço aos clientes. Duas novas políticas de controle de admissão, que fazem uso de sessões para a tomada de decisão de descarte, são definidas, e os resultados obtidos por meio de experimentos são relatados.

Finalmente, no Capítulo 7 são apresentadas as conclusões, retomando-se os principais resultados obtidos. As principais contribuições deste trabalho são discutidas, além de fornecer indicações para trabalhos futuros. 


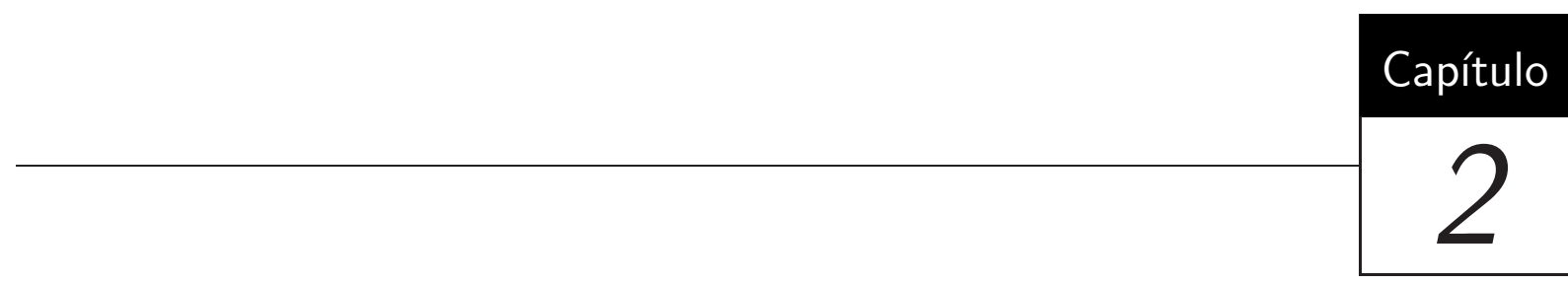

\section{Estrutura da Internet}

\subsection{Considerações Iniciais}

Uma das grandes aspirações da humanidade é a capacidade de comunicação com seus semelhantes, a qualquer tempo, a qualquer hora, em qualquer lugar. Assim, com o passar dos anos e a evolução da tecnologia, surgiram diferentes formas de comunicação, como os primeiros mensageiros, os correios, o telégrafo, o sistema telefônico, a televisão, com cada um desses meios atendendo as necessidades de sua época, sendo alguns deles ainda largamente utilizados e indispensáveis no mundo atual. No final do século passado surgiu a Internet, apontada como uma revolução na história da comunicação entre os seres humanos.

Quando a Internet surgiu, a maioria dos usuários era formada por cientistas e estudantes, sendo concebida como uma nova maneira de intercambiar dados científicos. Hoje a Internet está se tornando cada vez mais acessível, sendo utilizada para fins informativos, educacionais, de entretenimento e comerciais.

Enquanto a televisão, o rádio e o jornal trazem as notícias que selecionam conforme suas próprias diretrizes, inexistem, na Internet, grades de programação dos materiais informativos. Essa rede mundial de computadores permite que o usuário escolha e consuma informações nos horários e nas freqüências de sua preferência. Além disso, a Internet oferece diferentes formas de comunicação, como, por exemplo, a transmissão da palavra falada e escrita, e a transmissão de áudio e vídeo. 
Tamanhas facilidades oferecidas pela Internet justificam o seu intenso tráfego, tornando-se muito maior do que seus criadores podiam prever e cada vez mais sendo usada para fins comerciais e não apenas para pesquisas acadêmicas.

Neste capítulo são abordados os serviços mais comuns da Internet e os protocolos da arquitetura que constituem sua infra-estrutura. A World Wide Web, sua forma de organização, os tipos de aplicações que podem executar sobre a mesma e o protocolo HTTP, também são abordados.

\subsection{A Pilha de Protocolos da Internet}

Um protocolo define o formato e a ordem das mensagens trocadas entre duas ou mais entidades comunicantes, bem como as ações realizadas na transmissão e/ou no recebimento de uma mensagem ou outro evento.

O TCP (Transmission Control Protocol) e o IP (Internet Protocol) são os protocolos mais importantes da Internet, conhecidos coletivamente como TCP/IP.

A pilha de protocolos da Internet, ilustrada na Figura 2.1, consiste em cinco camadas: camada de aplicação, camada de transporte, camada de rede, camada de enlace e camada física (Kurose \& Ross, 2006). ${ }^{1}$

\subsubsection{Camada de Aplicação}

A camada de aplicação é responsável pelo suporte das aplicações de rede. Um protocolo de aplicação de rede tem normalmente dois lados: o lado cliente e o lado servidor.

Entre os protocolos da camada de aplicação estão o HTTP (Hypertext Transfer Protocol), para suportar a Web, o SMTP (Simple Mail Transfer Protocol), para suportar o correio eletrônico, e o FTP (File Transfer Protocol), para suportar o transporte de arquivos.

\footnotetext{
${ }^{1}$ As camadas do modelo TCP/IP fornecem serviços para suas camadas sucessoras, de forma independente. No entanto, em redes sem fio, tal modelo de camadas não é adequado dado que a camada física influencia as camadas acima dela. Nesse caso, a interdependência entre as camadas pode ser provida adotando-se a abordagem "cross-layer" (Presti, 2005).
} 


\begin{tabular}{|c|c}
\hline Aplicação & Camada 5 \\
Transporte & Camada 4 \\
Rede & Camada 3 \\
Enlace & Camada 1 \\
\hline
\end{tabular}

Figura 2.1: A Pilha de Protocolos da Internet.

\subsubsection{Camada de Transporte}

A camada de transporte fornece o serviço de transporte das mensagens da camada de aplicação entre os lados do cliente e do servidor de uma aplicação. Na Internet há dois tipos de protocolos de transporte: o TCP e o UDP (User Datagram Protocol).

O TCP provê serviços orientados à conexão para suas aplicações, isto é, o cliente e o servidor trocam informações de controle da camada de transporte antes que as mensagens da camada de aplicação comecem a fluir. Esse procedimento de apresentação alerta o cliente e o servidor, permitindo que eles se preparem para uma "rajada" de pacotes. O modelo de serviço TCP também inclui a entrega garantida das mensagens da camada de aplicação no destino, sem erros e na ordem correta, e o controle de fluxo, isto é, o ajuste entre as velocidades do remetente/receptor. O TCP também provê o mecanismo de controle de congestionamento, de modo que a origem regula sua velocidade de transmissão quando a rede está congestionada.

O UDP é um protocolo de transporte simplificado, que fornece às suas aplicações serviço não orientado à conexão. Ele oferece um serviço de transferência de dados não confiável, sem garantia sobre a entrega e ordem dos dados. O UDP não inclui um mecanismo de controle de congestionamento e, da mesma maneira que o TCP, não oferece garantias em relação aos atrasos. 


\subsubsection{Camada de Rede}

A camada de rede é responsável pelo roteamento dos datagramas da origem ao destino. O principal protocolo da camada de rede da Internet é o protocolo IP. Todos os componentes da Internet que têm uma camada de rede devem utilizar esse protocolo.

A camada de rede da Internet também contém protocolos de roteamento que determinam as rotas que os datagramas seguem entre origens e destinos. Dentro de uma rede da Internet, o administrador pode utilizar qualquer protocolo de roteamento desejado.

Embora a camada de rede contenha tanto o protocolo IP quanto diversos protocolos de roteamento, ela quase sempre é chamada simplesmente de camada IP, refletindo o fato de que o IP é o elemento-chave que mantém a integridade da Internet. Há duas versões do protocolo IP em uso atualmente: a versão 4, mais utilizada e conhecida como IPv4, e a versão 6, ou IPv6, proposta para substituir o IPv4 (Kurose \& Ross, 2006). A motivação primária para o desenvolvimento do sucessor do IPv4 foi a necessidade de maior capacidade de endereçamento.

Os protocolos da camada de transporte da Internet (TCP e UDP) da máquina origem passam um segmento e um endereço de destino à camada IP. A partir desses dados, a camada IP provê o serviço de roteamento do segmento a seu destino. Quando o pacote chega ao destino, o IP passa o segmento para a camada de transporte da máquina destino.

\subsubsection{Camada de Enlace}

A camada de rede realiza o roteamento do pacote por meio de uma série de roteadores entre a origem e o destino. Para realizar o envio de um pacote entre nós, a camada de rede depende dos serviços da camada de enlace.

A cada nó, o IP passa o datagrama para a camada de enlace, que o entrega no nó seguinte ao longo da rota. No nó destino, a camada de enlace passa o datagrama IP à camada de rede.

Os serviços prestados na camada de enlace dependem do protocolo empregado. Alguns protocolos, por exemplo, fornecem entrega garantida sobre os enlaces. Como exemplos de protocolos de camadas de enlace, podem ser citados a Ethernet, o PPP (Point-to-Point Protocol), o ATM e a rede Frame Relay.

Como o datagrama normalmente precisa transitar por diversos enlaces para ir da 
origem ao destino, ele vai ser manuseado por diferentes protocolos de camada de enlace em diferentes enlaces ao longo da rota. Por exemplo, um datagrama pode ser operado por Ethernet em um enlace e por PPP no enlace seguinte. O IP vai receber um serviço diferente de cada um dos diferentes protocolos de camada de enlace.

\subsubsection{Camada Física}

Enquanto a tarefa da camada de enlace é movimentar quadros inteiros de um elemento da rede até o elemento adjacente, a tarefa da camada física é movimentar os bits individuais interiores ao quadro de um nó para o nó seguinte.

Os protocolos dessa camada, além de dependerem da camada de enlace, dependem ainda do meio de transmissão utilizado (par de fios de cobre trançados, fibra ótica, etc.). Por exemplo, a Ethernet tem muitos protocolos para a camada física: um para par de fios de cobre trançado, outro para cabo coaxial, outro para fibra e assim por diante. Em cada caso, o bit é movimentado pelo enlace de maneira diferente.

\section{$2.3 \quad$ A World Wide Web}

Até a década de 90, a Internet era usada basicamente por pesquisadores, acadêmicos e estudantes universitários para interligação com hospedeiros remotos, transferência de arquivos, além do envio e recebimento de correio eletrônico. Embora essas aplicações fossem (e continuem a ser) muito úteis, a Internet não era muito difundida fora das comunidades acadêmicas e de pesquisa. No início da década de 90, surgiu a aplicação-chave da Internet: a WWW (World Wide Web) (Berners-Lee et al., 1994).

A Web é a aplicação que elevou a Internet para o nível que agora ocupa, como um dos mais importantes meios de comunicação. Com o início do funcionamento da WWW, a Internet foi levada para os lares e empresas de milhões e milhões de pessoas em todo o mundo, servindo como plataforma para a habilitação e a disponibilização de centenas de novas aplicações, inclusive negociação de ações em bolsa de valores e serviços bancários on-line, além de serviços sofisticados de multimídia.

Basicamente a WWW é formada de documentos chamados páginas Web, desenvolvidos em sua maioria em HTML (Hypertext Markup Language) (W3C, 1999). A HTML é o idioma universal falado na Web, onde suas tags descrevem a estrutura da página, fornecem informações sobre sua formatação e estabelecem conexões (links) com outros documentos 
e recursos da Web, proporcionando um padrão que garante a sua portabilidade.

Uma página Web é constituída de objetos. Um objeto é simplesmente um arquivo, tal como um arquivo HTML, uma imagem JPEG ou um applet Java, por exemplo. A maioria das páginas Web é constituída de um arquivo-base HTML e diversos objetos relacionados por meio de seus URLs. Um URL (Uniform Resource Locators), apresentado na Figura 2.2, é composto de:

- Protocolo. Informa qual é o protocolo utilizado para o transporte dos dados.

- Nome do servidor. Apresenta o endereço IP ou o nome do hospedeiro do servidor que abriga o objeto requisitado.

- Número da porta. Informa a porta onde um processo do servidor aguarda mensagens. Um valor padrão, como porta 80 para HTTP e 21 para FTP, pode ser utilizado.

- Localização do recurso. Apresenta o caminho até o objeto.

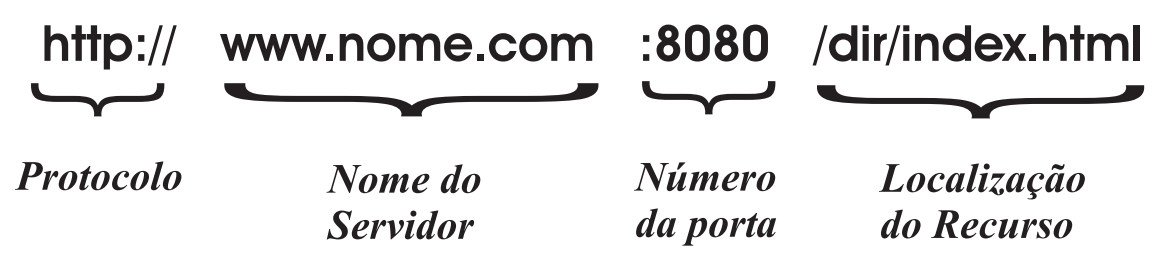

Figura 2.2: Estrutura de um URL.

Páginas Web podem ser classificadas como estáticas ou dinâmicas. As páginas estáticas são documentos fisicamente armazenados no sistema de arquivos de um servidor Web, disponíveis para leitura. As páginas dinâmicas são documentos gerados dinamicamente em tempo de execução por um programa ou script executado no servidor Web no momento em que a página é requisitada. Para a comunicação entre os clientes e servidores Web é empregado o protocolo HTTP, que funciona sobre o protocolo TCP.

\subsubsection{Protocolo HTTP}

O HTTP é um protocolo da camada de aplicação e define como os clientes Web, isto é, os browsers ou navegadores, solicitam páginas aos servidores Web e como os servidores transferem páginas aos clientes. 
Quando um usuário solicita uma página Web, o navegador envia ao servidor mensagens de requisição HTTP para os objetos da página. O servidor recebe as requisições e responde com uma mensagem de resposta HTTP que contém o objeto.

O servidor envia os arquivos solicitados ao cliente sem armazenar nenhuma informação de estado sobre o cliente. Se um determinado cliente solicita o mesmo objeto duas vezes em um período de poucos segundos, o servidor envia novamente o objeto. Além disso, em caso de problemas durante o período de comunicação entre o cliente e o servidor, é de responsabilidade do cliente submeter novamente a requisição. Como o servidor HTTP não mantém nenhuma informação sobre os clientes, ele é chamado de protocolo sem estado ou stateless.

Inicialmente, os navegadores e servidores Web implementavam a versão HTTP/1.0, definida no RFC 1945 (Berners-Lee et al., 1996). A partir de 1999, foi lançada a versão HTTP/1.1, definida no RFC 2616 (Fielding et al., 1999), compatível com a versão 1.0.

Tanto o HTTP/1.0 quanto o HTTP/1.1 usam o TCP como seu protocolo de transporte subjacente. Como discutido na Seção 2.2.2, o TCP fornece um serviço confiável de transferência de dados e, por isso, o HTTP não precisa se preocupar com a perda de dados.

\subsubsection{Conexões não persistentes e conexões persistentes}

O HTTP pode ou não usar conexões persistentes. Enquanto o HTTP/1.0 usa conexões não persistentes, o modo padrão do HTTP/1.1 usa conexões persistentes.

\section{Conexões não persistentes}

Como discutido na Seção 2.3, uma página Web é constituída de um arquivo-base HTML e de diversos outros objetos. A transferência de um objeto de uma página, requisitado por um cliente a um servidor Web, no caso de conexões não persistentes, segue os seguintes estágios:

1. O cliente HTTP inicia uma conexão TCP para o servidor.

2. O cliente HTTP envia uma mensagem de requisição HTTP ao servidor por meio da conexão TCP estabelecida no estágio 1. 
3. O servidor HTTP recebe a mensagem de requisição, recupera de seu sistema de armazenamento o objeto solicitado, encapsula o objeto em uma mensagem de resposta HTTP e envia a mensagem de resposta ao cliente.

4. O servidor HTTP ordena que o TCP encerre a conexão, que se encerrará somente quando o cliente receber a resposta.

5. O cliente HTTP recebe a mensagem de resposta e a conexão TCP é encerrada

6. Os estágios anteriores são repetidos para cada um dos objetos referenciados.

Os estágios apresentados na descrição anterior usam conexões não persistentes porque cada conexão TCP é fechada depois que o servidor envia o objeto, não persistindo para outros objetos. Cada conexão TCP transporta exatamente uma mensagem de requisição HTTP e uma mensagem de resposta HTTP. Nesse caso, as conexões TCP ocorrem em série. Porém, alguns navegadores permitem controlar o grau de paralelismo das conexões TCP. No modo padrão, a maioria dos navegadores abre de cinco a dez conexões TCP paralelas, cada uma das quais manipula uma transação requisição/resposta (Kurose \& Ross, 2006).

\section{Conexões persistentes}

Com o uso de conexões não persistentes, uma nova conexão TCP deve ser estabelecida e conservada para cada objeto solicitado. Para cada conexão devem ser alocados buffers e variáveis do TCP, tanto no cliente quanto no servidor, podendo sobrecarregar seriamente o servidor Web, principalmente quando estiver atendendo vários clientes ao mesmo tempo (Kurose \& Ross, 2006). Outra desvantagem de conexões não persistentes está no fato de que para cada objeto transmitido há um atraso de dois RTTs (Round-Trip Time), que é o tempo de viagem de ida e volta: um RTT para estabelecer a conexão TCP e outro para solicitar e receber o objeto. Por fim, o mecanismo de controle de congestionamento do TCP força que toda nova conexão inicie a transmissão dos dados a uma velocidade relativamente baixa, permitindo um aumento na velocidade caso a rede não esteja congestionada. A fase inicial de transmissão vagarosa é conhecida como "partida lenta" e o uso de conexões não persistentes faz com que cada objeto sofra com essa partida lenta do TCP.

Nas conexões persistentes, o servidor deixa a conexão TCP aberta após ter enviado uma resposta. As requisições e respostas subseqüentes entre os mesmos cliente e servidor 
podem ser enviadas por meio da mesma conexão. O servidor HTTP fecha a conexão quando esta não é usada durante um determinado intervalo de tempo.

As conexões persistentes podem ser com e sem paralelismo. Em conexões persistentes sem paralelismo, o cliente envia uma nova requisição somente após receber resposta para a solicitação anterior. No caso de conexões persistentes com paralelismo, o cliente HTTP envia a requisição no momento em que ocorre uma referência para algum objeto.

\subsubsection{Mensagens HTTP}

A seguir são apresentados os dois tipos de mensagens HTTP: mensagem de requisição e mensagem de resposta.

\section{Mensagem de Requisição HTTP}

A mensagem de requisição é definida pelo protocolo HTTP em um formato padrão e é formada tipicamente por:

- Linha de Requisição. Linha que informa a ação a ser executada no servidor onde se encontra o método invocado, a localização do objeto no servidor e a versão do protocolo HTTP utilizada.

- Linhas de Cabeçalho. Uma ou mais linhas de cabeçalho contendo informações do cliente, para informar ao servidor, por exemplo, os tipos de dados que ele é capaz de aceitar.

- Corpo da Mensagem. Opcional. É utilizado quando dados adicionais do cliente devem ser enviados ao servidor.

Na Figura 2.3 é apresentado um exemplo de uma requisição, onde um cliente solicita (GET) o arquivo /dir/index.html do servidor www.nome.com usando o protocolo HTTP/1.1. O campo Accept no cabeçalho informa que o cliente é capaz de receber textos em formato HTML (text/html) e imagens em formato JPEG (image/jpeg). O tipo de navegador do cliente é especificado no campo User-agent. 


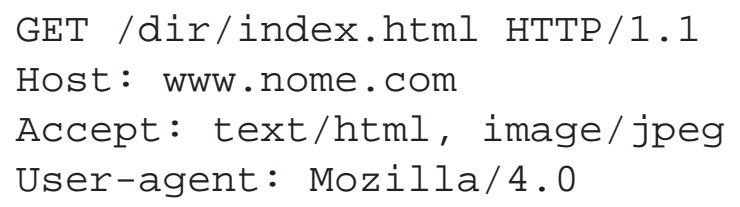

Figura 2.3: Exemplo de Requisição HTTP.

O cliente pode enviar comandos ao servidor invocando um conjunto de métodos definidos pelo protocolo HTTP ao servidor Web. Na versão 1.0 do protocolo HTTP estão definidos os métodos GET, HEAD e POST. No protocolo HTTP 1.1 são acrescentados os métodos OPTIONS, PUT, DELETE, TRACE e CONNECT a esse conjunto. Uma breve descrição desses métodos pode ser vista na Tabela 2.1.

Tabela 2.1: Métodos definidos pelo protocolo HTTP.

\begin{tabular}{|c||l|}
\hline \multicolumn{1}{|c||}{ Método } & Finalidade \\
\hline \hline GET & $\begin{array}{l}\text { Faz a requisição do objeto especificado pelo } \\
\text { URL. }\end{array}$ \\
\hline POST & $\begin{array}{l}\text { Envia ao servidor informações do cliente, ge- } \\
\text { ralmente digitados em formulários HTML. }\end{array}$ \\
\hline HEAD & $\begin{array}{l}\text { Disponibiliza informações de um objeto, sem } \\
\text { retorná-lo ao cliente. Testa a validade de } \\
\text { links, acessibilidade e a data da última atua- } \\
\text { lização. }\end{array}$ \\
\hline OPTIONS & $\begin{array}{l}\text { Retorna opções de comunicação disponíveis. } \\
\text { Permite ao cliente determinar os requisitos } \\
\text { associados ao objeto requisitado. }\end{array}$ \\
\hline PUT & Cria ou modifica um objeto no servidor. \\
\hline DELETE & $\begin{array}{l}\text { Faz a solicitação para apagar um objeto no } \\
\text { servidor, identificado no URL. }\end{array}$ \\
\hline TRACE & Envia mensagem de teste ao servidor. \\
\hline CONNECT & Reservado para servidores proxy. \\
\hline
\end{tabular}

\section{Mensagem de Resposta HTTP}

O protocolo HTTP determina que uma mensagem de resposta deve conter:

- Linha de Status. Essa linha é composta de três campos: o campo da versão do protocolo, uma codificação para o status e uma mensagem de estado correspondente. A codificação de status e a frase associada a ela indicam o resultado da requisição. 
- Linhas de Cabeçalho. Compostas por vários campos nos quais estão contidas informações das características do servidor e do objeto retornado para o cliente.

- Corpo da Mensagem. Armazena o objeto solicitado pelo cliente.

Para informar o resultado da execução realizada, o servidor retorna em sua resposta HTTP um código de status que se apresentam divididos nas classes apresentadas na Tabela 2.2 .

Tabela 2.2: Classes de código de status das respostas HTTP.

\begin{tabular}{|c||c|}
\hline Classe & Descrição \\
\hline \hline $1 \mathrm{xx}$ & Finalidade Informativa \\
\hline $2 \mathrm{xx}$ & Sucesso \\
\hline $3 \mathrm{xx}$ & Redirecionamento \\
\hline $4 \mathrm{xx}$ & Erro do cliente \\
\hline $5 \mathrm{xx}$ & Erro do servidor \\
\hline
\end{tabular}

A Figura 2.4 apresenta um exemplo de uma resposta HTTP. A resposta do servidor diz que ele está usando o HTTP/1.1 e que a requisição foi bem-sucedida, indicada pelo código 200. O tipo do servidor Web (Apache/1.3.0) é informado pelo campo Server e o campo Content-Type mostra que o objeto retornado é um documento HTML, cujo tamanho é de 3.351 bytes, indicado pelo campo Content-Lenght. Após a linha em branco, constituída de um carriage return e um line feed, encontra-se o objeto solicitado, representado por (dado dado dado ...).

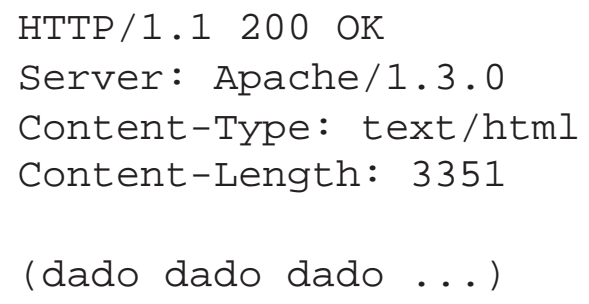

Figura 2.4: Exemplo de Resposta HTTP. 


\subsection{Sessões em Servidores Web}

Durante a apresentação do protocolo HTTP na Seção 2.3.1, comentou-se que esse é um protocolo sem estado (stateless). Isto significa que, após enviar uma resposta contendo o objeto solicitado ao cliente, o servidor Web "esquece" imediatamente do serviço prestado àquele cliente em particular.

Esse modelo se mostrou adequado quando teve início o uso da Web (Tanenbaum, 2002). Porém, atualmente a Web adquiriu novas funcionalidades, onde muitas vezes esse modelo torna-se inapropriado. Esse é o caso de alguns servidores Web como, por exemplo, aqueles que só permitem o acesso de clientes registrados. Nessa situação, o servidor deve ser capaz de distinguir as requisições vindas de usuários registrados daquelas vindas de clientes que não são. Situações como essa requerem que os servidores façam uso de sessões. A seguir, discute-se a respeito de como as sessões em servidores Web são caracterizadas.

\subsubsection{Caracterizando Sessões}

No contexto de e-commerce, um usuário de uma loja eletrônica pode adicionar vários itens em seu "carrinho de compras". O modo como o servidor mantém esses vários itens no carrinho de compras de determinado usuário, é feito por meio do uso de sessões.

Assim, em vários servidores Web, principalmente de comércio eletrônico, a maioria das requisições é baseada em sessão (Chen \& Mohapatra, 2002; Cherkasova \& Phaal, 2002).

Uma sessão contém uma seqüência de requisições, relacionadas, pertencentes a um mesmo cliente (Arlitt, 2000; Chen \& Mohapatra, 2002; Cherkasova \& Phaal, 2002; Wang et al., 2004).

Uma sessão é intuitivamente um período de trabalho contínuo de um usuário (Zilber et al., 2005). Porém, isto não significa que o usuário está 100\% ativo durante o tempo da sessão. Eventualmente, um usuário "pensa" ao receber a resposta de uma requisição antes de enviar a próxima, tudo isso ocorrendo dentro de uma mesma sessão. Esse tempo entre as requisições é conhecido como tempo de pensar.

O tempo de pensar varia muito dentro de uma mesma sessão. Quando o usuário faz uma requisição a um arquivo-base HTML que contém vários objetos referenciados, por exemplo, o tempo de pensar é curto. Porém, após o recebimento de todos os objetos que compõem o documento, o usuário pode "pensar" por alguns minutos antes de enviar a próxima "rajada" de requisições. 
As requisições pertencem a uma mesma sessão se há um tempo de pensar curto entre elas, isto é, se o tempo de pensar não ultrapassar um valor definido, denominado timeout. As sessões podem ser finalizadas explicitamente ou abortadas caso o tempo de pensar tenha alcançado o valor estipulado para timeout. Não exite uma definição formal para sessões e não há um valor de timeout para o tempo de pensar que seja amplamente aceito (Zilber et al., 2005).

Uma maneira que os servidores podem identificar os usuários é por meio da observação de seus endereços IP (Tanenbaum, 2002). Arlitt (2000), por exemplo, considera uma sessão como sendo todas as requisições vindas de um determinado endereço IP dentro de um determinado intervalo de tempo. Entretanto, o problema dessa abordagem surge quando vários usuários compartilham computadores e os endereços IP identificam as máquinas e não os usuários. Outro problema é que muitos IPs usam NAT (Network Address Translation $)^{2}$ e, nesse caso, os pacotes enviados por todos os usuários são vistos pelo servidor Web como pertencentes a um mesmo endereço IP.

Para permitir a identificação do usuário, o servidor Web pode utilizar o mecanismo oferecido pelos cookies, cujas características são apresentadas a seguir.

\section{Cookies}

Os cookies, definidos no RFC 2109 (Kristol \& Montulli, 1997), é um conceito introduzido pela Netscape, muito debatido quando surgiu, devido às conseqüências de guardar informações confidenciais.

O cookie tem como função principal manter a persistência de sessões HTTP e é usado para que os servidores Web obtenham informações de seus usuários (Kurose \& Ross, 2003). Para tanto, o servidor Web envia para o cliente, na mensagem de resposta HTTP, uma linha de cabeçalho iniciada por Set-cookie:, ativando um cookie no cliente. Freqüentemente, essa linha de cabeçalho contém um número de identificação gerado pelo servidor Web, como mostra o exemplo a seguir:

Set-cookie: 3459053

Quando o cliente HTTP recebe a mensagem de resposta, ao notar a linha de cabeçalho Set-cookie, ele anexa uma linha a um arquivo especial de cookies que está

\footnotetext{
${ }^{2}$ Através de um NAT, os endereços de uma rede privada (endereços falsos) são convertidos para endereços verdadeiros quando se torna necessário o acesso à Internet. Com esse mecanismo, diversos computadores com endereços falsos podem compartilhar um único endereço IP verdadeiro.
} 
armazenado em sua máquina. Essa linha inclui o nome do hospedeiro do servidor Web e o número de identificação associado ao usuário. Nas requisições subseqüentes ao mesmo servidor, o cliente inclui um cabeçalho de requisição Cookie:, especificando o número de identificação, como mostra o exemplo a seguir:

Cookie: 3459053

Dessa maneira, o servidor identifica o usuário e as requisições desse usuário que já foram atendidas.

\subsection{Considerações Finais}

Neste capítulo, foi abordada inicialmente a estrutura da Internet, sendo apresentadas as camadas de sua pilha de protocolos, responsáveis pela comunicação na rede. Foram também apresentados um panorama geral da Web e sua relevância em transformar a Internet em um dos principais meios de comunicação.

O funcionamento do protocolo de aplicação mais importante para acesso aos servidores Web, o HTTP, foi discutido para melhor compreensão do comportamento da Web. Foram apresentados os formatos das mensagens HTTP e discutiu-se sobre conexões persistentes e não persistentes.

Finalmente foram apresentados alguns motivos que levam à utilização de sessões em servidores Web, e como elas são caracterizadas. Para suprir a falta de estado do protocolo HTTP foram definidos os cookies, um mecanismo que permite o estabelecimento de sessões em servidores Web, fazendo com que o servidor consiga obter algumas informações de seus clientes.

Todos os tópicos abordados neste capítulo são considerados de grande importância para a proposta de trabalho, uma vez que a Web, mais especificamente, os servidores Web, são os objetos de estudo.

No próximo capítulo são abordados os problemas e limitações do modelo atual de serviços da Internet e a necessidade da introdução de qualidade de serviço na mesma. É discutida também a provisão de um serviço diferenciado em nível de aplicação, particularmente nos servidores Web. 


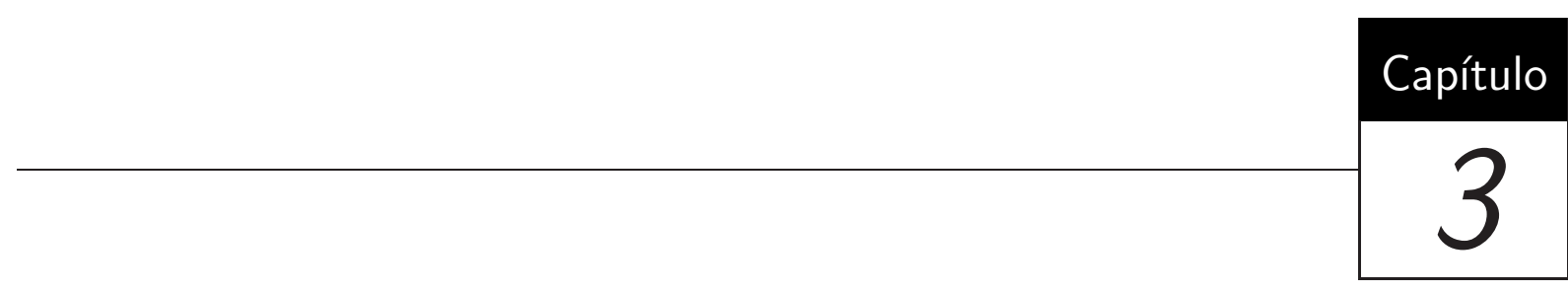

\section{Qualidade de Serviço na Internet}

\subsection{Considerações Iniciais}

A Internet é uma rede global que depende do protocolo IP para o transporte dos dados. Tal protocolo foi projetado para ser bastante flexível, podendo funcionar sobre uma gama de tecnologias de rede diferentes, fato que contribuiu para a disseminação da Internet e das redes IP por todo o mundo. Com isso, serviços como o correio eletrônico e a Web tornaram-se parte da vida das pessoas, seja para fins de entretenimento, educativos ou comerciais. Além disso, o que se nota atualmente é a convergência de outros tipos de redes, já há mais tempo estabelecidas, como as redes de telefonia, rádio e TV, para a Internet (Stardust, 1999b). A Internet deve tornar-se, em um futuro próximo, o principal meio de transmissão de informações, condução de negócios e entretenimento. A questão que se coloca é se a mesma está preparada para responder a essas novas demandas.

O protocolo IP que oferece suporte a Internet fornece um serviço de melhor esforço para todos os datagramas que transporta. Isso significa que a Internet se esforça para transportar os dados o mais rápido possível sem, contudo, apresentar garantias sobre os atrasos. Assim, desenvolver aplicações de sucesso na Internet que dependam da entrega de dados a tempo, é um problema desafiador, sobretudo quando há congestionamentos.

Alguns pesquisadores argumentam que para a Internet atender melhor as aplicações com limitações rígidas de temporização, não é necessário fazer nenhuma modificação fundamental no serviço de melhor esforço e nos protocolos subjacentes da Internet. A 
idéia é adicionar mais largura de banda. Os adversários dessa opção argumentam que largura de banda adicional pode ser dispendiosa, uma vez que a Internet é uma grande rede formada por redes, compreendendo diversas tecnologias e, portanto, não sendo tão simples incrementar a capacidade de todos os seus canais de comunicação. Argumenta-se, ainda, que não importa a quantidade de largura de banda que seja disponibilizada, a tendência é, em pouco tempo, tal quantidade ser completamente exaurida (Kurose \& Ross, 2003; Teixeira, 2004).

Em um outro extremo, alguns pesquisadores argumentam que devem ser feitas modificações fundamentais na Internet para que as aplicações possam reservar explicitamente largura de banda fim a fim. Porém, para permitir que aplicações façam reservas e exigir que a rede honre essas reservas, são necessárias grandes mudanças, exigindo novos e complexos softwares nos sistemas finais e intermediários, bem como novos tipos de serviços (Kurose \& Ross, 2003). Essa é a idéia do modelo denominado Serviços Integrados (IntServ), detalhado na Seção 3.2 .

Entre esses dois extremos há o denominado Serviços Diferenciados (DiffServ), apresentado na Seção 3.3. A idéia desse modelo é introduzir mudanças relativamente pequenas na rede e nas camadas de transporte, e introduzir esquemas simples de preço e de regulação na borda da rede.

\subsection{Serviços Integrados}

A abordagem de Serviços Integrados (IntServ), definida no RFC 1633 (Braden et al., 1994), foi a primeira das soluções propostas para dar suporte a QoS na Internet, no âmbito da IETF. A arquitetura IntServ apresenta duas características fundamentais (Kurose \& Ross, 2006):

- Recursos Reservados. O roteador deve saber que quantidade de seus recursos já está alocada para as aplicações em andamento.

- Estabelecimento de Chamada. Uma aplicação que exige garantias de QoS deve primeiramente estar habilitada a reservar os recursos suficientes em cada roteador da rede ao longo do seu trajeto, para garantir que suas exigências de QoS fim a fim sejam cumpridas. Esse processo exige a participação de cada roteador do trajeto e cada roteador deve determinar se tem recursos suficientes para satisfazer as exigências de QoS da nova aplicação, sem violar as garantias de QoS dadas às aplicações 
já em andamento.

A arquitetura IntServ define duas grandes classes de serviços: serviço garantido e serviço de carga controlada. Cada uma dessas classes fornece um modelo muito diferente de garantia de qualidade de serviço:

- Serviço Garantido. A especificação do serviço garantido, definida no RFC 2212 (Shenker et al., 1997), estabelece limites rígidos para o atraso fim a fim, além de garantir a disponibilidade de largura de banda.

- Serviço de Carga Controlada. O serviço de carga controlada, definido no RFC 2211 (Wroclawski, 1997), não oferece nenhuma garantia rígida, mas, em vez disso, assegura que a maior parte dos pacotes de uma aplicação atravessará uma Internet aparentemente descongestionada.

A arquitetura IntServ exige um protocolo de sinalização para reservar recursos dentro da rede. O protocolo RSVP (Resource Reservation Protocol), é um protocolo de controle e sinalização que atua na camada de rede, sendo responsável por reservar caminhos e recursos na sub-rede de comunicação.

\subsubsection{Protocolo RSVP}

O protocolo RSVP, definido no RFC 2205 (Braden et al., 1997), permite que as aplicações reservem recursos para seus fluxos de dados, não especificando, porém, como a rede realiza essa reserva.

O RSVP não é um protocolo de roteamento. Em vez disso, ele depende de um protocolo de roteamento subjacente para determinar as rotas dos fluxos. Assim que as rotas estiverem determinadas, o RSVP pode reservar os recursos ao longo dessas rotas (Kurose \& Ross, 2006).

Com o uso do protocolo RSVP, consegue-se atingir a maior QoS possível na Internet (Stardust, 1999a), pois ele permite fazer o gerenciamento em uma granulosidade bem fina, em nível de fluxo, conseguindo dar excelentes garantias de qualidade às aplicações. Entretanto, há um preço a se pagar por isso: o RSVP possui sérios problemas de gerenciamento e escalabilidade (Vasiliou \& Lutfiyya, 2000). Cada roteador ao longo do caminho precisa dar suporte a RSVP para que se possa assegurar a QoS. Com isso, vê-se que o 
RSVP introduz uma complexidade significativa no núcleo da Internet, o que representa uma ruptura com o seu modelo tradicional de serviços, que sempre procurou manter a rede simples e levar a complexidade para os hosts finais (Stardust, 1999a).

A abordagem de serviços integrados, portanto, aplica-se melhor a um ambiente de rede local (Teixeira, 2004). No âmbito da Internet, a abordagem de serviços diferenciados, tratada a seguir, revela-se mais adequada.

\subsection{Serviços Diferenciados}

Uma das desvantagens da arquitetura IntServ é a necessidade de roteadores para manter o estado por fluxo e uma possível falta de escalabilidade. Assim, deu-se início o desenvolvimento da arquitetura de Serviços Diferenciados (DiffServ), definida no RFC 2475 (Blake et al., 1998).

A arquitetura DiffServ visa a fornecer diferenciação de serviços escalável e flexível, ou seja, a capacidade de operar diferentes classes de tráfego de maneiras diferentes dentro da Internet.

A arquitetura dos serviços diferenciados consiste em dois conjuntos de elementos funcionais (Kurose \& Ross, 2003):

- Funções de Borda: classificação. Na borda de entrada da rede, os pacotes que chegam são marcados. A marca que um pacote recebe identifica a classe de tráfego à qual ele pertence, e assim, diferentes classes de tráfego receberão serviços diferenciados dentro do núcleo da rede.

- Funções do Núcleo: envio. Quando um pacote marcado chega a um roteador habilitado com DiffServ, ele é repassado até seu próximo roteador de acordo com o tratamento associado à classe do pacote. Esse tratamento influencia a maneira pela qual os buffers e a largura de banda de um roteador são compartilhados entre as classes de tráfego concorrentes.

Como o tratamento dado aos pacotes se baseia somente nas marcas, a arquitetura DiffServ evita a necessidade de manter nos roteadores os estados dos fluxos. Assim, a arquitetura DiffServ mantém a complexidade na fronteira da rede, princípio básico do projeto da Internet, ao contrário do modelo IntServ, que exige complexidade por todo o percurso da entrega de dados. 
A marca de um pacote é transportada dentro do campo Differentiated Service (DS) do cabeçalho do pacote IPv4 ou IPv6. Esse campo é uma substituição do campo ToS (Type of Service) do IPv4 e do campo Traffic Class do IPv6.

Atualmente, a arquitetura de serviços diferenciados define dois tratamentos dados aos pacotes no interior da rede: encaminhamento acelerado e encaminhamento garantido.

- Encaminhamento Acelerado. Esse serviço fornece a uma classe uma abstração simples de um enlace com largura de banda de enlace mínima garantida. Mesmo que outras classes de tráfego estejam sobrecarregando os recursos do roteador e do enlace, recursos suficientes deverão ser mantidos disponíveis para a classe, a fim de assegurar que ela receba sua taxa mínima garantida.

- Encaminhamento Garantido. Esse serviço divide o tráfego em quatro classes e garante, a cada classe, o fornecimento de alguma quantidade mínima de largura de banda e de buffer. Dentro de cada classe, os pacotes ainda são repartidos em uma de três categorias de "descarte preferencial". Quando ocorre um congestionamento dentro de uma classe, o roteador pode então descartar pacotes com base em seus valores de descarte preferencial.

\subsection{QoS em Nível de Aplicação}

Nas seções anteriores foram abordadas as arquiteturas de serviços integrados e de serviços diferenciados definidas para que os problemas relacionados ao serviço de melhor esforço oferecido pela Internet sejam superados.

Ambas as arquiteturas visam a oferecer melhores serviços em nível de rede. No entanto, a garantia de qualidade de serviço não terá sucesso se forem empregados apenas mecanismos em nível de rede, pois, em última instância, são os servidores Web os responsáveis pelo atendimento das solicitações dos usuários (Teixeira et al., 2005).

Atualmente, grande parte dos servidores Web trata as requisições igualmente, segundo a disciplina FCFS (First-Come First-Served). Esse tratamento uniforme pode inutilizar os esforços desprendidos em nível de rede para o oferecimento de qualidade de serviço. O uso de Serviços Diferenciados está sendo considerado uma solução eficiente para prover melhores serviços, não só em nível de rede como também em servidores Web, fato que pode ser comprovado por meio de vários trabalhos na área, como os discutidos a seguir, onde são apresentados alguns modelos de servidores Web com suporte a QoS. 


\subsubsection{Modelos de Servidores Web com Suporte a QoS}

Na Figura 3.1 é apresentado o modelo de Rede de Filas para servidores Web distribuídos proposto por Chen \& Mohapatra (1999). Esse servidor consiste de quatro componentes lógicos: um iniciador $S_{i}$, um escalonador $Q, N$ servidores de tarefa $S_{t}(t=1 \ldots N)$ e um canal de comunicação $N_{S}$. As requisições que chegam ao sistema são colocadas na fila, aguardando a admissão por $S_{i}$. Cada requisição aceita é associada a uma tarefa, e para cada tarefa é concedido um nível de prioridade pelo escalonador. As tarefas são escalonadas e processadas pelos servidores de tarefa de acordo com suas prioridades. As respostas são enviadas de volta para os clientes através do canal de comunicação.

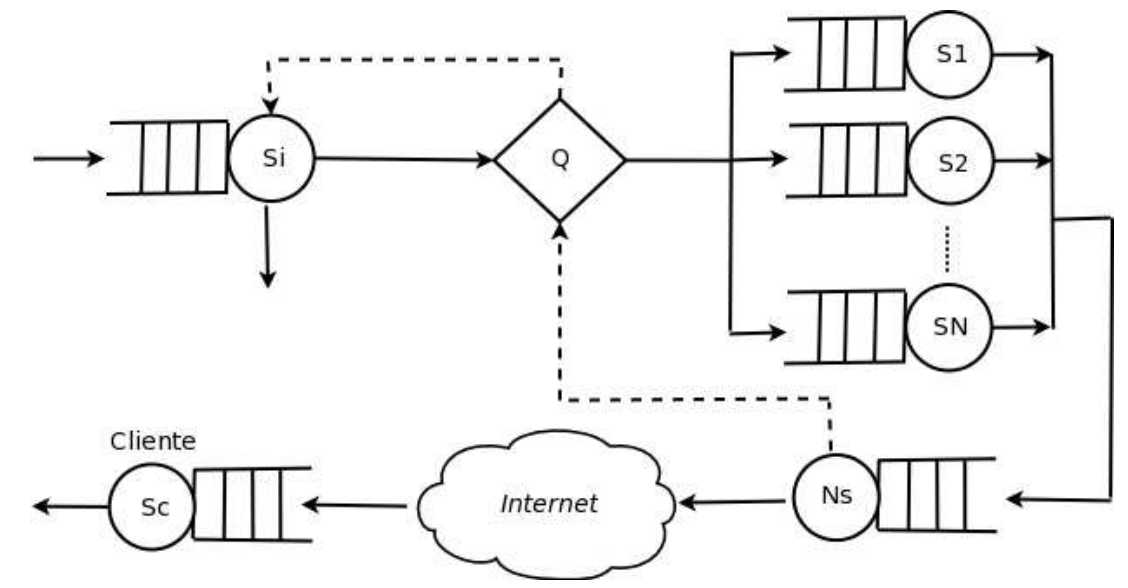

Figura 3.1: Modelo de um servidor Web distribuído (Chen \& Mohapatra, 1999).

No trabalho de Kanodia \& Knightly (2000) também é apresentado um modelo de um servidor Web com QoS (Figura 3.2). As requisições que chegam ao sistema são colocadas na fila ou rejeitadas caso essa esteja cheia. Todas as requisições são classificadas em diferentes classes. O controle de admissão determina se a admissão de uma nova requisição pode ser suportada dado os níveis de latência de todas as classes. As requisições são então escalonadas de acordo com um algoritmo de escalonamento e, finalmente, são submetidas aos nós back-end.

Ye et al. (2005) apresentam um modelo de servidor Web seqüencial com suporte a QoS, como mostra a Figura 3.3(a), cujo conceito é diferente do modelo tradicional de servidor Web multiprocessado ou multithread. Os autores concluem que essa abordagem apresenta um bom comportamento em termos de servidor Web com QoS. A diferença entre esse modelo e o modelo Best-Effort, é que no último não há controle de admissão. Os autores também sugerem um modelo DiffServ básico, como mostra a Figura 3.3(b), onde 


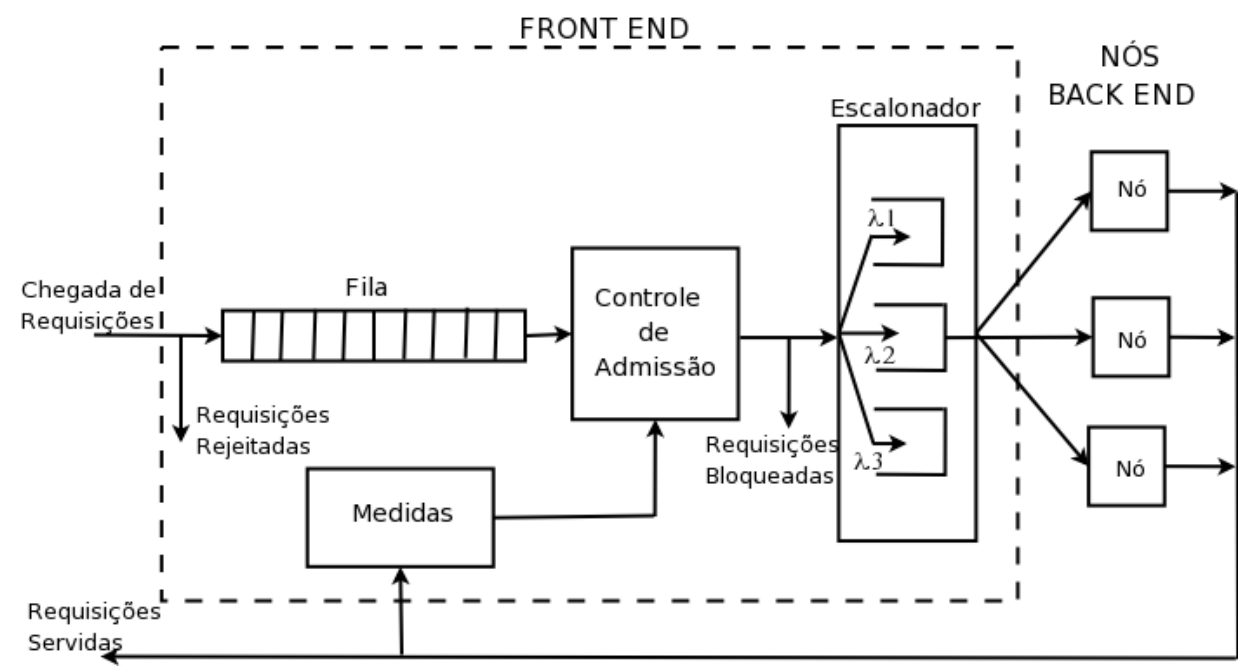

Figura 3.2: Modelo de um servidor Web com QoS (Kanodia \& Knightly, 2000).

as requisições são classificadas em diferentes prioridades e colocadas em filas separadas. Nesse modelo, o servidor sempre processa as requisições de alta prioridade antes de servir qualquer outra de menor prioridade. Baseando-se nesses dois modelos, os autores sugerem um servidor Web que consiste na "mistura" dos apresentados na Figura 3.3. Quando uma nova requisição chega nesse servidor, sua prioridade é computada e então é inserida na sua respectiva fila. Porém, antes da nova requisição ser inserida na fila, o controle de admissão é acionado, decidindo por sua aceitação ou não.

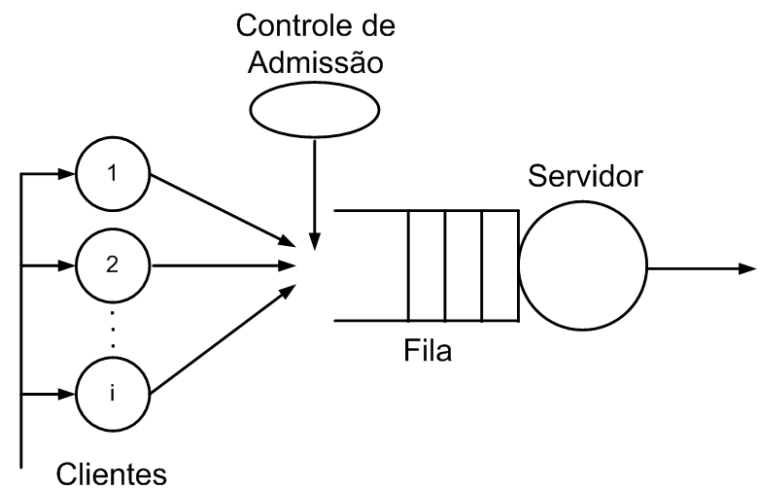

(a) Modelo de um servidor Web com QoS seqüencial.
Fila de alta prioridade

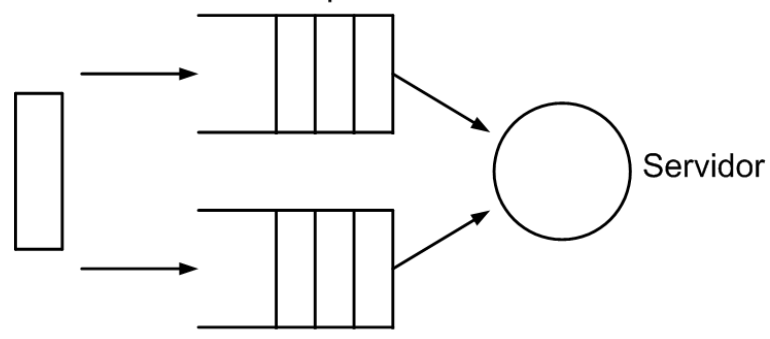

Fila de baixa prioridade

(b) Modelo DiffServ básico.

Figura 3.3: Modelos de servidores Web (Ye et al., 2005).

Teixeira (2004) define um modelo de Servidor Web com Diferenciação de Serviços (SWDS). O SWDS é detalhado no Capítulo 4 e é utilizado neste trabalho para a avaliação de desempenho das políticas desenvolvidas. 


\subsection{Considerações Finais}

Neste capítulo, foram abordadas as limitações do serviço de melhor esforço adotado na Internet, que tem se tornado ineficiente para as atuais aplicações que requerem melhores serviços.

As arquiteturas de Serviços Integrados (IntServ) e Serviços Diferenciados (DiffServ), que tem sido propostas como meios de oferecimento de qualidade de serviço em nível de rede, foram discutidas.

Finalmente, discutiu-se a importância de se prover qualidade de serviço não só em nível de rede, como também em nível de aplicação, sendo apresentados alguns modelos de servidores Web com suporte a QoS encontrados na literatura.

No próximo capítulo são apresentadas, com maiores detalhes, as características do modelo de servidor Web com serviços diferenciados utilizado neste projeto para a avaliação das políticas propostas. 
Capítulo

\section{Modelagem e Simulação de um Servidor Web com Diferenciação de Serviços e baseado em Sessões}

\subsection{Considerações Iniciais}

Como visto no capítulo anterior, para garantir qualidade de serviço para requisições Web deve-se considerar mecanismos tanto em nível de rede quanto em nível das aplicações, que no caso em questão considera os servidores Web.

Este capítulo apresenta o modelo a ser utilizado para avaliar as políticas propostas para um servidor Web com suporte a QoS, baseado em sessões. O modelo a ser utilizado se baseia no modelo definido por Teixeira (2004), o SWDS, que possui todas as características necessárias para avaliar um servidor Web com diferenciação de serviços, mas que originalmente não considera sessões. Assim, para a realização deste trabalho foi necessária a introdução de manipulação de sessões ao modelo proposto por Teixeira (2004).

Na Seção 4.2 é apresentada a arquitetura do modelo SWDS, onde são descritos os seus principais componentes. A forma de validação e parametrização desse modelo encontram-se na Seção 4.3. As modificações feitas no modelo original do SWDS, necessárias para a realização do controle de sessões, são apresentadas na Seção 4.4. A avaliação de desempenho do SWDS, quando utilizado diferentes algoritmos para o balanceamento 
de carga, é apresentada no final do capítulo, na Seção 4.5, sendo analisados os casos onde se considera ou não as sessões, tanto para cluster homogêneo quanto para cluster heterogêneo.

\subsection{Modelo do Servidor Web com Diferenciação de Serviços}

Teixeira (2004) define um modelo de Servidor Web com Diferenciação de Serviços (SWDS), cujo objetivo é o fornecimento de serviços diferenciados a seus usuários segundo os requisitos de QoS previamente estabelecidos. O SWDS, modelado por meio de Rede de Filas e apresentado na Figura 4.1, é composto pelos seguintes módulos: Classificador, Controle de Admissão e cluster de processos ou servidores Web.

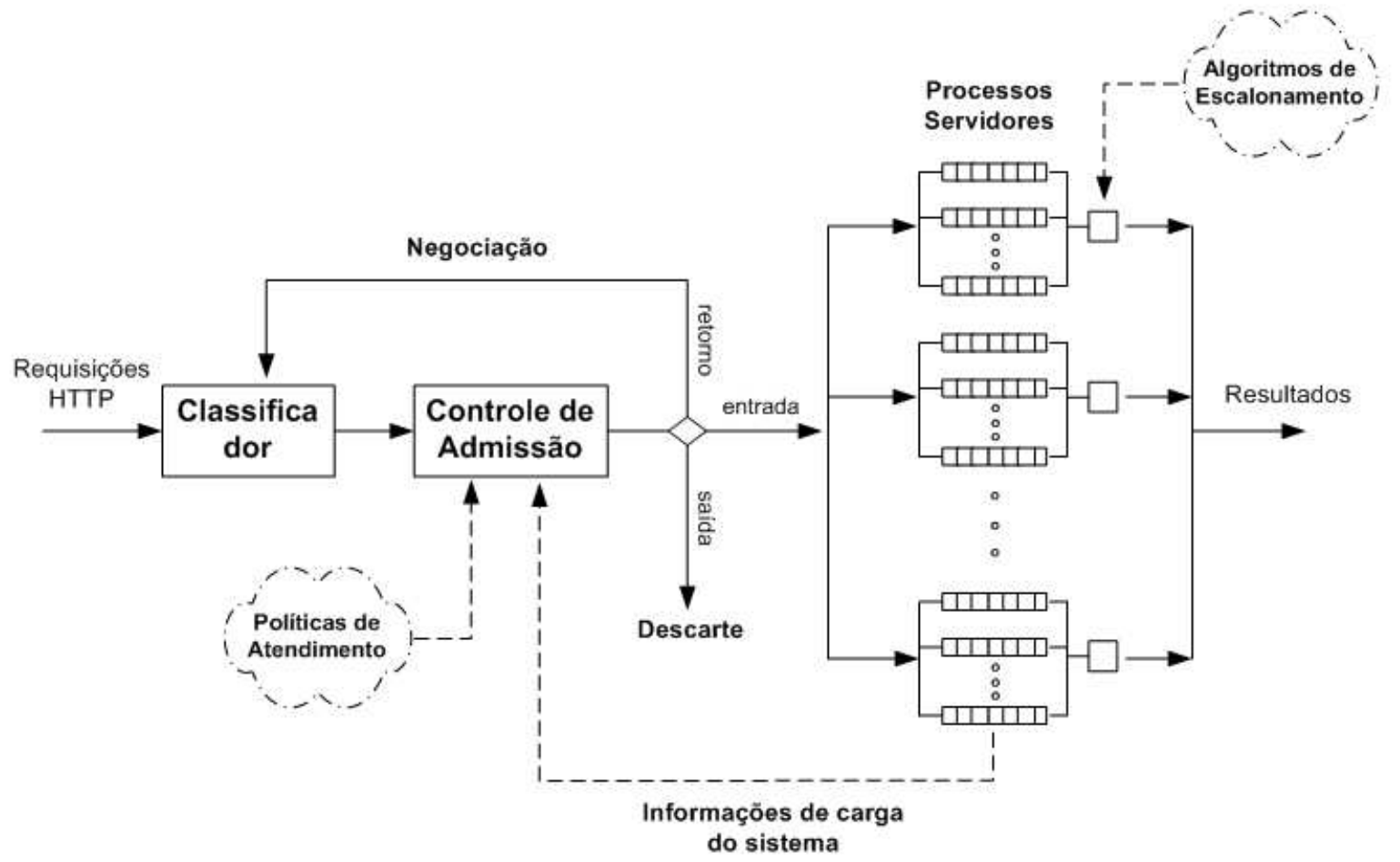

Figura 4.1: Servidor Web com Diferenciação de Serviços (SWDS) (Teixeira, 2004).

- Classificador. Módulo responsável por receber as requisições que chegam ao sistema e subdividí-las em classes de serviço, baseando-se em critérios préestabelecidos. Após a classificação, a nova requisição recebe o atendimento segundo a classe à qual pertence. 
- Controle de Admissão. Esse módulo recebe as requisições classificadas e gerencia a sua aceitação pelo servidor, segundo as políticas de atendimento e as informações da carga de trabalho do sistema. Se o servidor estiver sobrecarregado, a requisição poderá ser rejeitada (Descarte), ou ter suas exigências de qualidade de serviço relaxadas, de modo que possa ser aceita em uma classe de prioridade inferior (Negociação).

- Cluster de processos ou servidores Web. A requisição, após ser admitida no sistema, é enviada a um dos nós do cluster de servidores Web, sendo atendida conforme o algoritmo de escalonamento ou diferenciação de serviços vigente. Depois da fase de processamento, os resultados são retornados ao cliente que deu origem à solicitação.

Cada nó do cluster, modelado como um centro de serviço, é considerado como um servidor Web convencional, composto de CPU, disco e interface de rede. Cada nó possui múltiplas filas de prioridade, a fim de acomodar as diferentes classes de serviço.

\subsection{Validação e Parametrização do Modelo}

A abordagem escolhida para a solução do modelo SWDS foi a simulação, assim como feito por Teixeira (2004), autor do modelo. A simulação foi escolhida por tratar-se de uma abordagem flexível, que permite repetir os experimentos e reproduzir diversos cenários para estudos sem grandes esforços.

O simulador utilizado neste trabalho foi o SimPackJ (Fishwick, 2004), que possui uma pacote escrito na linguagem JAVA composto por vários métodos voltados à simulação de Rede de Filas, orientado a eventos discretos.

Como a Web apresenta uma grande variabilidade nas características da sua carga de trabalho, torna-se difícil definir um modelo de carga que se aplique a todas as situações. Portanto, dada a dificuldade de produzir sinteticamente a carga de um sistema Web, utilizou-se no modelo do SWDS uma simulação dirigida por "traces". Para geração de carga de trabalho para o modelo SWDS, foram utilizados logs de acesso a servidores Web reais. Os sistemas de comércio eletrônico, visando a proteção dos dados confidenciais de seus clientes, não disponibilizam as informações referentes às sessões de seus usuários. Assim, dada a dificuldade de obtenção de logs que contenham informações sobre sessões dos usuários, o log utilizado foi coletado durante a Copa do Mundo 98, na França. Tal log 
foi escolhido devido sua utilização em outros trabalhos como em Arlitt (2000) e Mourão et al. (2007), onde são apresentados estudos sobre as suas características, inclusives aquelas relacionadas às sessões.

Os registros do log são lidos seqüencialmente e usados como entrada para o modelo simulado. As requisições que chegam no sistema são divididas em classes de prioridade, sendo essa prioridade definida por meio da geração randômica de valores.

Seguindo a mesma parametrização utilizada por Teixeira (2004), resumida na Tabela 4.1, considerou-se um cluster onde cada nó é modelado separadamente, com sua própria CPU, disco e interface de rede. Adicionalmente, o servidor SWDS utiliza os módulos de Classificação e de Controle de Admissão. A capacidade de processamento do Classificador é definida como 8000 requisições/seg e a do módulo de Controle de Admissão como 4000 requisições/seg. Para o cálculo do tempo de serviço das requisições estáticas, os discos dos servidores são parametrizados com taxa de transferência e latência conforme indicados na Tabela 4.1, tomando-se como referência um disco IBM Deskstar 75GXP (IBM, 2003). O tempo de serviço das requisições dinâmicas é assumido como 10ms.

Tabela 4.1: Parâmetros do modelo SWDS (Teixeira, 2004).

\begin{tabular}{|l|r|}
\hline Parâmetro & Valor \\
\hline \hline Capacidade do Classificador & $8000 \mathrm{req} / \mathrm{seg}$ \\
Capacidade do Controle de Admissão & $4000 \mathrm{req} / \mathrm{seg}$ \\
Taxa de transferência do disco & $37 \mathrm{MBps}$ \\
Latência do disco & $8,5 \mathrm{~ms}$ \\
Capacidade da interface de rede & $80 \mathrm{Mbps}$ \\
Tempo de serviço das requisições dinâmicas & $10 \mathrm{~ms}$ \\
\hline
\end{tabular}

\subsection{Modificações no Modelo de Simulação do SWDS}

Algumas modificações foram realizadas no modelo de simulação original do SWDS visando a considerar uma carga de trabalho baseada em sessões. As principais alterações se referem à capacidade do modelo em manipular as sessões.

\subsubsection{Controle das Sessões}

Como o modelo original não faz uso de sessões, as primeiras modificações consistiram em fazer com que o modelo de simulação fosse capaz de manipulá-las. 
Para a definição das sessões, foram utilizadas as informações contidas no log utilizado como carga de trabalho. Cada registro contido no log contém vários campos, como os campos clientID e timestamp. O campo clientID é responsável pela identificação do cliente e consiste de um mapeamento do seu endereço IP. O valor contido no campo timestamp é utilizado nos experimentos para o cálculo do tempo de chegada da requisição ao sistema.

Segundo Arlitt (2000), uma sessão corresponde a uma seqüência de requisições feitas por um determinado usuário durante o acesso ao servidor Web. O autor, que também utiliza o log da Copa do Mundo 98 como carga de trabalho, considera que um único endereço IP contido no $\log$ de acesso refere-se a um único usuário, e alerta para o fato de que isso pode não ser verdade para todos os casos. Um exemplo é quando servidores proxies são utilizados e nesse caso um único endereço IP pode corresponder a vários usuários. No entanto, o autor acredita que o uso do endereço IP provê uma aproximação razoável de usuários que visitam o servidor Web.

Dessa forma, assim como em Arlitt (2000), o controle das sessões é feito a partir da análise do campo clientID das requisições que chegam ao sistema. Todas as requisições vindas do mesmo clientID pertencem a mesma sessão, desde que o tempo entre chegadas dessas requisições não ultrapasse o tempo limite definido pelo sistema, denominado timeout. Caso o tempo de chegada da nova requisição ultrapasse o timeout, uma nova sessão para clientID é iniciada. Ou seja:

\section{SE existir sessão para clientID $\mathbf{E}$ timestamp $\leq$ t_prox_req nova requisição pertence a sessão t_prox_req $=$ timestamp + timeout}

\section{SENÃO}

nova sessão é criada

onde t_prox_req $=$ tempo limite esperado por uma requisição pertencente a sessão

A finalização de uma sessão ocorre quando todas as suas requisições forem atendidas e o tempo máximo esperado para a chegada da próxima requisição (timeout) for atingido. Conforme apresentado na Seção 2.4.1, não há um valor para o timeout que seja amplamente aceito. Nos experimentos deste trabalho o valor do timeout é definido em 2 minutos, isto é, 120 segundos. 


\subsubsection{Módulo Classificador}

Conforme descrito nas Seções 4.2 e 4.3, o módulo Classificador é responsável pela classificação, em classes de serviços, das requisições que chegam ao sistema, por meio da geração randômica de valores.

Como o modelo original não faz uso de sessões, eventualmente as requisições pertencentes a uma mesma sessão não necessariamente recebem a mesma classificação. No entanto, todas as requisições de uma mesma sessão devem possuir o mesmo nível de prioridade para que a diferenciação de serviços entre os usuários seja obedecida.

Sendo assim, a alteração no módulo Classificador consistiu em classificar todas as requisições de uma mesma sessão em um mesmo nível de prioridade. Somente a primeira requisição da sessão é que recebe a classificação da mesma maneira que a realizada no modelo original do SWDS, ou seja, de acordo com critérios previamente estabelecidos. Definida a classe de prioridade da requisição, e conseqüentemente da sessão, todas as futuras requisições relacionadas à mesma sessão receberão o mesmo nível de prioridade. Dessa forma, quando utilizada alguma política de diferenciação de serviços, a distinção das classes será realizada em nível de sessão ao invés de nível de requisição como ocorria anteriormente.

\subsubsection{Gerenciamento do Estado das Sessões}

As informações do estado de uma sessão podem estar contidas nas variáveis de sessão, armazenadas em ficheiros de textos ou em uma base de dados, por exemplo, do servidor Web.

Quando considerado um cluster de servidores Web, onde não existe compartilhamento das variáveis entre os nós do sistema, o gerenciamento de estado das sessões pode ser realizado de forma a fazer com que um cliente, ao se conectar no sistema, tenha seus pedidos subseqüentes sempre direcionados para o mesmo servidor.

Dessa forma, para o gerenciamento do estado das sessões no SWDS, foi implementado o método que consiste em direcionar para o mesmo servidor todas as requisições de determinada sessão. Assim, cada servidor Web será responsável somente por manter as informações de estado das sessões encaminhadas a ele.

A aplicação de tal método, no entanto, pode prejudicar o balanceamento de carga caso não seja escolhido um bom algoritmo para a realização do balanceamento, como pode 
ser observado na seção a seguir.

\subsection{Algoritmos de Balanceamento de Carga}

Os primeiros experimentos realizados têm como objetivos a familiarização com o modelo de simulação do SWDS fazendo-se uso de sessões, e a análise do emprego de diferentes algoritmos de balanceamento de carga quando considerada as sessões para os casos de cluster homogêneo e heterogêneo. Dois algoritmos de balanceamento foram considerados para a alocação das tarefas aos nós do cluster:

- Round Robin $(R R)$. Esse algoritmo atribui as tarefas aos nós servidores segundo um esquema de rodízio.

- Shortest Queue First (SQF). Esse algoritmo encaminha as tarefas ao nó servidor que possuir o menor número de requisições em fila, visando alcançar um melhor balanceamento de carga. Quando comparado com o algoritmo RR, o algoritmo SQF introduz uma sobrecarga maior ao sistema, uma vez que o algoritmo precisa de informações precisas sobre a carga dos nós a cada momento.

Nos experimentos a seguir, o modelo SWDS foi simulado seguindo as configurações apresentadas na Seção 4.3, considerando um cluster com quatro servidores Web numerados de 0 a 3. Como carga de trabalho são utilizados 200.000 registros lidos dos logs de acesso ao site da Copa do Mundo 98. Não são consideradas as classes de serviços dos usuários e assim que as requisições chegam ao sistema, após serem direcionadas para o servidor Web apropriado de acordo com algoritmo de balanceamento adotado, essas requisições são atendidas segundo o algoritmo FIFO, ou seja, de acordo com a ordem de chegada. Optouse também por não utilizar o controle de admissão a fim de não interferir no desempenho dos algoritmos.

Para cada algoritmo de balanceamento considerado, é analisado seu desempenho variando-se o tipo de cluster e de carga de trabalho. Quanto ao tipo de cluster, considerase um cluster homogêneo e um cluster heterogêneo. Em um cluster homogêneo, todos os quatro nós considerados exibem a mesma configuração de hardware e software. Em um cluster heterogêneo, considera-se que um servidor (servidor 0) apresenta disco dez vezes mais lento que os demais. Quanto ao tipo de carga de trabalho, considera-se ou não o uso de sessões. 
Resumindo, para cada algoritmo de balanceamento, considera-se dois fatores, com dois níveis cada um:

- Fator 1 - Carga de Trabalho

- Nível I - Sem Sessões

- Nível II - Com Sessões

- Fator 2 - Cluster

- Nível I - Cluster Homogêneo

- Nível II - Cluster Heterogêneo

Foram realizados experimentos considerando todas as combinações possíveis entre os fatores, caracterizando um modelo fatorial completo (Jain, 1991) e resultando em quatro experimentos para cada algoritmo de balanceamento de carga considerado.

As métricas de desempenho utilizadas foram o tempo de residência das requisições, que compreende o tempo em que a requisição é admitida até o momento em que é enviada para o cliente, isto é, o tempo em fila mais o tempo em atendimento, e a vazão, medida como o número de requisições atendidas por segundo. Para a análise do desempenho obtido por cada algoritmo de balanceamento, é apresentado o tempo médio de residência das requisições por servidor Web, assim como o tempo médio de residência no sistema, isto é, sem distinção dos servidores.

\subsubsection{Algoritmo de Balanceamento Round Robin - RR}

Os resultados obtidos com o algoritmo RR, variando-se os níveis dos fatores citados na Seção 4.5, são apresentados na Tabela 4.2.

Tabela 4.2: Avaliação do algoritmo de balanceamento RR.

\begin{tabular}{|l|r|r||r|r|}
\hline \multirow{2}{*}{ Métricas } & \multicolumn{2}{|c||}{ Cluster Homogêneo } & \multicolumn{2}{c|}{ Cluster Heterogêneo } \\
\cline { 2 - 5 } & Sem Sessão & Com Sessão & Sem Sessão & Com Sessão \\
\hline \hline Tempo M. Resid. - serv. 0 (s) & 2,92 & 2,21 & 22,77 & 17,97 \\
Tempo M. Resid. - serv. 1 (s) & 2,98 & 5,68 & 2,98 & 5,68 \\
Tempo M. Resid. - serv. 2 (s) & 2,60 & 7,19 & 2,60 & 7,19 \\
Tempo M. Resid. - serv. 3 (s) & 2,78 & 2,82 & 2,78 & 2,82 \\
\hline \hline Tempo M. Resid. - Sistema (s) & 2,82 & 4,49 & 7,41 & 8,19 \\
Vazão (requisições/s) & 461,63 & 458,16 & 450,46 & 449,15 \\
\hline
\end{tabular}


A partir dos dados da Tabela 4.2, observa-se que o algoritmo RR realiza um bom balanceamento quando considerado um cluster homogêneo sem o uso de sessões. Nesse caso, observa-se que o tempo médio de residência em cada servidor foi diferente, dado que algumas requisições são maiores que outras. Quando considerada as sessões, as diferenças de tamanho entre as tarefas submetidas aos servidores tornam-se maiores. Nesse caso, o algoritmo RR distribui entre os servidores Web o mesmo número de sessões, porém a quantidade de requisições que cada sessão possui é diferente e, ainda, o tamanho das requisições também diferem. Assim, o uso de sessões prejudica o balanceamento oferecido pelo RR, uma vez que o algoritmo realiza um rodízio de sessões ao invés de requisições como no caso anterior. Observa-se que o tempo médio de residência no sistema subiu de 2, $82 s$ para 4, 49s quando considerada as sessões em um cluster homogêneo.

Observa-se que o algoritmo RR não fornece um bom balanceamento de carga em servidores Web distribuídos heterogêneos, dado que as requisições atendidas pelo servidor 0 sofreram muitos atrasos. Quando não se faz uso de sessões, o tempo médio de residência no servidor 0 , igual a 22,77s, foi cerca de oito vezes superior ao tempo obtido em um cluster homogêneo $(2,92 s)$. Comparando os resultados quando faz-se ou não o uso de sessões, verifica-se que o tempo médio de residência no servidor 0 é maior quando as sessões não são consideradas $(22,77 \mathrm{~s}$ contra $17,97 \mathrm{~s})$. Porém, o tempo médio de residência no sistema é maior quando se faz uso de sessões $(7,41 s$ contra $8,19 s)$, indicando que o balanceamento foi pior nesse caso.

\subsubsection{Algoritmo de Balanceamento Shortest Queue First - SQF}

Na Tabela 4.3 são exibidos os dados obtidos com o uso do algoritmo de balancemaneto SQF, considerando todos os níveis dos fatores exibidos na Seção 4.5.

Tabela 4.3: Avaliação do algoritmo de balanceamento SQF.

\begin{tabular}{|l|r|r||r|r|}
\hline \multirow{2}{*}{ Métricas } & \multicolumn{2}{|c||}{ Cluster Homogêneo } & \multicolumn{2}{c|}{ Cluster Heterogêneo } \\
\cline { 2 - 5 } & Sem Sessão & Com Sessão & Sem Sessão & Com Sessão \\
\hline \hline Tempo M. Resid. - serv. 0 (s) & 2,82 & 3,44 & 7,93 & 8,08 \\
Tempo M. Resid. - serv. 1 (s) & 2,82 & 2,81 & 7,08 & 7,00 \\
Tempo M. Resid. - serv. 2 (s) & 2,82 & 2,62 & 7,07 & 6,89 \\
Tempo M. Resid. - serv. 3 (s) & 2,81 & 2,88 & 7,07 & 6,82 \\
\hline \hline Tempo M. Resid. - Sistema (s) & 2,82 & 2,94 & 7,27 & 7,17 \\
Vazão (requisições/s) & 461,58 & 461,48 & 450,65 & 450,90 \\
\hline
\end{tabular}

Nota-se, a partir dos dados da Tabela 4.3, que o algoritmo SQF permite que os tempos médios de residência dos servidores considerados sejam equivalentes para o caso de 
cluster homogêneo sem o uso de sessões, resultando em um bom balanceamento de carga. Analisando o sistema como um todo e comparando com os resultados obtidos com o uso do algoritmo RR, nota-se que os dois algoritmos de balanceamento apresentaram praticamente o mesmo desempenho, como pode ser observado por meio dos valores de tempo médio de residência no sistema (ambos os casos iguais a 2, 82s) e a vazão (461, 63 requisições/s no algoritmo RR e 461, 58 requisições/s no algoritmo SQF). Quando consideradas as sessões no cluster homogêneo, o algoritmo SQF permitiu um melhor balancemaneto de carga comparando-se com o algoritmo RR. Nesse caso, o algoritmo SQF apresentou tempo médio de residência no sistema igual a 2,94s, próximo ao tempo de $2,82 s$ obtidos no caso onde não se faz uso de sessões, contra $4,49 s$ obtidos com o algoritmo RR.

Para os casos onde considera-se cluster heterogêneo, o desempenho obtido foi inferior aos casos do cluster homogêneo, como era esperado, uma vez que o servidor 0 apresenta disco dez vezes mais lento que os demais servidores. Observa-se que o algoritmo SQF apresentou um bom balanceamento de carga, mesmo para o cluster heterogêneo, diferentemente do algoritmo RR. A variação da carga de trabalho, isto é, sem ou com o uso de sessão, não influenciou o desempenho do sistema quando considerado o algoritmo SQF.

\subsubsection{Considerações sobre os Resultados Obtidos}

Os resultados obtidos dos experimentos mostram que em um cluster homogêneo o algoritmo RR apresenta desempenho equivalente ao algoritmo SQF quando não há uso de sessões. No entanto, quando a carga de trabalho é baseada em sessões e os servidores mantêm o estado dessas sessões direcionando todas as requisições do mesmo usuário para o mesmo servidor, o balanceamento de carga pode ser prejudicado. Nesse caso, o mau balanceamento realizado pelo algoritmo $R R$ faz com que o desempenho do sistema seja depreciado, diminuindo a vazão e aumentando consideravelmente o tempo de residência de algumas tarefas. Como era o esperado, o algoritmo RR comporta-se pior nos casos em que se utiliza um cluster heterogêneo, mesmo quando a carga de trabalho não é baseada em sessão.

Já o algoritmo SQF realizou um melhor balanceamento em todos os cenários analisados, isto é, em cluster homogêneo e heterogêneo, considerando-se ou não sessões.

Analisando a importância dos fatores considerados, em relação ao tempo médio de residência no sistema, tem-se que para o algoritmo $\mathrm{RR}$ o impacto do tipo de cluster 
(homogêneo ou heterogêneo) no desempenho é de 91,00\%, contra 7,95\% causado pelo tipo de carga de trabalho (sem ou com sessão). Quanto ao algoritmo SQF, tem-se que o tipo de cluster impacta 99,94\% no desempenho, enquanto que o tipo de carga de trabalho não apresenta impacto algum, isto é, 0,00\%. Para melhor visualização, esses dados são exibidos na Tabela 4.4.

Tabela 4.4: Efeitos dos fatores em relação ao tempo médio de residência no sistema.

\begin{tabular}{|l|r|r|}
\hline Fator & RR & SQF \\
\hline \hline Carga de Trabalho & $7,95 \%$ & $0,00 \%$ \\
Cluster & $91,00 \%$ & $99,94 \%$ \\
\hline
\end{tabular}

Portanto, o algoritmo SQF foi escolhido para a realização do balanceamento de carga nos próximos experimentos, uma vez que a consideração ou não das sessões não se revelou um fator relevante, diferentemente do ocorrido com o algoritmo RR.

\subsection{Considerações Finais}

Este capítulo apresentou um modelo de arquitetura para um Servidor Web com Diferenciação de Serviços (SWDS) desenvolvida por Teixeira (2004), cujo objetivo é oferecer aos seus clientes qualidade de serviço diferenciada. Também foram apresentados os modos de validação e parametrização do modelo, utilizados nos experimentos apresentados neste trabalho. As alterações feitas no modelo original do SWDS, necessárias para a realização do controle das sessões, foram descritas.

No final do capítulo foram apresentados os resultados de alguns experimentos considerando diferentes algoritmos de balanceamento de carga, isto é, algoritmos RR e SQF, além de considerar ou não o uso de sessões, adotando-se cluster homogêneo e heterogêneo. Tais experimentos permitiram maior familiaridade com o modelo de simulação do SWDS fazendo-se uso de sessões e, a partir dos resultados obtidos, avaliou-se a importância de se considerar as sessões na escolha do algoritmo de balanceamento. Os resultados obtidos mostram que o algoritmo RR pode não apresentar um bom desempenho quando se consideram sessões, enquanto que o desempenho oferecido pelo uso do algoritmo SQF foi superior nas mais diferentes situações analisadas.

Embora o modelo utilizado nos experimentos tenha suporte a QoS, os experimentos realizados neste capítulo não consideram mecanismos que garantem o oferecimento desse suporte, tais como os mecanismos de diferenciação de serviços e os mecanismos 
de controle de admissão. Esses mecanismos são tratados nos capítulos posteriores. No próximo capítulo, Capítulo 5, discute-se em detalhes a implementação e os resultados de novos algoritmos de diferenciação de serviços para sistemas que fazem uso de sessões. $\mathrm{O}$ Capítulo 6, por sua vez, trata dos mecanismos de controle de admissão. 


\section{Algoritmos de Escalonamento Baseados em Sessão}

\subsection{Considerações Iniciais}

No Capítulo 1 foram apresentados os quatro princípios para o fornecimento de garantias de QoS em nível de rede, Classificação, Isolamento, Alta Utilização dos Recursos e Controle de Admissão (Kurose \& Ross, 2000, 2003, 2006), que foram transportados para o nível de aplicação por Cardellini et al. (2001) introduzindo o conceito de QoWS, de modo que os servidores Web também possam oferecer QoS aos seus usuários..

Cardellini et al. (2001) afirmam que o Isolamento é um dos mais importantes princípios emprestados da teoria de QoS, podendo ser alcançado por meio de políticas de escalonamento e/ou por meio de políticas de particionamento de recursos (Andreolini et al., 2004).

Na Seção 5.2 são apresentados alguns desses algoritmos encontrados na literatura, responsáveis pela diferenciação de serviços. No entanto, os algoritmos apresentados não consideram sessões para a tomada das decisões, podendo fazer com que o desempenho esperado seja prejudicado caso o sistema possua carga de trabalho baseada em sessão, como os sistemas de comércio eletrônico, por exemplo. Assim, neste capítulo são propostos dois novos algoritmos para servidores Web com suporte à QoS que utilizam sessões: o algoritmo de escalonamento baseado em sessão (SBSA) e o algoritmo de escalonamento 
baseado em sessão com diferenciação de serviços (SBSA-DS), ambos detalhados nas Seções 5.3 e 5.4 , respectivamente.

\subsection{Trabalhos Relacionados}

A seguir são discutidas as políticas de escalonamento e as políticas de particionamento de recursos, sendo apresentados alguns algoritmos encontrados na literatura.

\subsubsection{Políticas de Escalonamento}

Na grande maioria dos servidores Web atuais, as requisições são atendidas segundo a disciplina First-Come First-Served.

As políticas de escalonamento para servidores Web com suporte a serviços diferenciados visam fornecer a diferenciação de serviços por meio de alterações nesse atendimento FIFO das filas desses servidores. Por isso, a implementação de algoritmos desse tipo em sistemas reais, requer alterações em nível de sistema operacional do servidor Web, uma vez que será necessária a realização de modificações no algoritmo de escalonamento dos processos, caso a arquitetura do servidor atenda as requisições por meio da criação de processos, ou modificações no algoritmo de escalonamento de threads, caso a arquitetura do servidor atenda as requisições por meio da criação de threads.

Entre as políticas de escalonamento para a diferenciação de serviços estão o Mecanismo de Prioridades Rigoroso (Teixeira et al., 2005), Mecanismo de Prioridades Adaptativo (PriAdap) (Teixeira et al., 2005) e Weighted Fair Queuing (WFQ) (Traldi et al., 2006).

\section{Mecanismo de Prioridades Rigoroso}

O Mecanismo de Prioridades Rigoroso (Teixeira et al., 2005) implementa o conceito básico de diferenciação de serviços (Ye et al., 2005), que consiste em atender todas as requisições de uma determinada classe, obedecendo a ordem de chegada, para que posteri-

ormente sejam atendidas aquelas requisições de prioridade inferior. Isto é, o atendimento das requisições obedece estritamente a ordem das prioridades, onde as requisição de mais alta prioridade são sempre atendidas primeiramente, e as requisições de prioridade inferior são atendidas quando não houver requisição de classe superior aguardando em fila. 
Esse mecanismo consegue realizar a diferenciação de serviços, porém, o seu uso pode fazer com que as requisições de alta prioridade monopolizem os recursos do sistema, ocorrendo negação de serviço às requisições de menor prioridade.

\section{Mecanismo de Prioridades Adaptativo (PRIAdap)}

O Mecanismo de Prioridades Adaptativo (PRIAdap) (Teixeira et al., 2005), procura fazer uma sintonia fina do emprego das prioridades, relaxando ou intensificando a sua utilização conforme o caso. Nesse mecanismo é utilizado um parâmetro que determina o número máximo de posições da fila de espera que serão percorridas a partir do início, à procura de uma requisição, de determinada prioridade, para ser atendida pelo servidor Web. Caso não encontre nenhuma requisição do tipo especificado, o algoritmo será repetido para o nível de prioridade imediatamente inferior e assim por diante. Dessa forma, pode-se atribuir uma maior ou menor importância às requisições de alta prioridade, a fim de evitar que estas venham a monopolizar o uso dos recursos do sistema.

O mecanismo adaptativo reconhece que as requisições de menor prioridade não podem esperar indefinidamente nas filas e por isso introduz uma certa flexibilidade na escolha da próxima requisição a ser atendida.

\section{Weighted Fair Queuing (WFQ)}

O algoritmo WFQ foi projetado para o nível de rede e está implementado em alguns roteadores fabricados atualmente, como os roteadores da Cisco (Cisco, 1997).

Considerando que existem dois fluxos ativos (não vazios), $A$ e $B$, em um roteador que utiliza o WFQ como algoritmo de escalonamento e, que todos os pacotes presentes no sistema tenham tamanhos iguais e estejam distribuídos entre esses fluxos, espera-se que a cada ciclo de atendimento sejam transmitidos dois pacotes do fluxo $A$ e um do fluxo $B$, se forem atribuídos os pesos dois e um para os fluxos $A$ e $B$, respectivamente. Nessa situação, o fluxo $A$ tem prioridade em relação ao $B$. À medida que o peso atribuído à $A$ assume valores maiores, maior diferenciação será observada entre os fluxos.

Na implementação para o nível de aplicação, o algoritmo WFQ deixa de trabalhar segundo uma visão de pacotes e passa a considerar requisições Web.

O algoritmo Weighted Fair Queuing (WFQ) (Traldi et al., 2006) considera um servidor Web com múltiplas filas, uma para cada classe de prioridade. Para cada classe 
atribui-se um peso que indica quantas requisições de sua respectiva fila devem ser atendidas. Após o atendimento dessas requisições, serão atendidas requisições da fila de prioridade inferior, e assim sucessivamente, segundo o algoritmo Round-Robin. Caso encontre uma fila de classe vazia, o algoritmo WFQ passa para a classe seguinte na seqüência de atendimento.

\subsubsection{Políticas de Particionamento}

As políticas de particionamento realizam a diferenciação de serviços por meio da reserva de recursos. A idéia dessas políticas é oferecer um tratamento diferenciado com um simples direcionamento das tarefas para os recursos apropriados, dando preferência para as tarefas de maior prioridade.

Assim, as políticas de particionamento, diferentemente das políticas de escalonamento, permitem que a diferenciação de serviços seja realizada juntamente com o balanceamento da carga. Dessa forma, as políticas de particionamento de recursos podem ser implementadas em níveis mais altos de abstração.

Essas políticas podem ser divididas em estáticas e dinâmicas. Entre os algoritmos de particionamento estático estão o StaticPartitioning (Cardellini et al., 2001), StaticPart (Andreolini et al., 2004) e Reserva de Recursos (RSV) (Teixeira, 2004). Entre os algoritmos de particionamento dinâmico podem ser destacados DynamicPartitioning (Cardellini et al., 2001), DDSD (Zhu et al., 2001), DynamicPart (Andreolini et al., 2004), Reserva Adaptativa de Recursos (RSVAdap) (Traldi et al., 2006) e WS-DSAC (Serra et al., 2005).

Existem no mercado produtos onde são implementados algoritmos de particionamento, como é o caso dos switches Alteon WebOS (Nortel Networks ${ }^{1}$ ), BigIP (F5²) e Central Dispatch $\left(\right.$ Resonate $\left.^{3}\right)$, por exemplo.

\section{Particionamento de Recursos Estático}

Nos algoritmos de particionamento estático, uma vez definida a divisão dos recursos entre as classes de serviço, essa é mantida permanentemente, até que seja alterada explicitamente pelo administrador do sistema. Alguns exemplos de algoritmos desse tipo são apresentados a seguir.

\footnotetext{
${ }^{1}$ http: //www. nortel.com

${ }^{2}$ http://www.f5.com

${ }^{3}$ http: //www.resonate.com
} 
O algoritmo StaticPartitioning (Cardellini et al., 2001) associa, para cada classe de serviço, um conjunto de servidores responsáveis pelo atendimento das requisições da classe associada. Para um sistema de $N$ servidores, os autores propõem, como solução trivial, um conjunto de servidores de $K$ elementos, onde $K=\lceil\rho N\rceil$ e $\rho$ é a porcentagem de requisições pertencentes à classe em questão. Ainda, esse número de elementos $K$ pode ser acrescido de algumas unidades, de modo a satisfazer o acordo de nível de serviço firmado com os usuários. Esse conjunto de servidores permanece constante até que o administrador do sistema o altere.

Em Andreolini et al. (2004), os autores consideram o algoritmo StaticPart, que diferencia do StaticPartitioning somente na escolha de quantos servidores devem ser acrescidos no valor $K$ para que o acordo de nível de serviço seja respeitado.

O algoritmo RSV (Teixeira, 2004) subdivide o cluster de servidores em partições e associa cada partição a uma classe ou conjunto de classes de serviço, de maneira estática. Nesse algoritmo, é necessário que o administrador conheça previamente a carga de trabalho que será imposta ao sistema, para que o particionamento do cluster resulte em uma diferenciação de serviços.

O particionamento estático de recursos aplica-se melhor a casos em que o padrão da carga de trabalho é razoavelmente conhecido e previsível. Contudo, em ambientes livres como a Web, esse esquema apresenta algumas desvantagens, dentre elas o fato de que variações na carga de trabalho, mesmo que pequenas, podem tornar inapropriada a alocação de recursos feita inicialmente, produzindo resultados contrários ao esperado.

Outra desvantagem no uso de algoritmos de particionamento estático está no fato de que os recursos reservados para uma determinada classe de serviço podem estar sobrecarregados enquanto os demais recursos do sistema estão subutilizados.

Nesse contexto surgem os algoritmos de particionamento dinâmico, desenvolvidos para superar as deficiências dos algoritmos estáticos.

\section{Particionamento de Recursos Dinâmico}

Nos algoritmos de particionamento dinâmico, a divisão dos recursos entre as classes de serviço muda constantemente, a medida que se altera a carga de trabalho imposta ao sistema. Alguns exemplos de algoritmos desse tipo são apresentados a seguir.

No algoritmo DynamicPartitioning (Cardellini et al., 2001), caso a soma da carga dos servidores da classe de maior prioridade for maior que um certo limite, um servidor da 
classe baixa é movido para a classe alta. Nesse ponto, o servidor movido receberá somente novas requisições da classe alta, enquanto continuará atendendo as requisições da classe baixa já aceitas e pendentes na fila do servidor. O servidor removido pode voltar para a classe baixa, caso sua ausência ainda permita que o SLA não seja violado.

Andreolini et al. (2004) consideram o algoritmo DynamicPart, semelhante ao algoritmo DynamicPartitioning descrito anteriormente, com ressalvas de que o DynamicPart considera o número de requisições para documentos estáticos e dinâmicos como medida de carga do sistema, diferente daquele proposto em Cardellini et al. (2001).

Zhu et al. (2001) propõem um algoritmo que garanta prioridade de serviços sem sobrecarregar o sistema e sem sacrificar as requisições de baixa prioridade. O algoritmo se adapta dinamicamente às variações na demanda de recursos, modificando o particionamento atual do cluster de servidores Web caso necessário. Esse algoritmo oferece garantias "leves" de desempenho calculando, periodicamente, quantos servidores devem ser associados para uma classe de requisição e qual a porcentagem de requisições dessa classe deve ser rejeitada para prover a diferenciação de serviços e alguma garantia de desempenho.

O algoritmo RSVAdap (Traldi et al., 2006) realiza a divisão dos recursos sob demanda, de acordo com a carga de trabalho vigente, objetivando sempre garantir melhores serviços para as tarefas prioritárias. Baseando-se na quantidade de requisições de cada classe de serviço presente no sistema, o algoritmo decide se mais ou menos recursos devem ser associados às classes, para que a diferenciação de serviços e a alta utilização dos recursos do sistema sejam alcançadas.

Serra et al. (2005) apresentam o mecanismo denominado WS-DSAC objetivando balancear a carga imposta ao sistema, permitir a diferenciação de serviços e utilizar de forma eficaz os recursos disponíveis. O algoritmo é considerado em um ambiente formado por vários clusters, onde cada um desses clusters pertence a um "domínio de uma classe". O algoritmo WS-DSAC realiza a diferenciação de serviços direcionando as requisições que chegam ao sistema para o cluster de seu domínio. Como um dos objetivos do algoritmo é utilizar de forma eficaz os recursos, é realizada a realocação dinâmica dos recursos entre as classes. Essa realocação consiste no compartilhamento dos recursos entre as classes envolvidas e só é efetuada caso a qualidade de serviço possa ser garantida. 


\subsection{Algoritmo de Escalonamento Baseado em Sessão (Session-Based Scheduling Algorithm - SBSA)}

Nos algoritmos encontrados na literatura, como os citados na Seção 5.2, a diferenciação de serviços é realizada utilizando uma carga de trabalho que não é baseada em sessão. No entanto, o uso de sessões em servidores Web tem se tornado cada vez mais freqüente, principalmente em sistemas de comércio eletrônico, e-commerce, que apresentam carga de trabalho baseada em sessão (Chen \& Mohapatra, 2003; Cherkasova \& Phaal, 2002). Nesses sistemas, é desejável que as requisições referentes ao processo de finalização de uma compra recebam prioridade maior que as demais requisições.

O trabalho de Cherkasova \& Phaal (1999) foi o pioneiro em analisar o desempenho de servidores de comércio eletrônico considerando uma carga de trabalho baseada em sessões. Nesse trabalho, os autores se preocuparam em analisar o desempenho do servidor em situações de sobrecarga e desenvolveram um controle de admissão baseado em sessões. Um dos objetivos do mecanismo desenvolvido é oferecer garantias de atendimento para as sessões longas, uma vez que os autores mostram que as sessões que resultam em vendas são maiores que sessões de não-venda.

Nesse contexto, é proposto nesta dissertação de mestrado um algoritmo de escalonamento baseado em sessão, o SBSA, cujo objetivo é oferecer melhores serviços para as sessões longas, caracterizadas por possuírem maior número de requisições. Dessa forma, quanto maior for a sessão, melhores serviços devem ser oferecidos às suas requisições.

Cada sessão possui um parâmetro denominado look-ahead (la) que aumenta à medida que as suas requisições chegam ao sistema. A velocidade com que o look-ahead cresce é definida como:

$$
\text { look_ahead }{ }_{i}=f(\text { num_requisicoes } i),
$$

onde look_aheadi e num_requisicoes $s_{i}$ são os valores atuais do look-ahead e do número de requisições que chegaram ao sistema da sessão $i$, respectivamente. A função $f\left(\right.$ num_requisicoes $\left._{i}\right)$ pode ser definida, por exemplo, como:

$$
\left.f(\text { num_requisicoes })_{i}\right)=\left\lfloor\left(\text { num_requisicoes }_{i}\right)^{K}\right\rfloor,
$$

onde $K \geq 0$. Quanto maior o valor atribuído à constante $\mathrm{K}$, maior será a velocidade de crescimento. Outras funções que também considerem o número de requisições da sessão proporcionalmente também podem ser utilizadas. 
O servidor Web possui informações de todas as sessões encaminhadas a ele, inclusive os valores de look-ahead, e uma única fila de espera na qual as requisições são inseridas por ordem de chegada. Após o término de atendimento de uma requisição, inicia-se a busca da próxima requisição a ser atendida. A primeira requisição a ser procurada é aquela que pertence a sessão de maior look-ahead $\left(l a_{1}\right)$. A busca inicia-se no início da fila de espera e são percorridas, no máximo, $l a_{1}$ posições. Caso não seja encontrada alguma requisição da sessão de maior look-ahead nas primeiras la posições, é iniciada a busca pela requisição pertencente à segunda maior sessão, cujo valor do look-ahead é $l a_{2}$, onde $l a_{2} \leq l a_{1}$, e assim por diante.

\subsubsection{Métrica de Desempenho}

Para cada sessão finalizada é contabilizado o seu tempo em fila, denominado t_fila, que corresponde à soma de todos os tempos em fila gasto pelas suas requisições.

O desempenho do novo algoritmo pode ser obtido por meio da análise do tempo médio em fila $t_{-}$fila das sessões finalizadas. Como a média aritmética não considera o tamanho das sessões, utilizou-se como métrica de desempenho uma média ponderada.

O algoritmo SBSA oferece melhores serviços às sessões longas, adiantando o atendimento de suas requisições, diminuindo, portanto, o tempo em fila dessas tarefas. Sendo assim, como o objetivo do algoritmo SBSA é diminuir o t_fila das sessões longas, adotou-se como métrica de desempenho a média do tempo em fila das sessões finalizadas, ponderada pelo tamanho da sessão que compreende o número de requisições que ela possui, isto é:

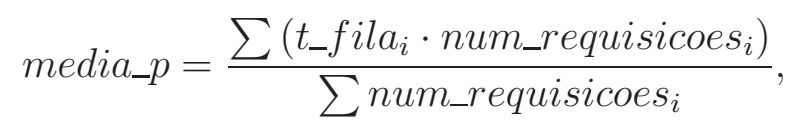

onde media_p é a média ponderada do tempo em fila das sessões finalizadas, $t_{-} f i l_{i}$ e num_requisicoes ${ }_{i}$ compreendem o tempo em fila e o número de requisições da i-ésima sessão finalizada, respectivamente.

\subsubsection{Resultados Experimentais}

Em todos os experimentos realizados nesta seção são utilizados os parâmetros do modelo SWDS descritos na Seção 4.3, considerando um cluster homogêneo composto por quatro servidores Web. Para não interferir no desempenho do algoritmo, o módulo de Controle de Admissão não é acionado, assim como o módulo Classificador, uma vez que 
o algoritmo SBSA não realiza a distinção das classes de serviço dos usuários. Como carga de trabalho, foram utilizados 200.000 registros lidos dos logs de acesso ao site da Copa do Mundo 98. Experimentos foram realizados utilizando outros trechos do log como carga de trabalho. Devido essa mudança na carga de trabalho, que resulta em quantidade e tamanho de sessões diferentes, os resultados obtidos apresentaram diferença na grandeza dos valores, como era esperado. No entanto, o algoritmo SBSA apresentou o mesmo comportamento diante das diferentes cargas de trabalho, dado que a análise dos resultados foi equivalente para os vários trechos do log considerados. Portanto, os resultados apresentados referem-se aos experimentos que consideram um trecho do $\log$.

Para efeitos de comparação, foram realizados experimentos sem a utilização do algoritmo SBSA, isto é, as requisições são atendidas segundo a disciplina FIFO. Quando utilizado o algoritmo SBSA, a Equação 5.1 descrita na Seção 5.3 foi escolhida para a definição dos valores de look-ahead das sessões que chegam ao sistema.

A Tabela 5.1 apresenta os valores obtidos dos experimentos quando utilizado os algoritmos FIFO e SBSA, variando nesse último os valores da constante $K$. Para cada experimento são apresentados os valores da média ponderada, calculada por meio da Equação 5.2, e média aritmética do tempo em fila das sessões finalizadas, assim como o desvio padrão. Em todos os experimentos tem-se a mesma quantidade de sessões finalizadas e, além disso, o número de requisições das sessões de um experimento é igual ao das sessões dos demais experimentos. Ou seja, em todos os experimentos tem-se o mesmo conjunto de sessões finalizadas.

Tabela 5.1: Médias e desvio padrão do tempo em fila das sessões finalizadas.

\begin{tabular}{|c|r|r|r|r|r|}
\hline Estatísticas & \multicolumn{1}{|c|}{ FIFO } & \multicolumn{4}{|c|}{ SBSA } \\
\cline { 3 - 6 } & & $\mathrm{K}=0$ & $\mathrm{~K}=1$ & $\mathrm{~K}=1,25$ & $\mathrm{~K}=1,50$ \\
\hline \hline Média Ponderada (s) & 173,69 & 173,69 & 156,02 & 135,80 & 108,35 \\
Média Aritmética (s) & 70,15 & 70,15 & 69,85 & 70,14 & 71,57 \\
Desvio Padrão (s) & 100,61 & 100,61 & 90,47 & 86,59 & 80,12 \\
\hline
\end{tabular}

A partir dos dados da Tabela 5.1, verifica-se que quando utilizado o algoritmo SBSA com $K=0$, o comportamento do sistema é idêntico àquele quando utilizado o algoritmo FIFO, como era o esperado, uma vez que os valores de look-ahead de todas as sessões são iguais a um. Nota-se que a medida que aumentou-se os valores de $K$, a média ponderada do tempo em fila das sessões finalizadas diminuiu, enquanto que a média aritmética permaneceu praticamente a mesma. Isso mostra que o uso do algoritmo SBSA fez com que o tempo em fila gasto pelas sessões maiores, que possuem maior peso 
no cálculo da média ponderada, sofresse redução. Verifica-se que quando utilizado o algoritmo SBSA, para valores de $K>0$, o tempo médio em fila das sessões ficam menos dispersos, como mostram os valores do desvio padrão.

Para melhor visualização, o gráfico da Figura 5.1 apresenta o tempo médio em fila das sessões finalizadas, agrupadas de acordo com o número de requisições que elas possuem.

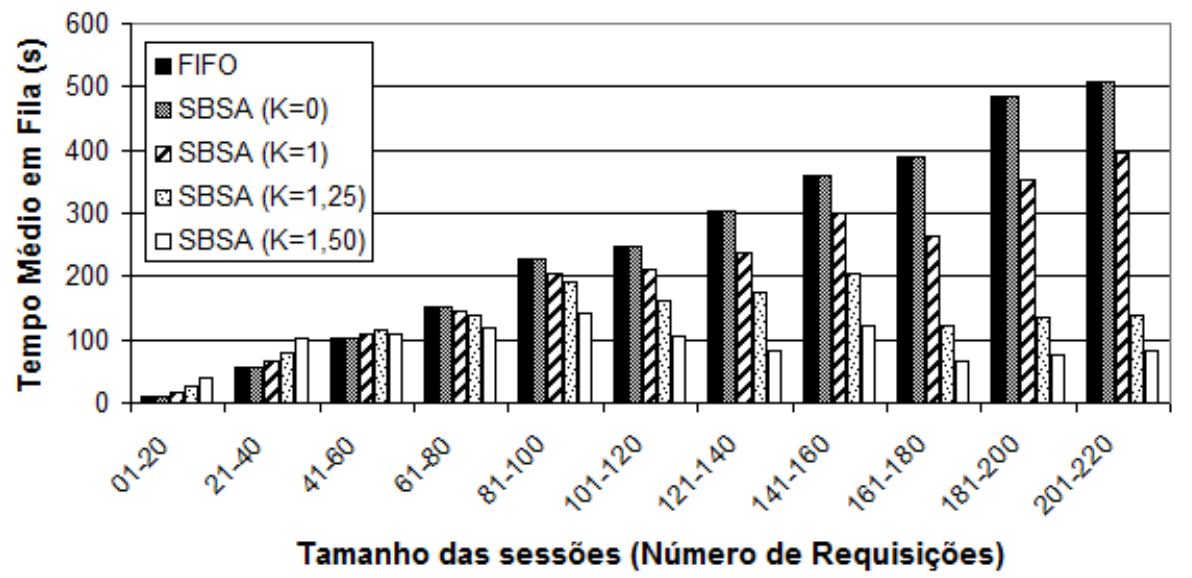

Figura 5.1: Tempo médio em fila das sessões finalizadas (SBSA - variando os valores de $K)$.

Pode-se observar, no gráfico da Figura 5.1, que quando utilizado o algoritmo FIFO o tempo médio em fila das sessões aumenta a medida que seus tamanhos crescem. O uso do algoritmo SBSA, para valores de $K>0$, proporcionou às sessões longas melhores serviços, diminuindo o tempo em fila dessas tarefas. Por outro lado, o custo do adiantamento das sessões longas é pago pelo atraso das sessões menores, cujo tempo médio em fila aumentou.

A melhora do atendimento das sessões longas é resultado da redução do tempo de residência gasto por suas requisições. O gráfico da Figura 5.2 apresenta o tempo médio de residência gasto pelas requisições das sessões finalizadas, evidenciando tal fato.

Nota-se, a partir dos valores do gráfico da Figura 5.2, que as requisições pertencentes às sessões longas tiveram o seu tempo de residência atenuado a medida que os valores de $K$ aumentaram. As requisições das sessões que possuem mais de 160 tarefas, por exemplo, tiveram o tempo de residência reduzido de aproximadamente $2,5 \mathrm{~s}(K=0)$ para menos de $0,5 \mathrm{~s}(K=1,50)$. Por outro lado, como era esperado, as requisições das sessões menores sofreram atrasos e os tempos de residência gastos por essas tarefas foram maiores à medida que aumentaram os valores de $K$. 


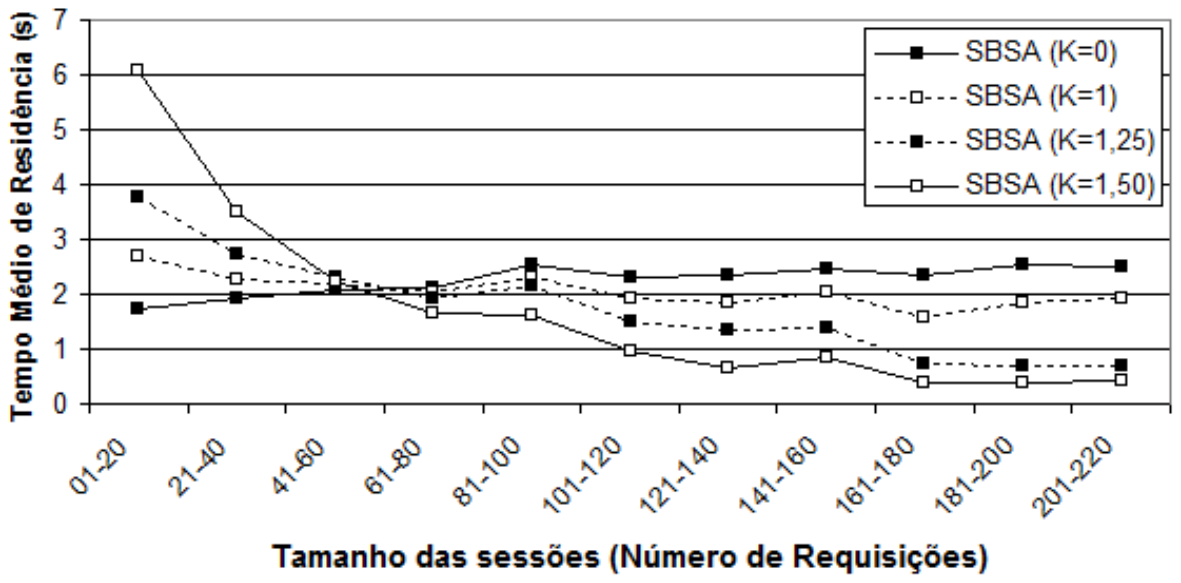

Figura 5.2: Tempo médio de residência das requisições pertencentes às sessões finalizadas (SBSA - variando os valores de $K$ ).

A medida que aumenta-se o valor de $K$, têm-se maiores look-ahead e, portanto, um maior número de requisições pertencentes a sessões longas são adiantadas. Quanto mais requisições são adiantadas, os atrasos das requisições em sessões menores tornam-se maiores. Esses atrasos podem diminuir a vazão de sessões. Como dito anteriormente, todos experimentos realizados nesta seção possuem a mesma quantidade de sessões finalizadas, mesmo no caso onde se atribuiu à $K$ o valor de 1,50. Para mostrar que para valores maiores de $K$ a vazão é reduzida, fez-se um experimento considerando $K=3$. Os resultados desse experimento são apresentados na Tabela 5.2 e na Figura 5.3, juntamente com os resultados dos experimentos onde $K=0$ e $K=1,50$. A Tabela 5.2 apresenta a quantidade de sessões finalizadas enquanto que no gráfico da Figura 5.3 são apresentados os tempos médio em fila dessas sessões, agrupadas de acordo com o número de requisições que elas possuem.

Como observado na Tabela 5.2, a quantidade de sessões finalizadas foi menor quando $K=3$, onde 51 sessões a menos deixaram de ser completadas ao final da simulação. No entanto, as sessões que não conseguiram ser completadas foram aquelas que possuem menor número de requisições. Apesar de apresentar menor vazão de sessões, observa-se no gráfico da Figura 5.3 que para $K=3$ o algoritmo SBSA apresentou comportamento semelhante aos casos anteriores, diminuindo o tempo em fila das sessões longas ao custo do aumento desse tempo gasto pelas sessões menores. Nesse caso, conforme esperado, a diferença é mais acentuada. Comparando com os resultados obtidos quando assumiu-se valores de $K$ inferiores a 3 , verifica-se que para $K=3$ as sessões que 
Tabela 5.2: Quantidade de sessões finalizadas.

\begin{tabular}{|c|c|c|c|}
\hline Tamanho das sessões & \multicolumn{3}{|c|}{ SBSA } \\
(Número de Requisições) & \multicolumn{3}{|c|}{} \\
\cline { 2 - 4 } & $\mathrm{K}=0$ & $\mathrm{~K}=1,50$ & $\mathrm{~K}=3$ \\
\hline \hline 01 até 20 & 1406 & 1406 & $\mathbf{1 3 5 5}$ \\
21 até 40 & 334 & 334 & 334 \\
41 até 60 & 189 & 189 & 189 \\
61 até 80 & 199 & 199 & 199 \\
81 até 100 & 185 & 185 & 185 \\
101 até 120 & 86 & 86 & 86 \\
121 até 140 & 49 & 49 & 49 \\
141 até 160 & 18 & 18 & 18 \\
161 até 180 & 7 & 7 & 7 \\
181 até 200 & 5 & 5 & 5 \\
201 até 220 & 1 & 1 & 1 \\
\hline Total & 2479 & 2479 & 2428 \\
\hline
\end{tabular}

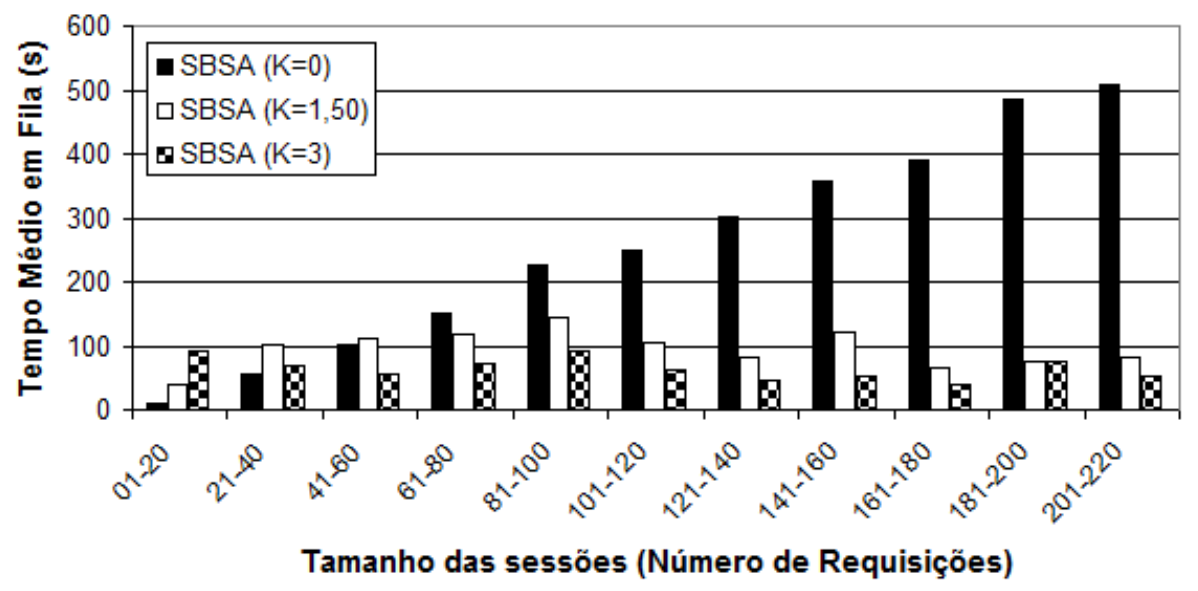

Figura 5.3: Tempo médio em fila das sessões finalizadas (SBSA - valor de $K$ elevado).

possuem acima de 40 requisições apresentaram tempo médio em fila reduzido e, por outro lado, as sessões menores tiveram desempenho ainda mais prejudicado. 


\subsection{Algoritmo de Escalonamento Baseado em Ses- são com Serviços Diferenciados (Session-Based Scheduling Algorithm with Differentiated Servi- ces - SBSA-DS)}

O algoritmo SBSA apresentado na Seção 5.3 tem como objetivo diminuir o tempo de espera das requisições pertencentes às sessões longas. Como descrito anteriormente, a motivação para o desenvolvimento do algoritmo SBSA refere-se ao fato levantado por Cherkasova \& Phaal (1999), onde os autores afirmam que as sessões relacionadas à venda, num sistema de comércio eletrônico, são maiores que aquelas que não finalizam com uma venda.

No entanto, em sistemas de comércio eletrônico, por exemplo, é interessante que não somente as sessões relacionadas a venda recebam melhor atendimento, como também aqueles clientes que costumam comprar com certa freqüência, ou cujos valores de compras ultrapassaram determinado valor.

Assim, foi desenvolvido o algoritmo de escalonamento baseado em sessão com serviços diferenciados (Session Based Scheduling Algorithm with Differentiated Services SBSA-DS), cujo objetivo é diferenciar os serviços dados aos cliente, levando em conta as sessões. No contexto de comércio eletrônico, por exemplo, enquanto o algoritmo SBSA visa priorizar somente as sessões de vendas, o algoritmo SBSA-DS prioriza as sessões de vendas considerando também o histórico (ou tipo) do cliente. Nesse caso, existe a necessidade de classificação dos clientes em classes de serviço. Um cliente pode pertencer a classe alta, média ou baixa; ou a classe ouro, prata ou bronze; ou a classe $A, B$ ou $C$.

O algoritmo SBSA-DS consiste de uma pequena adaptação do algoritmo SBSA. A diferença entre os dois algoritmos está na definição da função que determina o valor do look-ahead das sessões. No algoritmo SBSA-DS, o valor de look-ahead é definido não somente em função do número de requisições como também em função da classe da sessão, ou seja:

$$
l o o k \_ \text {ahead }_{i}=f\left(n u m \_r e q u i s i c o e s_{i}, p e s o \_c l a s s e_{i}\right),
$$

onde look_ahead ${ }_{i}$ e num_requisicoes $s_{i}$ são os valores atuais do look-ahead e do número de requisições que chegaram ao sistema da sessão $i$, respectivamente, enquanto que peso_classe $_{i}$ refere-se ao peso referente a classe da sessão, ou classe do cliente, onde quanto maior o peso da classe, maior prioridade a classe possui. 
A função $f\left(\right.$ num_requisicoes ${ }_{i}$, peso_classe $\left._{i}\right)$ pode ser definida, por exemplo, como:

$$
f\left(\text { num_requisicoes }{ }_{i}, \text { peso_classe }_{i}\right)=\left\lfloor\left(\text { num_requisicoes }_{i}\right)^{K} \cdot\left(\text { peso_classe }_{i}\right)\right\rfloor,
$$

onde $K \geq 0$ e peso_classe ${ }_{i} \geq 0$. Para maiores valores de $K$, maior será o valor do lookahead e, portanto, maiores serão as chances de adiantamento das requisições pertencentes às sessões longas. A variável peso_classe ${ }_{i}$ é responsável pela diferenciação de serviços das classes dos usuários, onde quanto maior for o peso atribuído, maior prioridade a classe possui em relação às demais. Ainda, quanto maior a diferença entre os pesos atribuídos às classes de serviço, maior distinção entre as classes é observada.

A função $f\left(\right.$ num_requisicoes $_{i}$, peso_classe $\left.{ }_{i}\right)$, dessa maneira, realiza automaticamente a diferenciação de serviços baseando-se em sessões, dada a utilização das variáveis peso_classe ${ }_{i}$ e num_requisicoes . $_{\text {. }}$.

\subsubsection{Resultados Experimentais}

Para a avaliação da eficiência do algoritmo SBSA-DS, foram realizados alguns experimentos considerando-se os parâmetros do modelo SWDS relatados na Seção 4.3. Da mesma forma que no exemplo anterior, para não afetar o desempenho do algoritmo, o módulo de Controle de Admissão não foi acionado e 200.000 registros do log da Copa do Mundo 98 foram utilizados como carga de trabalho para o modelo de simulação. Como o algoritmo SBSA-DS também realiza a diferenciação dos usuários, o módulo Classificador é acionado e três classes de serviços são consideradas: A, B e C, onde a classe A tem prioridade sobre a classe $\mathrm{B}$, e essa tem prioridade em relação a classe C. A quantidade de sessões é igualmente distribuída ente as classes de serviço e, portanto, 1/3 do total das sessões que chegam ao sistema pertence a cada classe de prioridade.

O cálculo do look-ahead é feito utilizando-se a Equação 5.3, atribuindo-se $K=$ 1,25. Inicialmente, foram considerados pesos 3, 2 e 1 para as classes de serviço A, B e C, respectivamente. Para efeitos de comparação, os resultados do algoritmo SBSA-DS são exibidos juntamente com aqueles obtidos com os algoritmos FIFO e SBSA, onde todos os algoritmos foram submetidos às mesmas condições do sistema. Quando utilizado o algoritmo SBSA, foram considerados a função de look-ahead definida na Equação 5.1 e o valor de $K=1,25$.

Na Tabela 5.3 são apresentados os resultados obtidos dos experimentos. Os resul- 
tados da tabela correspondem às médias e ao desvio padrão do tempo em fila de todas as sessões finalizadas, sem distinção de classes de serviços.

Tabela 5.3: Médias e desvio padrão do tempo em fila das sessões finalizadas.

\begin{tabular}{|l|c|c|c|}
\hline Estatísticas & FIFO & $\begin{array}{c}\text { SBSA } \\
\mathrm{K}=1,25\end{array}$ & $\begin{array}{c}\text { SBSA-DS } \\
\mathrm{K}=1,25\end{array}$ \\
\hline \hline Média Ponderada (s) & 173,69 & 135,80 & 114,56 \\
Média Aritmética (s) & 70,15 & 70,14 & 68,86 \\
Desvio Padrão (s) & 100,61 & 86,59 & 82,66 \\
\hline
\end{tabular}

Observa-se, pelos dados da Tabela 5.3, que as médias ponderada e aritmética, assim como o desvio padrão, foram menores quando utilizado o algoritmo SBSA-DS. Tal fato indica que no algoritmo SBSA-DS as sessões maiores apresentaram melhores tempos em fila, uma vez que essas sessões possuem maior peso para o cálculo da média ponderada. No entanto, as sessões maiores que obtiveram menor tempo em fila foram as mais prioritárias, dado que os pesos atribuídos às suas classes proporcionaram maiores valores de look-ahead para essas sessões, conforme definido na Equação 5.3. Para melhor visualização dessa evidência são apresentados alguns gráficos referentes aos mesmos experimentos.

Os gráficos apresentados na Figura 5.4 correspondem aos resultados obtidos nos experimentos considerando os algoritmos de escalonamento FIFO, SBSA e SBSA-DS. Os gráficos apresentam o tempo médio em fila gasto pelas sessões finalizadas, agrupadas conforme o número de requisições que possuem. O gráfico da Figura 5.4(a) mostra o tempo médio em fila de todas as sessões do sistema que foram finalizadas, sem distinção da classe de serviços. Os gráficos das Figuras 5.4(b), 5.4(c) e 5.4(d) apresentam somente os tempos das sessões pertencentes a classe A, B e C, respectivamente.

Analisando-se o gráfico da Figura 5.4(a), observa-se que o algoritmo SBSA-DS apresenta comportamento semelhante ao algoritmo SBSA, onde os tempos em fila gastos pelas sessões longas foram reduzidos quando comparados com os tempos obtidos com o algoritmo FIFO. Em relação ao algoritmo SBSA, nota-se que o algoritmo SBSA-DS priorizou ainda mais as sessões longas na maioria dos casos, fato também evidenciado pelo valor da média ponderada apresentada na Tabela 5.3. Portanto, os valores de lookahead do algoritmo SBSA-DS são maiores que os obtidos com o algoritmo SBSA e, como visto nos experimentos da Seção 5.3.2, quando maior os valores de look-ahead (obtidos por meio do aumento da constante $K$ ) melhores serviços são oferecidos às sessões longas.

No gráfico da Figura 5.4(b) têm-se os resultados das sessões pertencentes à classe de maior prioridade. Observa-se que o desempenho obtido com o uso do algoritmo SBSA- 


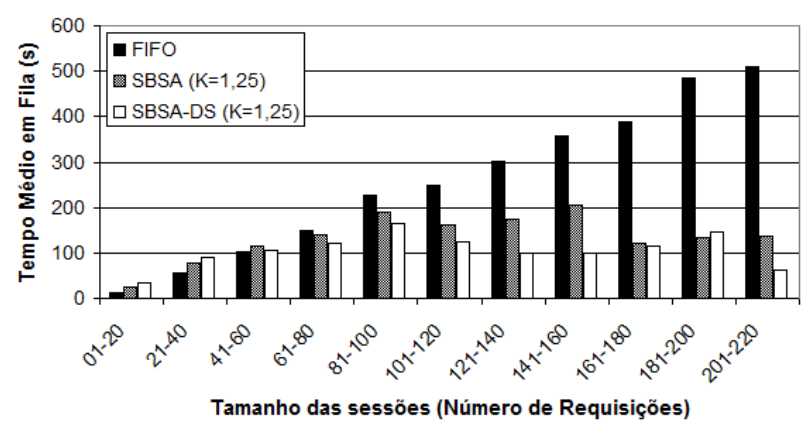

(a) Sistema - sem distinção de classes.

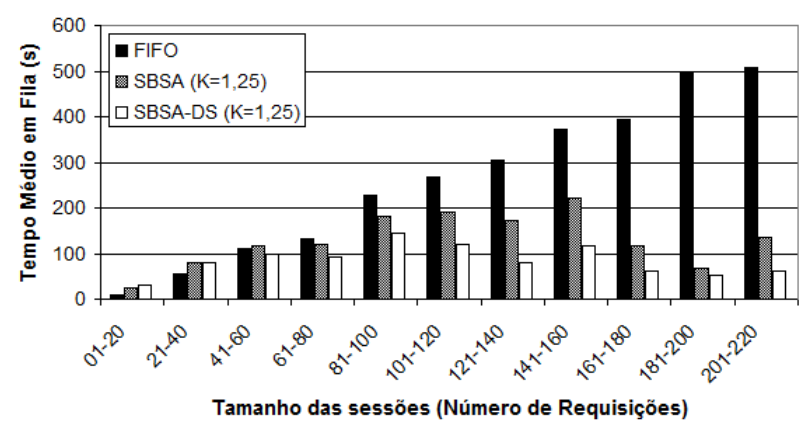

(c) Sessões pertencentes à classe B.

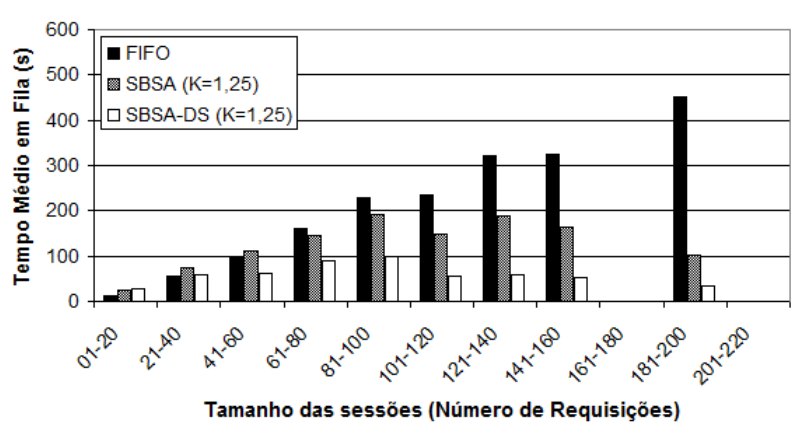

(b) Sessões pertencentes à classe A.

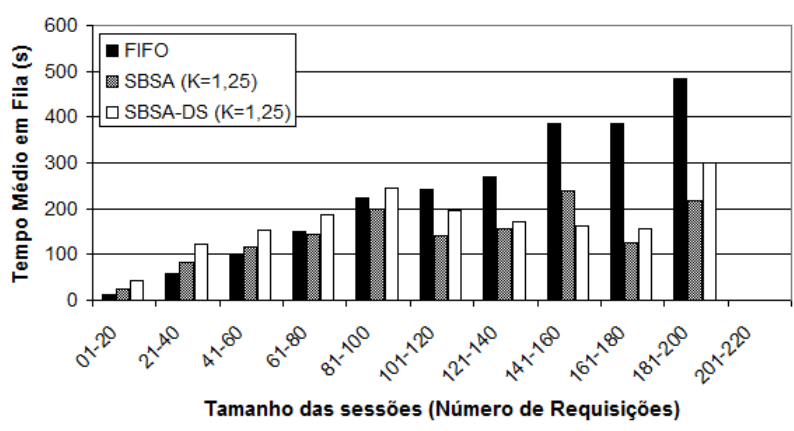

(d) Sessões pertencentes à classe C.

Figura 5.4: Tempo médio em fila das sessões finalizadas (FIFO x SBSA x SBSA-DS).

DS para essas tarefas foi superior ao obtido com o algoritmo SBSA, dado que esse último algoritmo não realiza a diferenciação de serviços. Comparando com o algoritmo SBSA, nota-se que as sessões com mais de 80 requisições apresentaram, no mínimo, tempo médio em fila $50 \%$ inferior quando utilizado o algoritmo SBSA-DS. Comportamento semelhante é notado para as sessões da classe B, cujo resultado é apresentado no gráfico da Figura 5.4(c). Para as sessões com mais de 40 requisições, o tempo médio em fila dessas tarefas obtido com o algoritmo SBSA-DS foi sempre inferior àquele obtido com o algoritmo SBSA. Contudo, de modo geral, observa-se que a diferença no desempenho entre os algoritmos SBSA e SBSA-DS foi menor para as sessões da classe B quando comparada com as sessões da classe A.

Os bons desempenhos das classes superiores, observado quando utilizado o algoritmo SBSA-DS, são "pagos" pela redução do desempenho das sessões pertencentes à classe C, como mostra o gráfico da Figura 5.4(d). Os resultados apresentados evidenciam que o tempo em fila dessas sessões foi superior ao obtido com o algoritmo SBSA, onde a diferenciação de serviços não é realizada. Ainda assim, comparando com o algoritmo FIFO, o algoritmo SBSA-DS ofereceu às sessões longas, com tamanho superior a 100 requisições, atendimento preferencial, mesmo para as tarefas pertencentes à classe de menor 
prioridade.

Para melhor visualizar a diferenciação de serviços fornecida pelo uso do algoritmo SBSA-DS, o gráfico da Figura 5.5 apresenta o tempo médio de residência das requisições, considerando todo o sistema, isto é, sem distinção de classes de serviço, e o tempo gasto pelas requisições de cada classe de prioridade considerada, ou seja, classes A, B e C.

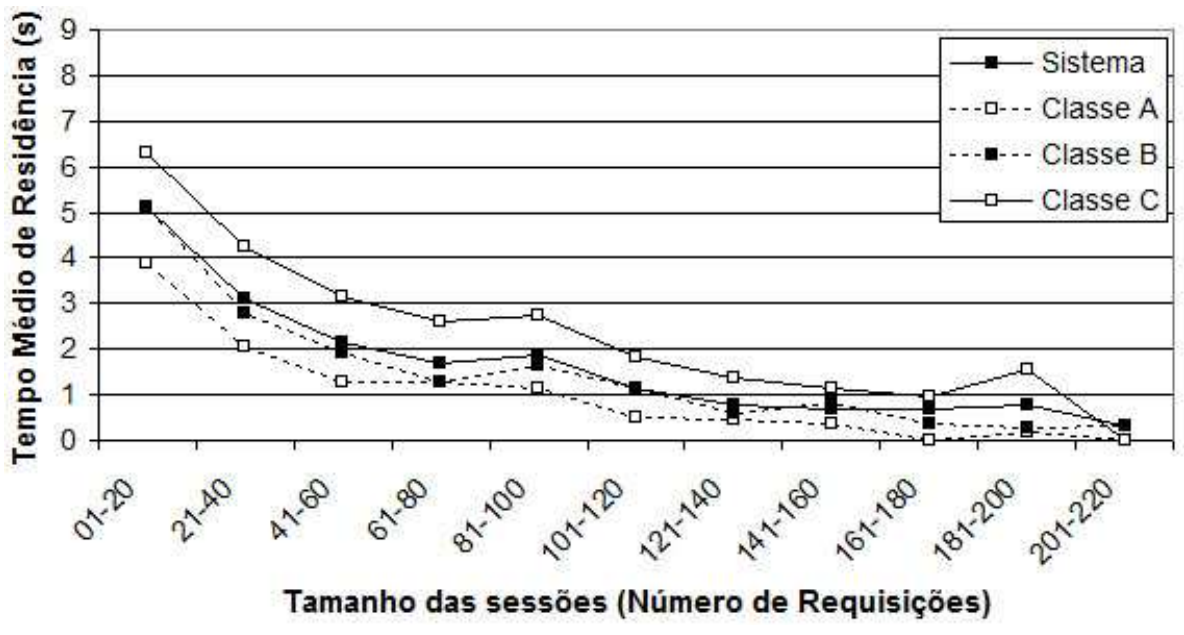

Figura 5.5: Tempo médio de residência das requisições pertencentes às sessões finalizadas (SBSA-DS - pesos $\{1,2,3\})$.

Observa-se, no gráfico da Figura 5.5, que as requisições pertencentes à classe prioritária receberam serviço preferencial, apresentando sempre menores tempos de residência que as requisições das demais classes. As requisições da classe B tiveram desempenho semelhante ao desempenho médio do sistema, enquanto que as requisições da classe de menor prioridade receberam pior atendimento. Analisando individualmente cada grupo de sessões, agrupadas conforme o número de requisições que possuem, confirma-se a eficácia do algoritmo SBSA-DS dado que em todos os casos as requisições e, conseqüentemente, as sessões, receberam qualidade de serviços equivalentes aos de suas classes de prioridade. É interessante notar que as requisições da classe C pertencentes às sessões longas (acima de 100 requisições, por exemplo), receberam melhor serviço que as requisições da classe A pertencentes às sessões com menos de 40 requisições. Tais fatos evidenciam a eficiência do algoritmo e mostram que, apesar do algoritmo proposto priorizar as sessões longas e os clientes de classes mais altas, o tamanho da sessão é predominante. Essa predominância pode ser alterada por meio de alterações na Equação 5.3, de mudanças no valor de $K$ ou alterando-se os pesos das classes.

Conforme apresentado no início da Seção 5.4, durante a apresentação do algoritmo 
SBSA-DS, maior distinção entre as classes de serviços pode ser realizada quanto maior for a diferença entre os pesos atribuídos às classes. Dessa forma, realizou-se outro experimento com o algoritmo SBSA-DS atribuindo-se os pesos 9, 4 e 1 para as classes A, B e C, respectivamente. Para efeitos de comparação com o experimento anterior, os mesmos parâmetros para o sistema foram adotados, assim como o valor para a constante $K$. O gráfico da Figura 5.6 apresenta os resultados obtidos do experimento, sendo apresentados os tempos médios de residência gastos pelas requisições de cada classe de serviço.

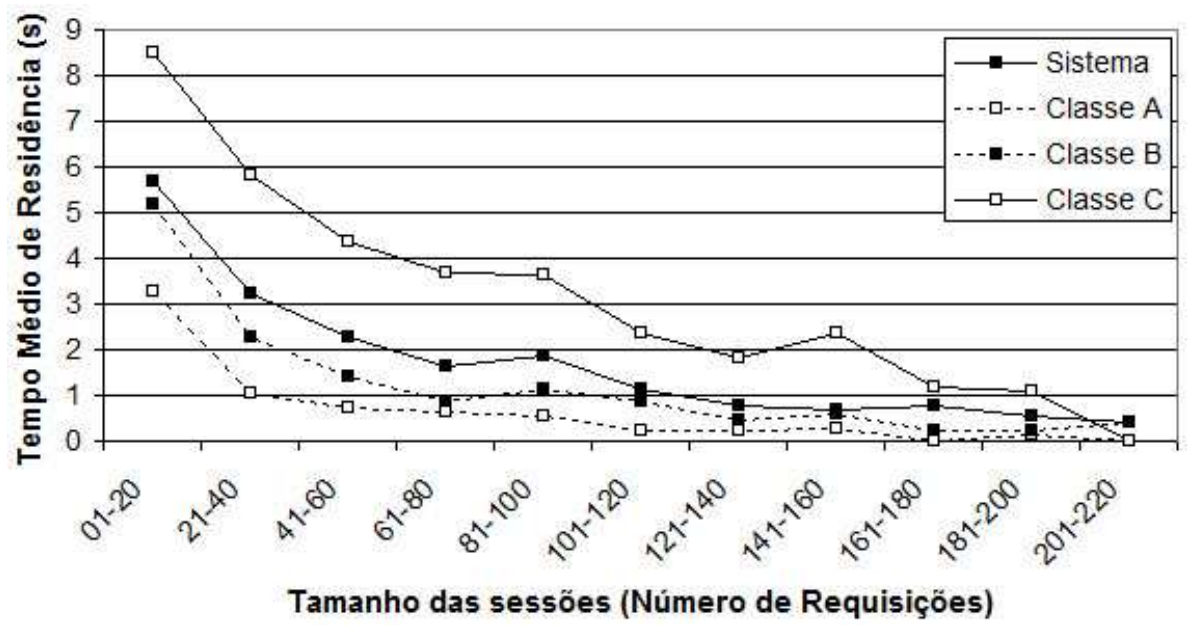

Figura 5.6: Tempo médio de residência das requisições pertencentes às sessões finalizadas (SBSA-DS - pesos $\{1,4,9\})$.

Analisando o gráfico da Figura 5.6, percebe-se que o algoritmo SBSA-DS realizou a diferenciação entre as classes de serviços, fato evidenciado pela divergência das curvas. Comparando os resultados dos gráficos das Figuras 5.5 e 5.6, nota-se que as requisições das classes A e B apresentaram melhor desempenho quando atribuídos maiores pesos a essas classes. Por outro lado, as requisições da classe C tiveram o desempenho prejudicado. Observa-se que nesse caso as requisições da classe $\mathrm{C}$ pertencentes às sessões com mais de 100 requisições tiveram melhor desempenho apenas em relação àquelas requisições referentes às sessões da classe $\mathrm{A}$ com menos de 20 requisições. Com o aumento dos pesos atribuídos às classes de serviços, o tamanho da sessão foi menos predominante que no experimento anterior, onde menores pesos foram considerados. 


\subsection{Considerações Finais}

Neste capítulo foram apresentados dois novos algoritmos de escalonamento para servidores Web que fazem uso de sessões e visam oferecer qualidade de serviço aos seus clientes: o SBSA e o SBSA-DS.

Inicialmente foram apresentados alguns algoritmos, encontrados na literatura, utilizados em servidores Web e responsáveis pelo oferecimento de qualidade de serviço aos usuários do sistema. Tais algoritmos fornecem QoS por meio da diferenciação de serviços e analisam as requisições individualmente, sem considerar sessões.

No entanto, vários sistemas onde o provimento de QoS é fundamental, como os de comércio eletrônico, apresentam carga de trabalho baseada em sessão. Visando a oferecer melhores serviços para sistemas que fazem uso de sessões, foi desenvolvido um novo algoritmo de escalonamento, o SBSA, cujo objetivo é fazer com que as sessões longas recebam atendimento preferencial, uma vez que as sessões relativas a venda são maiores que as demais. Para tanto, o algoritmo faz uso de uma função que determina quão preferencial uma sessão longa é em relação às demais. O nível de preferência pode ser modificado variando-se a função empregada ou algum parâmetro utilizado na mesma. O algoritmo SBSA revelou-se eficiente para o objetivo proposto, funcionando satisfatoriamente. Contudo, o algoritmo SBSA provê melhorias no atendimento das sessões longas sem considerar o tipo de usuário.

Nesse contexto, um outro algoritmo foi desenvolvido, o SBSA-DS, que consiste de uma adaptação do algoritmo SBSA. Diferentemente do algoritmo SBSA, o algoritmo SBSA-DS, além de oferecer melhores serviços para as sessões longas, também realiza a diferenciação de serviços entre os diferentes tipos de clientes. Maior ou menor diferenciação entre as classes de serviço pode ser obtida variando-se os pesos atribuídos às classes. Os resultados obtidos dos experimentos realizados comprovaram a eficiência do SBSA-DS, algoritmo capaz de realizar de maneira automática a diferenciação de serviços considerando o tamanho das sessões.

Os algoritmos apresentados e desenvolvidos nesse capítulo visam a oferecer melhores serviços a alguns usuários e/ou tarefas. Porém, o uso isolado desse tipo de algoritmo não garante que os acordos de nível de serviços (Service Level Agreement - SLA), firmados com os clientes, sejam respeitados em quaisquer condições de carga de trabalho como, por exemplo, em situações de sobrecarga do sistema. Esse é o papel das políticas de controle de admissão, discutidas no capítulo seguinte. 


\section{Políticas de Controle de Admissão}

\subsection{Considerações Iniciais}

Assim como o Isolamento, alcançado por meio da utilização de políticas para a diferenciação de serviços (Capítulo 5), o Controle de Admissão - CA também compõe os quatros princípios para a garantia de QoS.

Dessa forma, além do uso de políticas para a diferenciação de serviços, o uso de políticas de controle de admissão também é necessário para a garantia de QoS em quaisquer condições do sistema.

Este capítulo trata das políticas de controle de admissão utilizadas em servidores Web que visam oferecer melhores serviços a seus usuários. Inicialmente, na Seção 6.2, são discutidos os motivos que levam a utilização do CA em servidores Web. Algumas políticas de controle de admissão encontradas na literatura são apresentadas na Seção 6.3. Na Seção 6.4 é apresentada uma classificação hierárquica proposta durante o desenvolvimento deste projeto de mestrado, que representa como as políticas para o controle de admissão podem ser definidas. Os dois mecanismos de controle de admissão utilizados (o mecanismo que consiste em limitar o tamanho da fila dos nós servidores e o mecanismo que limita a utilização dos recursos do sistema), assim como as duas políticas desenvolvidas (a política de controle de admissão baseada em sessão e a política de controle de admissão híbrida), são descritos na Seção 6.5. Os resultados obtidos em diversos experimentos realizados são apresentados e analisados. 


\subsection{Controle de Admissão em Servidores Web}

O tráfego da Internet apresenta um comportamento instável, sendo difícil prever a carga de trabalho imposta a um servidor Web. Devido a essa instabilidade, torna-se difícil determinar a capacidade desses servidores, uma vez que a carga imposta a eles apresenta variações devido a diferentes fatores, como por exemplo os hábitos de trabalho das pessoas, a distribuição geográfica dos usuários e certos eventos difíceis de serem previstos.

Aumentar a capacidade dos servidores Web é uma alternativa de evitar a sobrecarga desses sistemas. Porém, alocar mais recursos para acomodar todo o tráfego dos servidores Web, além de não ser uma solução com melhor custo-benefício, pode não ser efetiva (Zhu et al., 2001), uma vez que a sobrecarga pode ocorrer esporadicamente, fazendo com que os novos recursos fiquem ociosos a maior parte do tempo.

Por outro lado, a alternativa de deixar os servidores Web sobrecarregados, faz com que o tempo médio de residência das requisições no sistema sejam de várias ordens de magnitude maiores que o esperado, causando o efeito de Negação de Serviço (Denial of Service - DoS $)^{1}$ (Chen et al., 2001).

Sob condições de saturação dos servidores Web, algumas requisições podem ser rejeitadas, ao invés de fazer com que todas elas sejam submetidas a tempos de resposta inaceitáveis (Welsh \& Culler, 2003). Esse é o trabalho do Controle de Admissão.

O controle de admissão é um mecanismo que previne os servidores Web da sobrecarga, situação na qual o volume das requisições excede a capacidade do sistema.

Nas situações de sobrecarga, a QoS pode ser assegurada mantendo o sistema dentro de certos "limiares" (thresholds). O controle de admissão possibilita a manutenção do sistema dentro desses limiares (Chen \& Mohapatra, 1999).

O controle de admissão faz com que o sistema não exceda a sua capacidade em caso de um grande volume de carga, tendo mais chances de honrar o acordo de nível de serviço firmado com seus clientes, por meio da rejeição do serviço para algumas requisições.

O uso do controle de admissão em servidores Web tradicionais evita que esses sistemas "quebrem", pois evita o efeito DoS. Em servidores Web com suporte a QoS, seu uso se torna fundamental para que sejam dadas garantias de SLA sob quaisquer condições do sistema, particularmente, em condições de sobrecarga.

\footnotetext{
${ }^{1}$ A Negação de Serviço é resultado de uma grande quantidade de trabalho submetida ao servidor, impossibilitando sua utilização.
} 


\subsection{Trabalhos Relacionados}

Diversos trabalhos discutem como são feitas, e em que são baseadas, as decisões do controle de admissão para a rejeição das tarefas. Alguns desses trabalhos são apresentados a seguir.

Cherkasova \& Phaal (1999) introduzem o Controle de Admissão Baseado em Sessão (Session Based Admission Control - SBAC) para um servidor com carga de trabalho baseada em sessões. O mecanismo de controle de admissão aceita uma nova sessão somente quando o servidor tem capacidade de processar todas as futuras requisições relacionadas a ela, isto é, quando o servidor pode garantir que essa sessão possa ser completada com sucesso. Caso o servidor esteja funcionando próximo de sua capacidade, a nova sessão será rejeitada. Os autores mostram que nesse tipo de sistema, a vazão, medida como o número de sessões completadas com sucesso, é menor quando o controle de admissão descarta as requisições de forma independente de sessões.

A combinação de controle de admissão baseado em sessão e serviços diferenciados é encontrada em Kanodia \& Knightly (2000). Nesse trabalho há a preocupação em como os efeitos de desempenho de uma classe sobre a outra podem ser incorporados nas decisões do controle de admissão, que pode ou não ser baseado em sessão. Com a chegada de uma nova requisição (ou sessão), o algoritmo de controle de admissão desenvolvido por Kanodia \& Knightly (2000) verifica, primeiro, se o atraso previamente estabelecido para a classe da nova requisição é satisfeito e, segundo, se a chegada da nova requisição não fará com que as outras classes sofram a violação de QoS. Caso não seja possível respeitar os limites de latência estabelecidos para todas as classes, a nova requisição deve ser rejeitada ou redirecionada para uma classe de menor prioridade.

O redirecionamento das requisições para classe de menor prioridade, ao invés do descarte, é citado em Teixeira (2004) como uma Negociação. Essa funcionalidade, definida no modelo de Servidor Web com Diferenciação de Serviços (SWDS) (Teixeira, 2004) (como mostra a Figura 4.1), foi desenvolvida em um projeto de mestrado no LaSDPC ${ }^{2}$ (Estrella, 2005; Estrella et al., 2005), onde, em caso de sobrecarga, uma requisição tem suas exigências de qualidade de serviço relaxadas, a fim de que possa ser aceita em uma classe de prioridade inferior.

Na proposta de Cardellini et al. (2001), o controle de admissão leva em conta a diferenciação de classes de clientes para que o tempo de residência dos usuários privile-

\footnotetext{
${ }^{2}$ Laboratório de Sistemas Distribuídos e de Programação Concorrente - ICMC/USP.
} 
giados não sofra na presença de sobrecarga. Segundo os autores, o controle de admissão pode recusar o acesso aos servidores Web para algumas classes de serviços. A idéia básica é negar serviço para as requisições pertencentes à classe de menor prioridade quando a capacidade do sistema excede um dado limite, e rejeitar as requisições da classe de maior prioridade somente em condições altamente críticas do sistema. Esse mesmo mecanismo de controle de admissão é utilizado em Andreolini et al. (2004).

Em Chen et al. (2001) é proposto um algoritmo cuja estratégia também é garantir o desempenho das tarefas de maior prioridade, em condições de sobrecarga, por meio da restrição de admissão de tarefas de baixa prioridade. A admissão da requisição é decidida comparando a capacidade disponível do servidor com o tempo de serviço estimado para a requisição. Essa estimativa do tempo de serviço é feita baseando-se no tipo da requisição.

Zhu et al. (2001) propõem um algoritmo que garanta prioridade de serviços sem sobrecarregar o sistema e sem sacrificar as requisições de baixa prioridade. O algoritmo se adapta dinamicamente às variações na demanda de recursos, modificando o particionamento atual do cluster de servidores Web caso necessário. Esse algoritmo também emprega controle de admissão para rejeitar excessivas requisições de usuários e oferecer garantias "leves" de desempenho. Para tanto, o algoritmo calcula, periodicamente, quantos servidores devem ser associados para uma classe de requisição e qual porcentagem de requisições dessa classe deve ser rejeitada para prover a diferenciação de serviços e alguma garantia de desempenho.

Lee et al. (2002) consideram um servidor Web que pode prover serviços diferenciados de atraso proporcional, em que o operador do sistema pode fornecer um espaço de desempenho fixo e pré-especificado entre as diferentes classes de requisições. Os autores propõem um algoritmo de controle de admissão no qual a nova requisição é rejeitada caso a sua admissão viole a QoS dos clientes já admitidos.

Como exemplo de um controle de admissão que não considera a classe das tarefas, tem-se o trabalho de Chen \& Mohapatra (1999). No modelo de servidor Web definido pelos autores, apresentado na Figura 3.1, a admissão das requisições é feita antes da classificação das mesmas. Assim que chegam no sistema, as requisições são colocadas em uma fila aguardando para serem admitidas. Caso a taxa de acesso exceda a capacidade, as requisições que chegam ao sistema são rejeitadas. Somente após sua aceitação, o escalonador atribui à requisição um certo nível de prioridade. Dessa forma, o controle de admissão descarta uma requisição independentemente de sua classe. 
Teixeira (2004) desenvolveu três tipos de mecanismos de controle de admissão, que diferem no modo sobre quais parâmetros de carga do sistema são utilizados para que o controle de admissão seja acionado. Essas políticas consideram apenas as informações de carga do sistema, tratando as requisições individualmente.

Em Barbato et al. (2005) são realizadas alterações nos mecanismos propostos em Teixeira (2004), de modo que esses também considerem a classe das tarefas.

\subsection{Definição de uma Política para o Controle de Ad- missão}

Como visto anteriormente, com a adoção de algum mecanismo responsável em controlar a admissão, é possível fazer com que o sistema não enfrente situações de sobrecarga, ao custo da rejeição de algumas requisições.

A rejeição das tarefas pode ser feita de diferentes formas, variando de acordo com a política empregada no sistema.

A Figura 6.1 apresenta, de forma hierárquica, como podem ser definidas as políticas do controle de admissão para o descarte das tarefas.

Observa-se, no primeiro nível da hierarquia da Figura 6.1, que o controle de admissão pode considerar as requisições individualmente ou reconhecer sessões. No

primeiro caso, o controle de admissão se preocupa somente com a nova requisição, isto é, se o sistema, dadas as suas condições atuais, é capaz de atendê-la. No segundo caso, o controle de admissão aceita uma nova sessão, somente se o sistema apresenta condições em atender todas as futuras requisições relacionadas com essa sessão.

Descendo um nível da hierarquia, nota-se que o controle de admissão sempre decide se uma nova tarefa (requisição ou sessão) deve ser rejeitada a partir de informações da carga do sistema. O controle de admissão, além de informações da carga do sistema, pode ainda considerar a classe da requisição (ou classe da sessão) ou o estágio da sessão, quando for o caso.

Quando o controle de admissão é capaz de reconhecer sessões, ele possui informações de quantas sessões ativas há no sistema em determinado momento da análise. Quando o estágio da sessão é considerado, o controle de admissão pode analisar se essas sessões estão no começo, no meio, ou próximas, por exemplo, de serem finalizadas, podendo assim, melhorar o controle sobre o sistema. Além do estágio da sessão, o controle 

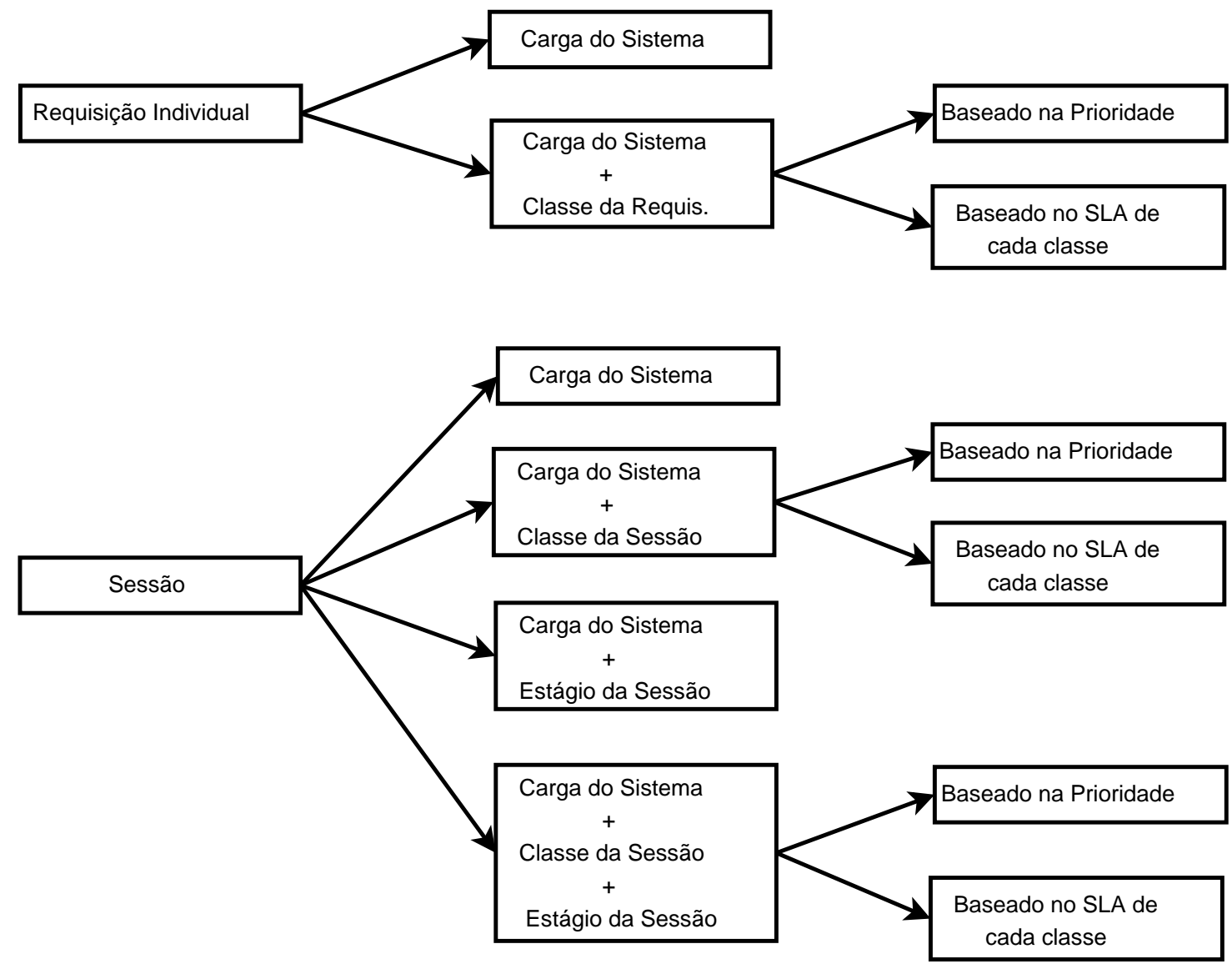

Figura 6.1: Classificação das Políticas de Controle de Admissão (Barbato et al., 2005).

de admissão também pode considerar a classe da sessão.

Quando o controle de admissão considera, além da carga do sistema, a classe da tarefa, tem-se o terceiro nível da hierarquia, onde a política de controle de admissão pode apresentar duas abordagens:

- Baseado na Prioridade. Essa abordagem prioriza sempre as requisições (ou sessões) das classes favorecidas. Nesse caso, a restrição da admissão é feita somente para as requisições (ou sessões) das classes inferiores, fazendo com que as tarefas das classes favorecidas sejam descartadas somente em condições altamente críticas do sistema.

- Baseado no SLA de cada classe. Nessa abordagem as requisições (ou sessões) de todas as classes sofrem restrição de admissão. Nesse caso, os acordos de nível de serviço (SLA) são estabelecidos para todas as classes e, caso a aceitação da nova 
tarefa faça violar algum desses acordos, mesmo que seja o de uma classe inferior à sua, essa tarefa será descartada.

O descarte das tarefas pode ainda ser substituído por uma "negociação", de forma que a tarefa a ser descartada pode ter suas exigências de qualidade de serviço negociadas, a fim de que possa ser aceita em uma outra classe de prioridade.

A escolha da política de admissão a ser adotada deve ser tomada considerando os acordos de nível de serviço firmado com os clientes. Os acordos de serviço, por sua vez, devem ser definidos a partir de medições realizadas no sistema em questão. Essas medições têm o objetivo de mostrar quais são as limitações do sistema e, portanto, quais serão os possíveis acordos de nível de serviço oferecidos pelo sistema aos seus clientes. As diversas configurações do sistema, tais como a política de escalonamento e/ou particionamento para a diferenciação de serviços, e a política de controle de admissão adotados, definem o modo como esses acordos podem ser alcançados.

\subsection{Mecanismos e Políticas de Controle}

O servidor Web deve possuir algum mecanismo para evitar a sobrecarga do sistema. Uma forma de manter a carga do sistema em níveis aceitáveis é por meio de mecanismos de controle de admissão, que gerenciam o descarte das requisições, utilizando informações atuais da carga do sistema.

Os mecanismos existentes podem diferir na métrica utilizada para a verificação do nível de carga do sistema.

Neste trabalho os seguintes mecanismos de controle de admissão foram utilizados:

- Mecanismo que limita o tamanho da fila. Esse é um dos mecanismos mais simples e usado por grande parte dos servidores Web. Com o uso desse mecanismo, tarefas devem ser descartadas quando o tamanho da fila do servidor atinge um limite pré-estabelecido. Nos experimentos deste trabalho, esse limite foi configurado em 1.024 requisições para cada um dos servidores do cluster, como definido em Teixeira (2004).

- Mecanismo que limita a utilização média do cluster. Esse mecanismo, proposto por Teixeira (2004) e semelhante ao encontrado em Cherkasova \& Phaal (1999), emprega a utilização média do cluster de servidores Web como métrica, 
que é obtida por meio de uma média exponencialmente ponderada. Assim que uma requisição chega ao sistema, a utilização atual do cluster $\left(U_{\text {atual }}\right)$ é medida. Usando esse valor e algum dado que caracteriza a utilização dos servidores no passado recente $\left(U_{\text {ant }}\right)$, tem-se a média exponencialmente ponderada, $U_{m e d}$. Se essa utilização média estiver acima do limiar previamente estabelecido, deverá haver descartes de tarefas. O cálculo da média exponencialmente ponderada é definido por:

$$
U_{\text {med }}=(1-p) U_{\text {ant }}+p U_{\text {atual }}
$$

O peso $p$ funciona como um coeficiente de sensibilidade a mudanças na carga do sistema. Quando $p \rightarrow 1$ o mecanismo de controle torna-se mais sensível a mudanças na utilização do sistema, reagindo prontamente. Quando $p \rightarrow 0$ o mecanismo de controle considera mais o histórico de carga no sistema, apresentando comportamento mais estável. Nos experimentos realizados neste capítulo, adotou-se $p=0,9$ para que o mecanismo reaja mais rapidamente às mudanças na utilização do sistema. Quanto ao limiar de utilização, este foi fixado em $90 \%$.

Definida a métrica de verificação do nível de carga do sistema, outra decisão a ser tomada é a respeito de qual tarefa deve ser descartada quando a carga do sistema estiver no seu limite. Nesse ponto é que atuam as políticas de controle de admissão que, a partir das informações da carga do sistema, escolhem a tarefa a ser rejeitada para que o servidor não sobrecarregue. Na Seção 6.4 foram apresentadas diversas formas de como uma política de controle de admissão pode ser definida, considerando-se o agrupamento das tarefas (sessões ou requisições individualmente) e a classe de serviço das mesmas.

Neste trabalho foram desenvolvidas duas novas políticas de controle de admissão descritas a seguir:

- Política de Controle de Admissão Baseado em Sessão (CA-BS). Como o próprio nome diz, tal política considera as sessões para a decisão do descarte das tarefas. Quando o mecanismo de controle de admissão informa que o sistema está no limite de sua carga de trabalho, a política decide por rejeitar novas sessões ao sistema. A fim de garantir a finalização das sessões já aceitas, todas as futuras requisições dessas sessões são admitidas e encaminhadas aos servidores Web apropriados. Portanto, no uso dessa política, algumas requisições podem ser admitidas mesmo que o mecanismo de controle acuse a sobrecarga do sistema. Nesses casos, a carga 
dos servidores Web pode ser superior ao limite imposto pelo mecanismo de controle, prejudicando o desempenho do sistema. Uma solução para o problema é subestimar o limite de carga, de modo que a aceitação, além desse limite, de requisições das sessões ativas, resulte em uma carga mais próxima do limite de carga suportado pelo sistema.

- Política de Controle de Admissão Híbrida (CA-Híb). Diferentemente da política CA-BS que realiza o descarte de sessões, como descrito anteriormente, a política de controle de admissão híbrida (CA-Híb) faz o descarte de requisições. Assim como as políticas não baseadas em sessão, a política CA-Híb realiza o descarte das requisições quando o sistema torna-se sobrecarregado, mesmo que tais requisições pertençam a alguma sessão ativa. No entanto, a política híbrida decide sobre qual requisição deve ser descartada baseando-se nas sessões ativas no sistema. Para a decisão da escolha, a política opta em rejeitar as requisições pertencentes às menores sessões ativas, de modo a minimizar a perda do trabalho já desprendido para o atendimento dessas sessões. Dessa forma, de acordo com a definição de políticas de controle de admissão apresentada na Seção 6.4, a política de controle de admissão híbrida apresenta características das políticas baseadas em sessão e das políticas que consideram as requisições individualmente.

\subsection{Resultados Experimentais}

Nos experimentos realizados neste capítulo são utilizados os parâmetros do modelo SWDS descritos na Seção 4.3, assim como as alterações realizadas em tal modelo, descritas na Seção 4.4. Um cluster homogêneo composto por quatro nós servidores é considerado e, diferentemente dos experimentos anteriores onde foram utilizados 200.000 registros do log de acesso, os experimentos deste capítulo consideram 1 milhão de registros, a fim de sobrecarregar o sistema e motivar o uso do controle de admissão.

Para a avaliação de desempenho das políticas de controle de admissão, as seguintes métricas foram consideradas:

- Sessões Finalizadas. Corresponde à quantidade das sessões finalizadas com sucesso até o final da simulação, onde todas as requisições dessas sessões foram admitidas e atendidas pelo sistema. A quantidade de sessões finalizadas é expressa em termos de porcentagem, em relação ao total de sessões que chegaram ao sistema. 
- Sessões Descartadas. Tal métrica indica a porcentagem, em relação ao total de sessões que chegaram ao sistema, das sessões que não tiveram nenhuma requisição admitida. Ou seja, a primeira requisição da sessão descartada não foi admitida no sistema e, assim, contabiliza-se um descarte de sessão.

- Sessões Abortadas. Equivale ao total de sessões admitidas no sistema, porém, diante da sobrecarga do sistema, tiveram suas requisições descartadas. Assim como nos casos anteriores, a quantidade de sessões abortadas também é expressa em termos de porcentagem, em relação ao total de sessões que chegaram ao sistema.

- Utilização Efetiva dos Recursos. Corresponde ao tempo em que os recursos do sistema estiveram ocupados por tarefas bem sucedidas, não contabilizando, portanto, o tempo gasto com o processamento das requisições pertencentes às sessões abortadas.

- Vazão de sessões. Quantidade de sessões finalizadas por segundo.

- Vazão de requisições. Quantidade de requisições finalizadas por segundo.

- Tempo Médio de Residência das Requisições. Tempo médio gasto no sistema pelas requisições finalizadas. Compreende os tempos em fila e em atendimento, expressos em segundos.

- Tamanho Médio das Sessões. Exprime o tamanho médio, em termos de quantidade de requisições, das sessões finalizadas.

Nesta seção são apresentados os resultados de alguns experimentos realizados, considerando-se os diferentes mecanismos e políticas de controle de admissão descritos na Seção 6.5. Assim, quanto aos mecanismos de controle de admissão foram considerados aquele que limita o tamanho da fila e aquele que limita a utilização média do cluster. Quanto às políticas de controle de admissão, além da CA-BS e CA-Híb apresentadas na Seção 6.5, também é considerada para efeitos de comparação a política de controle de admissão não baseada em sessão CA-nBS. A política CA-nBS descarta novas requisições quando o sistema está sobrecarregado, independentemente dessas pertencerem ou não a alguma sessão ativa no sistema.

Na Seção 6.6.1 são exibidos os resultados quando utilizado o mecanismo que limita o tamanho da fila e as políticas de controle de admissão CA-nBS, CA-BS e CA-Híb. Os resultados obtidos com o mecanismo que limita a utilização média do cluster, juntamente com as políticas CA-nBS, CA-BS e CA-Híb, são exibidos na Seção 6.6.2. 


\subsubsection{Mecanismo que limita o tamanho da fila}

Nesta seção têm-se os resultados de experimentos quando o mecanismo que limita o tamanho da fila foi utilizado juntamente com diferentes políticas de controle de admissão. As políticas de controle de admissão consideradas foram a CA-nBS, a CA-BS e a CA-Híb. Na Tabela 6.1 são apresentados os resultados obtidos nesses experimentos.

Tabela 6.1: Avaliação das políticas de CA - Mecanismo que limita o tamanho da fila.

\begin{tabular}{|l|r|r|r|}
\hline Métricas & CA-nBS & CA-BS & CA-Híb \\
\hline \hline Sessões Finalizadas (\%) & 84,45 & 83,92 & 83,65 \\
Sessões Descartadas (\%) & 0,00 & 3,57 & 0,29 \\
Sessões Abortadas (\%) & 3,01 & 0,00 & 3,99 \\
Utilização Efetiva dos Recursos (\%) & 96,01 & 100,00 & 99,65 \\
Vazão de Sessões (sessões/s) & 7,82 & 7,77 & 7,75 \\
Vazão de Requisições (requisições/s) & 463,48 & 463,84 & 463,49 \\
Tempo Médio Residência Requisições (s) & 3,98 & 5,28 & 4,24 \\
Tamanho Médio Sessões (\# requisições) & 48,39 & 50,78 & 50,77 \\
\hline
\end{tabular}

A partir dos dados da Tabela 6.1, nota-se que a política CA-BS atingiu seu objetivo, que é o de não abortar as sessões já admitidas no sistema. Segundo informações da tabela, na política CA-BS nenhuma sessão foi abortada (0,00\%), havendo somente sessões descartadas (3,57\%). Observa-se também que nesse caso a utilização efetiva dos recursos foi de $100 \%$, isto é, durante todo o tempo que os recursos do sistema estiveram ocupados, foram com sessões concluídas (ou a serem concluídas) com sucesso. Conforme descrito na Seção 6.5, a política CA-BS pode admitir requisições além da capacidade imposta pelo mecanismo de controle. Tal fato pode ser evidenciado pelo tempo de residência das requisições na política CA-BS $(5,28 \mathrm{~s})$, que foi superior ao das outras políticas, indicando que o tamanho das filas dos servidores foi maior, provocando maiores atrasos e, conseqüentemente, maiores tempos de residência.

Comparando a política CA-BS com a política não baseada em sessão CA-nBS, a política CA-nBS finaliza uma quantidade maior de sessões (83,92\% na política CA-BS contra 84,45\% na política CA-nBS). No entanto, o uso da política CA-nBS fez com que algumas sessões fossem abortadas (3,01\%), impactando na utilização efetiva dos recursos (96,01\%). A política híbrida CA-Híb, por sua vez, descartou algumas sessões (0,29\%) e abortou várias outras (3,99\%). Diferentemente da política não baseada em sessão CAnBS, a política CA-Híb tenta diminuir a utilização não efetiva dos recursos do sistema, escolhendo para o descarte as requisições pertencentes às sessões menores. Por meio da Tabela 6.1, nota-se que a política CA-Híb alcançou seu objetivo, fazendo com que a 
utilização efetiva dos recursos, igual a 99,65\%, fosse superior àquela produzida pela política CA-nBS, mesmo abortando maior quantidade de sessões. Observa-se que as políticas CABS e CA-Híb finalizaram menor número de sessões, em relação à política CA-nBS, porém, o tamanho médio das sessões finalizadas foi maior. Para ilustrar melhor tal fato, a Tabela 6.2 apresenta a quantidade de sessões finalizadas, agrupadas de acordo com o número de requisições que possuem, para cada política de controle de admissão considerada.

Tabela 6.2: Porcentagem de sessões finalizadas - Mecanismo que limita o tamanho da fila.

\begin{tabular}{|l|r|r|r|}
\hline $\begin{array}{l}\text { Tamanho da Sessão } \\
\text { (Número de Requisições) }\end{array}$ & $\begin{array}{r}\text { CA-nBS } \\
\mathbf{( \% )}\end{array}$ & $\begin{array}{r}\text { CA-BS } \\
(\mathbf{\%})\end{array}$ & $\begin{array}{r}\text { CA-Híb } \\
\mathbf{( \% )}\end{array}$ \\
\hline \hline $01-20$ & 88,35 & 85,23 & 85,24 \\
$21-40$ & 84,42 & 83,30 & 81,84 \\
$41-60$ & 80,90 & 80,42 & 79,37 \\
$61-80$ & 82,65 & 83,44 & 82,82 \\
$81-100$ & 82,32 & 83,85 & 83,31 \\
$101-120$ & 81,81 & 83,87 & 84,28 \\
$121-140$ & 78,78 & 82,59 & 83,13 \\
$141-160$ & 77,05 & 82,99 & 82,99 \\
$161-180$ & 78,08 & 82,58 & 84,08 \\
$181-200$ & 78,57 & 84,18 & 83,16 \\
$201-220$ & 69,72 & 80,99 & 80,99 \\
$221-300$ & 69,80 & 79,70 & 80,20 \\
$301-1200$ & 51,40 & 67,29 & 65,42 \\
\hline
\end{tabular}

Observa-se, a partir dos dados da Tabela 6.2, que as políticas CA-BS e CA-Híb finalizaram maior quantidade de sessões que possuem mais que 60 requisições, quando comparadas com a política CA-nBS. Conforme visto no Capítulo 5, em um sistema de comércio eletrônico as sessões que possuem maior número de requisições são relativas a vendas e, por isso, merecem serviço preferencial. Nota-se que as políticas CA-BS e CAHíb priorizaram as sessões maiores, prejudicando, por outro lado, as sessões menores. Já a política não baseada em sessão CA-nBS, realiza o descarte de requisições sem analisar a que sessões essas tarefas pertencem, prejudicando boa parte das sessões que deveriam receber melhor atendimento. Analisando juntamente as Tabelas 6.1 e 6.2, conclui-se que a política CA-nBS finalizou mais sessões que as demais políticas, porém, grande parte dessas sessões não eram prioritárias, e outra grande parte das sessões prioritárias tiveram o atendimento prejudicado, não sendo finalizadas com sucesso. 


\subsubsection{Mecanismo que limita a utilização média do cluster}

Os experimentos apresentados nesta seção fazem uso do mecanismo de controle de admissão que limita a utilização média do cluster, descrito na Seção 6.5. As políticas CA-nBS, CA-BS e CA-Híb são utilizadas juntamente com tal mecanismo. Os resultados dos experimentos são apresentados na Tabela 6.3.

Tabela 6.3: Avaliação das políticas de CA - Mecanismo que limita a utilização média do cluster.

\begin{tabular}{|l|r|r|r|}
\hline Métricas & CA-nBS & CA-BS & CA-Híb \\
\hline \hline Sessões Finalizadas (\%) & 77,30 & 74,49 & 77,06 \\
Sessões Descartadas (\%) & 1,07 & 14,36 & 1,26 \\
Sessões Abortadas (\%) & 10,14 & 0,00 & 10,32 \\
Utilização Efetiva dos Recursos (\%) & 88,02 & 100,00 & 92,40 \\
Vazão de Sessões (sessões/s) & 7,16 & 6,90 & 7,14 \\
Vazão de Requisições (requisições/s) & 417,26 & 417,11 & 417,37 \\
Tempo Médio Residência Requisições (s) & 0,66 & 0,63 & 0,61 \\
Tamanho Médio Sessões (\# requisições) & 43,98 & 51,45 & 45,93 \\
\hline
\end{tabular}

Conforme esperado, as análises dos resultados obtidos dos experimentos realizados, ilustrados na Tabela 6.3, são semelhantes às análises dos resultados obtidos quando utilizado o mecanismo que limita o tamanho da fila, apresentados na Tabela 6.1. De acordo com os dados da Tabela 6.3, nota-se que a política CA-BS não abortou nenhuma sessão (0,00\%), realizando somente descartes (14,36\%). Dessa forma, a utilização efetiva dos recursos foi de 100\%, diferentemente das demais políticas consideradas. A política CA-nBS realizou muito mais abortos do que descartes de sessões (10,14\% contra 1,07\%), reduzindo a utilização efetiva dos recursos $(88,02 \%)$. A política CA-Híb, por sua vez, é criteriosa para a rejeição de requisições e, por isso, a utilização efetiva dos recursos, igual a 92,40\%, foi superior à política CA-nBS.

Ainda na análise dos resultados da Tabela 6.3, verifica-se que o tempo médio de residência das requisições na política CA-BS $(0,63 \mathrm{~s})$ foi inferior ao tempo obtido com a política CA-nBS $(0,66 \mathrm{~s})$. Isso significa que, diferentemente do caso analisado no mecanismo que limita o tamanho da fila, a política CA-BS utilizada em conjunto com o mecanismo que limita a utilização não extrapolou o limite de carga imposto por esse mecanismo. No entanto, para admitir as requisições das sessões ativas no sistema e manter a carga do sistema no limite imposto pelo mecanismo, a política CA-BS rejeitou muito mais sessões que as outras políticas quando considerada a soma dos descartes e dos abortos. Observase também que na política CA-BS menor quantidade de sessões foram finalizadas. Por 
outro lado, o tamanho médio das sessões finalizadas na política CA-BS foi maior que o das políticas CA-nBS e CA-Híb, indicando que a política CA-BS finalizou maior quantidade de sessões longas, como mostram os dados da Tabela 6.4.

Tabela 6.4: Porcentagem de sessões finalizadas - Mecanismo que limita a utilização média do cluster.

\begin{tabular}{|l|r|r|r|}
\hline $\begin{array}{l}\text { Tamanho da Sessão } \\
\text { (Número de Requisições) }\end{array}$ & $\begin{array}{r}\text { CA-nBS } \\
\mathbf{( \% )}\end{array}$ & $\begin{array}{r}\text { CA-BS } \\
\mathbf{( \% )}\end{array}$ & $\begin{array}{r}\text { CA-Híb } \\
(\mathbf{\%})\end{array}$ \\
\hline \hline $01-20$ & 86,77 & 74,81 & 85,83 \\
$21-40$ & 77,51 & 72,88 & 76,10 \\
$41-60$ & 70,87 & 71,51 & 68,86 \\
$61-80$ & 71,62 & 76,03 & 68,57 \\
$81-100$ & 69,62 & 75,04 & 70,44 \\
$101-120$ & 67,24 & 75,31 & 68,56 \\
$121-140$ & 66,53 & 76,73 & 63,27 \\
$141-160$ & 58,81 & 73,98 & 65,78 \\
$161-180$ & 60,06 & 75,08 & 64,56 \\
$181-200$ & 55,10 & 76,53 & 65,82 \\
$201-220$ & 57,04 & 71,13 & 69,01 \\
$221-300$ & 50,99 & 71,78 & 64,85 \\
$301-1200$ & 34,58 & 60,75 & 56,07 \\
\hline
\end{tabular}

A partir dos dados da Tabela 6.4, verifica-se que a política CA-BS finalizou maior quantidade de sessões que possuem mais que 40 requisições, prejudicando, por outro lado, as sessões menores, ao contrário da política CA-nBS. A política híbrida, CA-Híb, conseguiu realizar um balanceamento entre as duas políticas, finalizando mais sessões longas do que a política CA-nBS, sem prejudicar as sessões menores como na política CA-BS.

\subsubsection{Oferecendo garantias de QoS}

Conforme visto no início deste capítulo e nos capítulos anteriores, a garantia de fornecimento de QoS aos clientes do servidor Web só pode ser satisfeita se forem utilizadas técnicas para a distinção dos diferentes tipos de usuários, além de técnicas para restringir o controle de acesso, de modo a evitar a sobrecarga do sistema.

Em servidores que não fazem uso dessas técnicas, não é possível oferecer garantias de QoS aos usuários desses sistemas. Para ilustrar tal fato, na Figura 6.2 é apresentado o resultado do experimento onde se utiliza o algoritmo de escalonamento FIFO, isto é, escalonamento não prioritário, e ainda nenhum mecanismo para o controle de admissão é acionado. São apresentados os gráficos do tempo médio em fila das sessões finalizadas 
e o tempo médio de residência das requisições pertencentes a essas sessões, agrupandose de acordo com o tamanho dessas tarefas. Três classes de serviços, A, B e C, são consideradas e os resultados obtidos são exibidos individualmente, para cada classe de serviço, assim como o desempenho obtido por todo o sistema, considerando-se todas as classes de serviços.

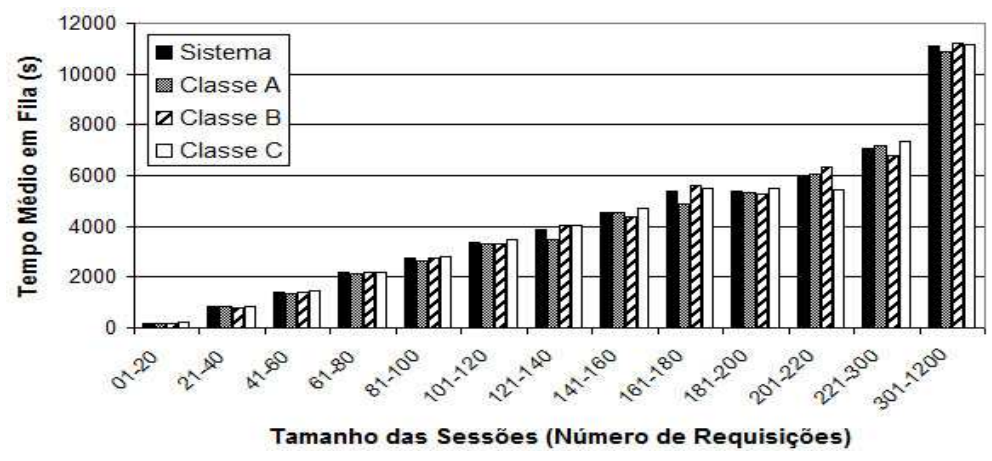

(a) Tempo médio em fila das sessões finalizadas.

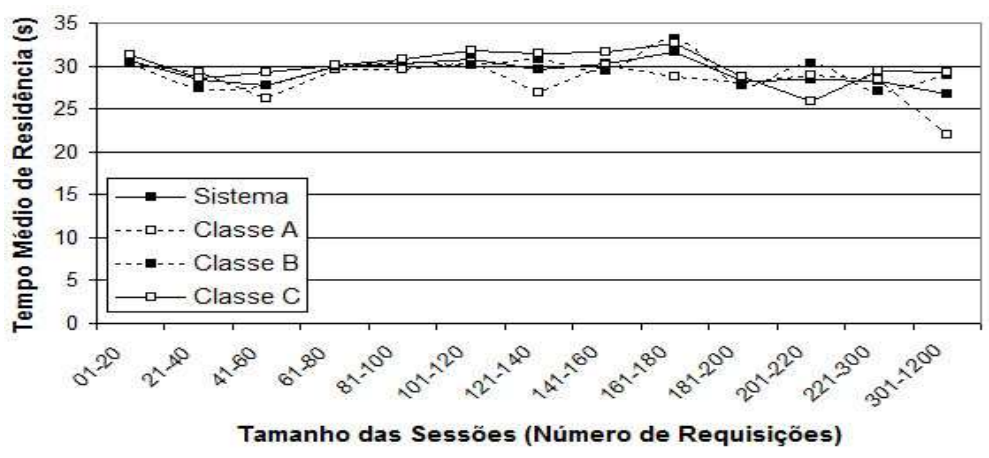

(b) Tempo médio de residência das requisições.

Figura 6.2: Avaliação do sistema - Algoritmo de escalonamento FIFO sem controle de admissão.

Observando os dados dos gráficos da Figura 6.2, verifica-se que não há diferenciação entre as classes de serviços e o tempo em fila das sessões aumentou proporcionalmente ao tamanho das mesmas, como observado no gráfico da Figura 6.2(a). Nota-se ainda, pelo gráfico da Figura 6.2(b), que a falta do controle de admissão fez com que as tarefas do sistema fossem submetidas a elevados tempos de residência, cuja média foi em torno de 30s para requisições pertencentes a qualquer sessão.

Os elevados tempos de residência obtidos na situação apresentada na Figura 6.2, resultantes do grande número de requisições submetidas ao sistema, podem ser reduzidos com o acionamento do controle de admissão. Na Figura 6.3 são apresentados gráficos referentes aos resultados obtidos quando o mecanismo de controle de admissão que limita 
o tamanho da fila é utilizado, juntamente com a política CA-Híb. O mecanismo que limita o tamanho da fila foi escolhido por ser o mais simples e o mais comumente utilizado pelos servidores Web. A política CA-Híb, conforme apresentado na Seção 6.6.1, atende o seu objetivo e oferece um bom desempenho, sem admitir mais requisições além da capacidade do sistema, ao contrário da política CA-BS quando essa é utilizada com o mecanismo que limita o tamanho da fila. Assim como no caso anterior, a diferenciação de serviços não é realizada, uma vez que o algoritmo FIFO é utilizado para o escalonamento das sessões. Os gráficos apresentam o tempo médio em fila das sessões finalizadas e o tempo médio de residência de suas requisições, agrupadas de acordo com o número de requisições que essas sessões possuem.

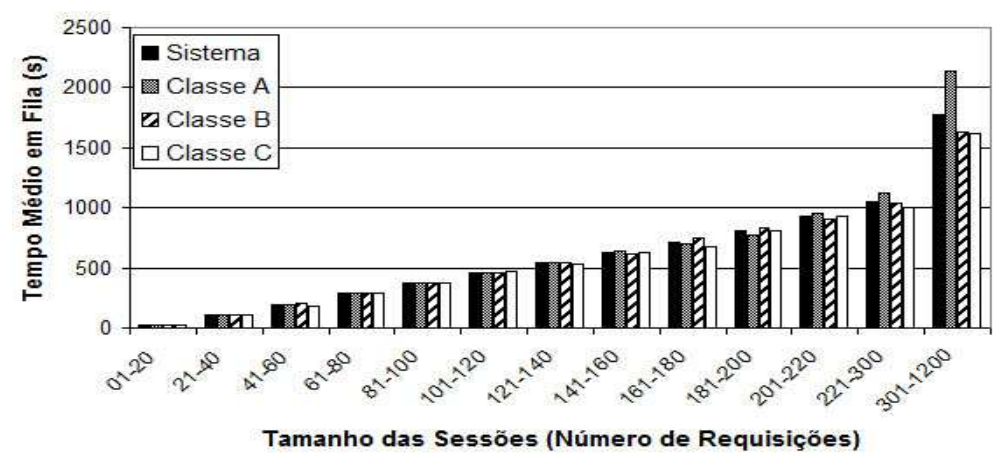

(a) Algoritmo FIFO - tempo médio em fila.

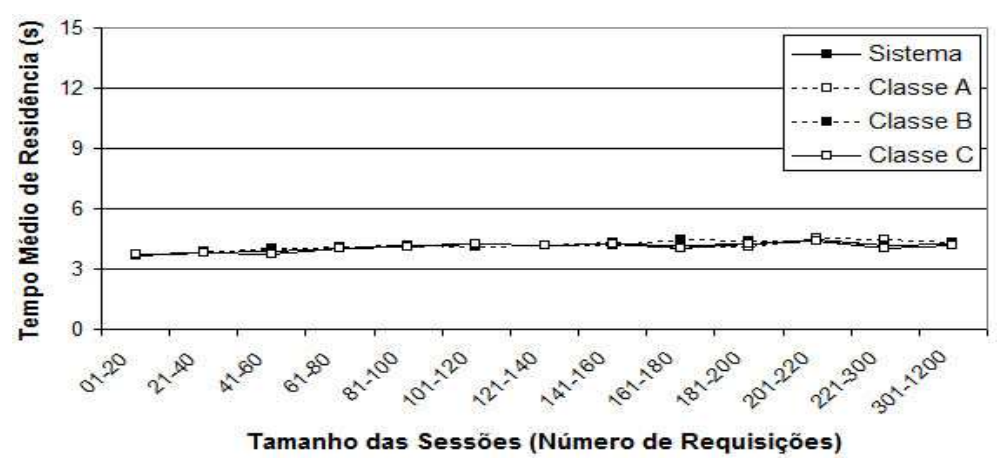

(b) Algoritmo FIFO - tempo médio de residência

Figura 6.3: Avaliação do sistema - Algoritmo de escalonamento FIFO e política CA-Híb.

Analisando os gráficos da Figura 6.3, nota-se que o tempo de residência das requisições não sofreu com a sobrecarga do sistema, dado o uso do controle de admissão. Comparando com os resultados obtidos quando não se fez uso do mecanismo, exibidos na Figura 6.2, os tempos foram reduzidos quase 6 vezes. No entanto, da mesma forma que o caso anterior, a diferenciação de serviços entre as classes consideradas não foi realizada e, analisando somente o gráfico da Figura 6.3(a), observa-se que o tempo em fila gasto pelas 
sessões aumentou a medida que seus tamanhos cresceram.

O fornecimento de serviços diferenciados é obtido com o uso de algoritmos responsáveis em oferecer melhores serviços às classes preferenciais. Os resultados obtidos com o uso de um algoritmo com diferenciação de serviços, juntamente com uma política de controle de admissão, são apresentados na Figura 6.4. O algoritmo de diferenciação utilizado é o SBSA-DS, apresentado na Seção 5.4, e os pesos atribuídos às classes A, B e C são iguais a 3,2 e 1 , respectivamente.

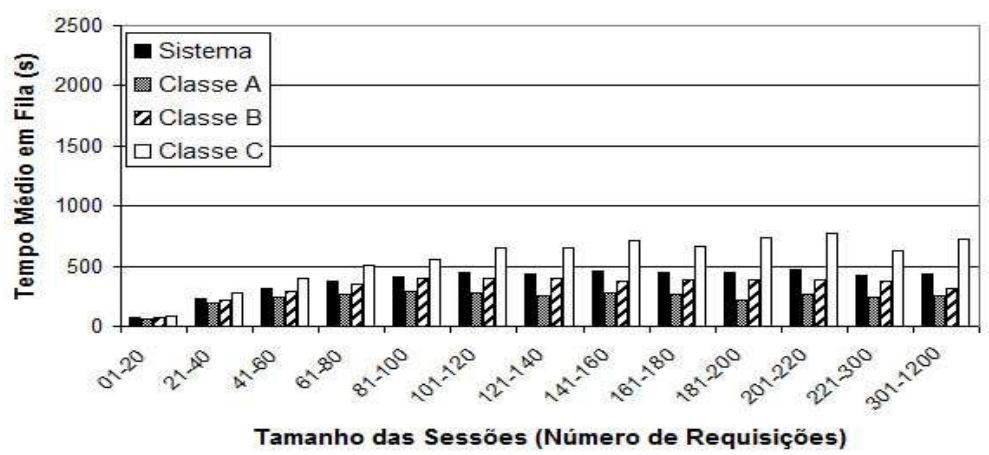

(a) Algoritmo SBSA-DS - tempo médio em fila.

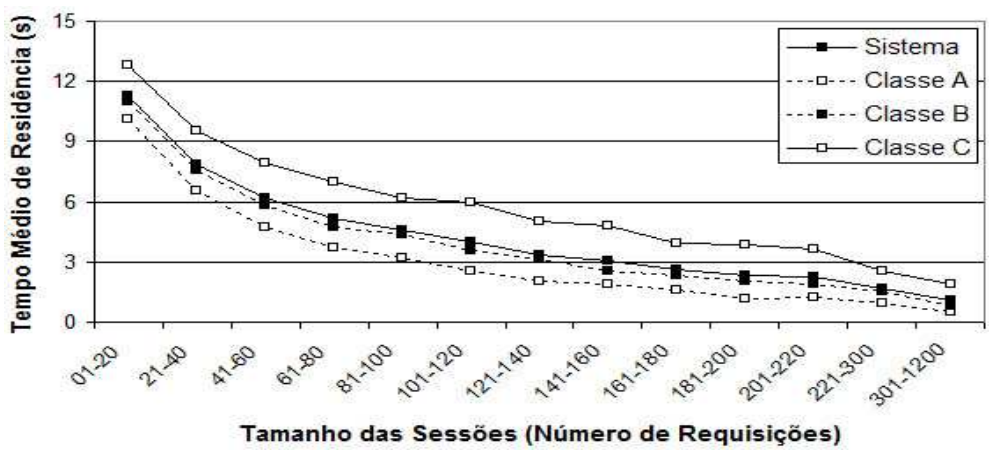

(b) Algoritmo SBSA-DS - tempo médio de residência.

Figura 6.4: Avaliação do sistema - Algoritmo de escalonamento SBSA-DS e política CAHíb.

Comparando os gráficos da Figura 6.4 com os gráficos da Figura 6.2, observase a melhora no desempenho obtido quando o controle de admissão é acionado, fato já verificado no experimento cujos resultados são exibidos na Figura 6.3. Verifica-se que o uso do algoritmo SBSA-DS permitiu que os tempos médios em fila das sessões maiores fossem reduzidos ainda mais. Diferentemente dos casos onde se utilizou o algoritmo de escalonamento FIFO, o algoritmo SBSA-DS também foi capaz de realizar a diferenciação entre as classes de serviços consideradas.

Constata-se, a partir dos resultados apresentados, que o último caso analisado 
está mais apto a oferecer garantias de QoS aos seus clientes, graças ao uso do controle de admissão e do algoritmo de escalonamento prioritário SBSA-DS. Além disso, como a política de controle de admissão e algoritmo de escalonamento prioritário consideram as sessões, melhores serviços são fornecidos às sessões que merecem serviços preferenciais.

\subsection{Considerações Finais}

Esse capítulo tratou sobre as técnicas utilizadas em servidores Web para o controle de admissão de tarefas.

Inicialmente foram discutidos os motivos que levam à utilização de técnicas responsáveis pelo controle de admissão das tarefas, de modo a evitar a sobrecarga do sistema. Para evitar a sobrecarga do servidor deve ser utilizado algum mecanismo que limite a carga do sistema como, por exemplo, limitar o tamanho da fila do servidor ou limitar a utilização dos recursos.

A partir da definição da métrica a ser utilizada para o controle de admissão, isto é, o mecanismo a ser utilizado, o próximo passo está na decisão sobre o que descartar diante da sobrecarga do sistema. Tal escolha é feita pela política de controle de admissão. Neste capítulo foi apresentado um diagrama hierárquico que representa como as políticas de controle de admissão podem ser definidas. A escolha do tipo de política dependerá dos objetivos que o sistema pretende alcançar. Além disso, algumas políticas presentes na literatura foram apresentadas.

Duas novas políticas de controle de admissão foram definidas: a política baseada em sessão CA-BS e a política híbrida CA-Híb. Diferentemente das políticas encontradas comumente nos servidores Web, a política CA-BS preocupa-se em finalizar com sucesso todas as sessões admitidas no sistema. No entanto, dependendo do mecanismo de controle de admissão utilizado, o uso de tal política pode fazer com que a carga do sistema seja superior àquela estabelecida pelo mecanismo, podendo prejudicar o desempenho do sistema. Já a política CA-Híb pondera as vantagens das políticas não baseada em sessão e baseada em sessão, não permitindo que a carga de trabalho submetida ao sistema seja superior ao limite estabelecido pelo mecanismo de controle, rejeitando criteriosamente as tarefas de modo a minimizar o impacto sofrido pelo aborto de sessões ativas no sistema. Os resultados de experimentos considerando as políticas desenvolvidas foram apresentados e confirmaram que os objetivos foram atingidos. 
No final do capítulo experimentos foram realizados utilizando conjuntamente o algoritmo SBSA-DS e a política CA-Híb. A partir dos resultados, verificou-se que o controle de admissão e a diferenciação de serviços, necessárias para a garantia de QoS, foram fornecidos considerando-se sessões, proporcionando melhores serviços para essas tarefas, principalmente aquelas que merecem serviços preferenciais.

O próximo capítulo apresenta as conclusões obtidas com o desenvolvimento deste trabalho e principais contribuições. Também são abordadas propostas de trabalhos futuros relacionados com a avaliação de desempenho de sistemas Web que fazem uso de sessões. 


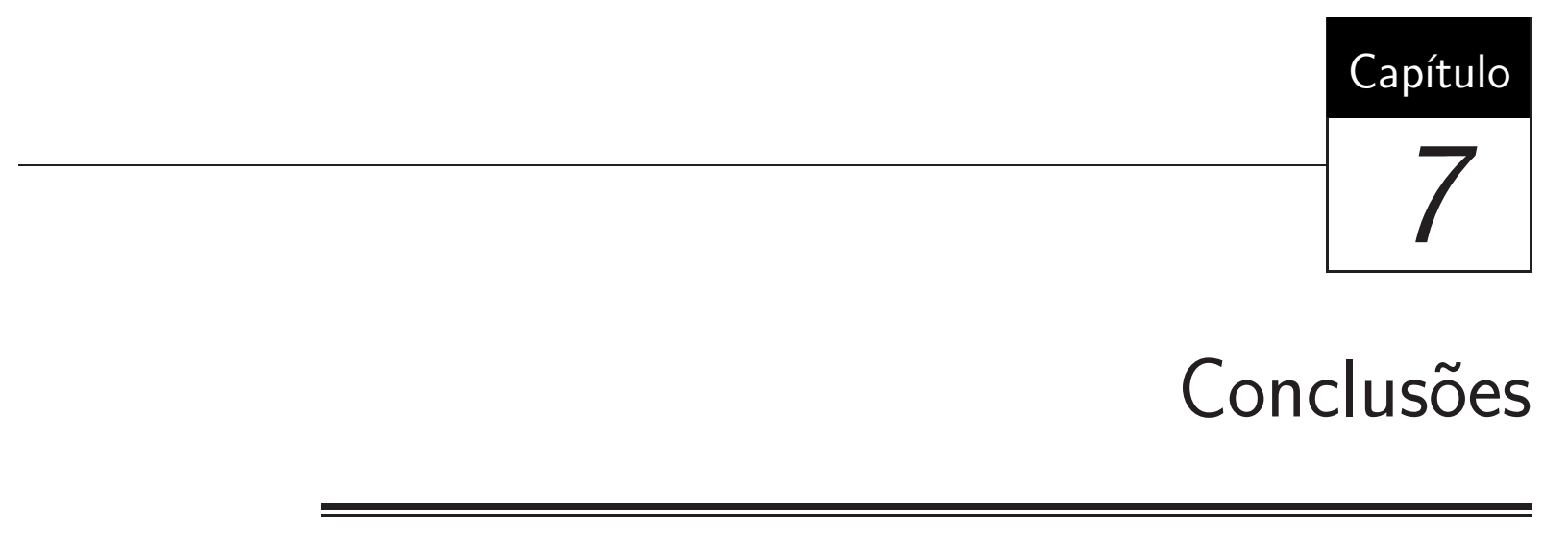

\subsection{Considerações Iniciais}

O objetivo deste trabalho de mestrado é desenvolver políticas para servidores Web com serviços diferenciados considerando sessões, de modo a garantir a QoS oferecida por esses sistemas aos seus usuários. Para tanto, é necessário que sejam desenvolvidos algoritmos de diferenciação de serviços e políticas de controle de admissão que considerem sessões.

O algoritmo de diferenciação de serviços torna-se necessário pois permite que o sistema ofereça diferentes níveis de atendimento aos seus usuários, de acordo com as prioridades atribuídas. A política de controle de admissão restringe o atendimento de tarefas no sistema, de modo a garantir a QoS definida aos usuários durante os períodos de sobrecarga. O uso de sessões para o auxílio na tomada de decisão por tais técnicas torna-se necessário em ambientes que apresentam esse tipo de carga de trabalho, como os sistemas de comércio eletrônico, por exemplo, que fazem uso de sessões para o reconhecimento de seus clientes.

Para alcançar o objetivo deste trabalho, inicialmente fez-se uma revisão geral de estrutura da Internet no Capítulo 2, sendo também apresentados os motivos que levam ao uso de sessões em servidores Web. No Capítulo 3 foram abordados os problemas e limitações do modelo atual de serviços da Internet e a necessidade da introdução de qualidade de serviço na mesma, discutindo também sobre a provisão de um serviço diferenciado em 
nível de aplicação, particularmente nos servidores Web.

No Capítulo 4 foram apresentadas as características do modelo de servidor Web com serviços diferenciados (SWDS) utilizado neste projeto para a avaliação das políticas desenvolvidas, e as modificações feitas no modelo original, necessárias para a realização do controle de sessões. Os algoritmos de escalonamento desenvolvidos de modo a prover melhores serviços para as tarefas prioritárias, isto é, o algoritmo de escalonamento baseado em sessão SBSA e o algoritmo de escalonamento baseado em sessão com diferenciação de serviços SBSA-DS, foram apresentados no Capítulo 5. Para o controle de admissão, foram desenvolvidas duas novas políticas, a política de controle de admissão baseada em sessão CA-BS e a política de controle de admissão híbrida CA-Híb, detalhadas no Capítulo 6.

Neste capítulo são apresentados os principais resultados e contribuições deste trabalho, além dos trabalhos futuros relacionados à área de avaliação de desempenho de servidores Web que fazem uso de sessões e desejam oferecer melhores serviços.

\subsection{Principais Resultados e Contribuições}

Os principais resultados deste trabalho são relacionados a seguir:

1. Revisão Bibliográfica - Uma revisão da bibliografia foi realizada a fim de contextualizar o presente trabalho. Entre as pesquisas realizadas, merece destaque aquelas referentes aos algoritmos de diferenciação de serviços e às políticas de controle de admissão. A partir da análise dos trabalhos relacionados às políticas de controle de admissão, deu-se origem à classificação hierárquica de definição de políticas de controle, apresentada neste trabalho. Essa classificação auxilia na escolha da política de controle de admissão que melhor se ajusta aos objetivos pretendidos pelo sistema.

2. Modificações no modelo SWDS - Algumas modificações no modelo original do SWDS foram realizadas com o objetivo de torná-lo apto para avaliar o desempenho do sistema diante dos novos algoritmos e políticas. Entre as modificações realizadas, destacam-se:

- Controle de sessões. Para geração da carga de trabalho foram utilizados logs de acesso ao site da Copa do Mundo 98, tomando-se como base o modelo de simulação original do SWDS, assim como outros trabalhos desenvolvidos 
no LaSDPC. Como o modelo original não faz uso de sessões, foi necessário realizar algumas modificações para a realização do controle de sessões. Essas modificações consistiram em utilizar um campo de identificação de usuários (clientID), presente no log em questão, assim como um novo parâmetro para limitar o tempo de inatividade da sessão, o timeout. A partir dessas alterações, o SWDS pode aceitar tanto requisições quanto sessões.

- Classificador. Para que a diferenciação de serviços fosse realizada em nível sessão, atribuiu-se a mesma prioridade para todas as requisições pertencentes a mesma sessão.

- Gerenciamento do estado das sessões. Como o sistema em questão tratase de um cluster de servidores Web, para a manutenção do estado das sessões optou-se em direcionar para o mesmo servidor todas as requisições de uma mesma sessão. Tal método, no entanto, pode prejudicar a balanceamento de carga dependendo do algoritmo utilizado. Neste trabalho foi utilizado o algoritmo de balanceamento SQF, que se mostrou adequado às diversas situações analisadas por meio de experimentos.

3. Métricas de Desempenho - Para a avaliação de desempenho dos algoritmos e políticas desenvolvidos, novas métricas de desempenho foram propostas, destacandose:

- Média ponderada do tempo em fila. Tal métrica corresponde à média do tempo em fila gasto pelas sessões finalizadas com sucesso, ponderada pelo tamanho das mesmas. Assim, quando comparadas duas médias ponderadas para as mesmas sessões finalizadas, a média que apresentar menor valor indica que as sessões maiores, isto é, que possuem maior peso para o cálculo da média, tiveram os seus tempos em fila reduzidos. Essa métrica é importante para a análise dos algoritmos de escalonamento desenvolvidos, uma vez que um dos objetivos desses algoritmos é reduzir o tempo em fila das sessões maiores, que devem possuir prioridade no atendimento.

- Quantidade de sessões descartadas e de sessões abortadas. As políticas de controle de admissão efetuam o descarte de tarefas de modo a não sobrecarregar o sistema. Dependendo da política utilizada, a tarefa a ser descartada pode pertencer a alguma sessão ativa no sistema. Quando uma sessão ativa no sistema tem alguma requisição rejeitada, contabiliza-se uma sessão abortada. 
Caso a sessão ainda não esteja ativa no sistema, isto é, nenhuma requisição de tal sessão foi admitida, a requisição descartada refere-se à primeira requisição da sessão e nesse caso contabiliza-se uma sessão descartada. Essas métricas indicam se a política de controle de admissão considerada é ou não baseada em sessão.

- Utilização efetiva dos recursos. Indica a fração do tempo em que os recursos do sistema estiveram ocupados no atendimento de tarefas finalizadas com sucesso. O ideal é que se tenha a utilização efetiva dos recursos igual a 100\%, indicando que durante todo o tempo que os recursos estiveram ocupados foram com sessões que finalizaram com sucesso. Quando a política de controle de admissão realiza o aborto de sessões, tal métrica tem seu valor reduzido, indicando a fração de tempo perdida no atendimento de sessões que não conseguiram completar com sucesso.

4. Algoritmos de Escalonamento - Dois novos algoritmo de escalonamento baseados em sessão foram propostos e implementados com o objetivo de proverem melhores serviços para as tarefas prioritárias de servidores Web que utilizam sessões. Os algoritmos desenvolvidos são descritos a seguir:

- Algoritmo de Escalonamento Baseado em Sessão (SBSA). Estudos mostram que as sessões relativas à venda são maiores que as demais e, portanto, o objetivo do algoritmo SBSA é oferecer melhores serviços às sessões longas, aumentando a prioridade dessas tarefas a medida que a interação com o sistema aumenta. Para tanto, o algoritmo faz uso de uma função que determina quão preferencial uma sessão longa é em relação às demais. Assim, para intensificar ou diminuir a diferenciação entre as sessões, deve-se alterar a função empregada ou algum parâmetro utilizado na mesma. Contudo, o algoritmo SBSA provê melhorias para as sessões longas sem considerar o tipo de usuário.

- Algoritmo de Escalonamento Baseado em Sessão com Diferenciação de Serviços (SBSA-DS). Diferentemente do algoritmo SBSA, o algoritmo SBSA-DS, além de oferecer melhores serviços para as sessões longas, também realiza a diferenciação de serviços entre os diferentes tipos de clientes. O algoritmo SBSA-DS consiste de uma adaptação do algoritmo SBSA. A diferença entre os dois algoritmos está na definição da função a ser empregada. Na definição da função do algoritmo SBSA-DS, também são considerados os pesos atribuídos às diferentes classes de usuários, onde maior ou menor diferenciação 
pode ser obtida variando-se os pesos atribuídos às classes. Dessa forma, o algoritmo SBSA-DS é capaz de realizar de maneira automática a diferenciação de serviços considerando o tamanho das sessões.

5. Políticas de Controle de Admissão - Para o controle de admissão das tarefas em sistemas cuja carga de trabalho é baseada em sessão, duas novas políticas foram definidas:

- Política de Controle de Admissão Baseada em Sessão (CA-BS). Essa política não realiza o aborto de sessões, admitindo todas as requisições relacionadas às sessões já ativas no sistema, permitindo que a utilização efetiva dos recursos seja igual a 100\%. A partir dos experimentos realizados, constatouse que o uso dessa política resulta em uma maior quantidade de finalizações de sessões longas, tornando o seu uso ainda mais viável para os casos onde esse tipo de sessão é prioritária. Contudo, dependendo do mecanismo de controle utilizado, o método empregado pela política CA-BS pode fazer com que a carga submetida aos servidores seja superior àquela suportada, prejudicando o desempenho do sistema.

- Política de Controle de Admissão Híbrida (CA-Híb). Assim como as políticas não baseadas em sessão, a política CA-Híb realiza o descarte das requisições quando o sistema torna-se sobrecarregado, mesmo que tais requisições pertençam a alguma sessão ativa. Como a política CA-Híb não impede o aborto de sessões, a utilização efetiva dos recursos não é 100\%. No entanto, a política híbrida opta em rejeitar as requisições pertencentes às menores sessões ativas, de modo a minimizar a perda do trabalho já desprendido para o atendimento dessas sessões, provocando o aumento da utilização efetiva quando comparada com políticas não baseadas em sessão.

Analisando os resultados descritos, conclui-se que esta dissertação de mestrado atingiu os objetivos propostos, que compreende o desenvolvimento de políticas para servidores Web com serviços diferenciados considerando sessões. Inicialmente foram abordados os tópicos referentes ao reconhecimento e gerenciamento do estado das sessões, fato importante dado a sua influência no balanceamento de carga, podendo comprometer o desempenho do sistema se tais fatores não forem considerados na análise. Os pontos mais relevantes deste trabalho foram os novos algoritmos e políticas desenvolvidas. Este trabalho preocupou-se em desenvolver novas políticas para servidores Web cuja carga de 
trabalho é baseada em sessão, de modo que esses sistemas possam oferecer garantias de QoS aos seus clientes. Assim, o trabalho tratou de algoritmos de diferenciação de serviços e de políticas de controle de admissão que consideram sessões para a tomada de decisão. Os resultados obtidos dos experimentos comprovaram a eficácia dos novos algoritmos e políticas para servidores Web cuja carga de trabalho é baseada em sessão, permitindo a garantia do oferecimento de QoS aos usuários desses sistemas.

A partir de alguns resultados obtidos durante o desenvolvimento desta dissertação, as seguintes publicações foram geradas até a presente data:

Barbato, A. K.; Traldi, O. A.; Santana, R. H. C.; Santana, M. J.; Teixeira, M. M. Algoritmo de Escalonamento para Servidores Web Baseado em Sessão. XII Simpósio Brasileiro de Sistemas Multimídia e Web (WebMedia 2006), Natal, RN, nov., 2006.

Barbato, A. K.; Santana, R. H. C.; Santana, M. J. Oferecendo Garantias de QoS a Servidores Web Baseados em Sessão. XIII Simpósio Brasileiro de Sistemas Multimídia e Web (WebMedia 2007), Gramado, RS, out., 2007.

\subsection{Trabalhos Futuros}

A partir do desenvolvimento deste trabalho, outros podem ser desenvolvidos visando o aprimoramento e/ou as elaborações de novas soluções para a garantia de QoS em servidores Web que consideram sessões. Algumas sugestões para trabalhos futuros são apresentadas a seguir:

- Carga de Trabalho. O estudo de cargas de trabalho reais atualizadas, que apresentem dados das sessões, é importante para a verificação do comportamento dos algoritmos e políticas desenvolvidas, diante dos diferentes perfis de carga. Entretanto, devido às dificuldades na obtenção de tais carga de trabalho, dado o uso comercial pelas empresas e por conterem informações dos usuários, pode-se desenvolver ou incorporar a algum gerador de carga sintética as características das sessões.

- Gerenciamento do Estado das Sessões. Outros métodos podem ser empregados para o gerenciamento do estado das sessões em um cluster de servidores Web, além daquele utilizado neste trabalho que consiste em direcionar para o mesmo servidor todas as requisições pertencentes a uma mesma sessão. Caso o novo método consistir na troca de mensagens entre os servidores, por exemplo, deve-se considerar o impacto do emprego de tal método no desempenho do sistema. 
- Algoritmos de Balanceamento de Carga. Novos algoritmos de balanceamento de carga, que considerem sessões, podem ser desenvolvidos. Nesse caso, é interessante que tais algoritmos estejam integrados ao método de gerenciamento de estado das sessões em questão, de modo a serem mais eficientes.

- Algoritmos de Diferenciação de Serviços. Novos algoritmos de diferenciação de serviços que façam uso de sessões, ou adaptação dos algoritmos existentes, podem ser desenvolvidos.

- Políticas de Controle de Admissão. A definição de uma nova política de controle de admissão que considere os estágios das sessões mostra-se interessante, pois permite um controle mais refinado no processo de admissão ou rejeição de tarefas.

- Avaliação com o mecanismo de negociação. Os algoritmos baseados em sessão, assim como as políticas de controle de admissão desenvolvidas, podem ser analisados juntamente com o mecanismo de negociação do modelo SWDS, não acionado neste trabalho. 


\section{Referências Bibliográficas}

Andreolini, M.; Casalicchio, E.; Colajanni, M.; Mambelli, M. (2004). A cluster-based web system providing differentiated and guaranteed services. Cluster Computing, v.7, n.1, p.7-19.

Arlitt, M. (2000). Characterizing web user sessions. SIGMETRICS Perform. Eval. Rev., v.28, n.2, p.50-63.

Barbato, A. K.; Santana, R. H. C.; Traldi, O. A.; Santana, M. J.; Teixeira, M. A. M. (2005). Avaliação de Políticas de Controle de Admissão para Servidores Web com Serviços Diferenciados. XIII Simpósio Internacional de Iniciação Científica da Universidade de São Paulo (SIICUSP), São Carlos, Brasil.

Berners-Lee, T.; Fielding, R.; Frystyk, H. (1996). Hypertext Transfer Protocol HTTP/1.0. RFC 1945, IETF.

Berners-Lee, T.; R.Cailliau; Luotonen, A.; Nielsen, H. F.; Secret, A. (1994). The worldwide web. Communications of the ACM, v.37, n.8, p.76-82.

Blake, S.; Black, D.; Carlson, M.; Davies, E.; Wang, Z.; Weiss, W. (1998). An Anchitecture for Differentiated Services. RFC 2475, IETF.

Braden, R.; Clark, D.; Shenker, S. (1994). Integrated Services in the Internet Architecture. RFC 1633, IETF.

Braden, R.; Zhang, L.; Berson, S.; Herzog, S.; Jamin, S. (1997). Resource ReSerVation Protocol (RSVP) - Version 1 Functional Specification. RFC 2205, IETF.

Cardellini, V.; Casalicchio, E.; Colajanni, M.; Mambelli, M. (2001). Web switch support for differentiated services. SIGMETRICS Perform. Eval. Rev., v.29, n.2, p.14-19. 
Chen, H.; Mohapatra, P. (2002). Session-based overload control in qos-aware web servers. IEEE INFOCOM 2002.

Chen, H.; Mohapatra, P. (2003). Overload control in qos-aware web servers. Comput. Networks, v.42, n.1, p.119-133.

Chen, X.; Mohapatra, P. (1999). Providing differentiated services from an Internet server. Proceedings of the IEEE International Conference on Computer Communications and Networks, p. 214-217.

Chen, X.; Mohapatra, P.; Chen, H. (2001). An admission control scheme for predictable server response time for web accesses. $W W W$ '01: Proceedings of the tenth international conference on World Wide Web, p. 545-554. ACM Press.

Cherkasova, L.; Phaal, P. (1999). Session Based Admission Control: a Mechanism for Improving Performance of Commercial Web Sites. Proceedings of IEEE/IFIP IWQoS '99.

Cherkasova, L.; Phaal, P. (2002). Session-based admission control: A mechanism for peak load management of commercial web sites. IEEE Trans. Comput., v.51, n.6, p.669-685.

Cisco (1997). Advanced QoS Services for the Intelligent Internet. Cisco Systems Inc. Disponível em http://www.cisco.com/warp/public/cc/cisco/mkt/ios/qos/tech/qos_wp. htm.

Comer, D. E. (2000). Internetworking with TCP/IP: Principles, Protocols and Architecture. Prentice Hall, 4. edição.

Dovrolis, C.; Ramanathan, P. (1999). A case for relative differentiated services and the proportional differentiation model. IEEE Network, v.13, n.5, p.26-34.

Elnikety, S.; Nahum, E.; Tracey, J.; Zwaenepoel, W. (2004). A method for transparent admission control and request scheduling in e-commerce web sites. WWW'04: Proceedings of the 13th international conference on World Wide Web, p. 276-286. ACM Press.

Estrella, J. C. (2005). Mecanismos de Negociação no Módulo de Controle de Admissão na Arquitetura de Servidor Web com Diferenciação de Serviços. Qualificação de mestrado, Instituto de Ciências Matemáticas e de Computação - Universidade de São Paulo.

Estrella, J. C.; Santana, M. J.; Bruschi, S. M.; Teixeira, M. A. M. (2005). Qualidade de Serviço em Servidores Web: Uma nova abordagem utilizando negociação. XI Simpósio Brasileiro de Sistemas Multimídia e Web, Poços de Caldas, MG. 
Estrella, J. C.; Teixeira, M. A. M.; Santana, M. J.; Santana, R. H. C.; Bruschi, S. M. (2006). Negotiation mechanisms on application level: A new approach to improve quality of service in web servers. WCCIA The 2nd International Workshop on Colaborative Computing, Integration and Assurance, p. 255-259. IEEE Proceedings.

Fielding, R.; Gettys, J.; Mogul, J.; Frystyk, H.; Masinter, L.; Leach, P.; Berners-Lee, T. (1999). Hypertext Transfer Protocol - HTTP/1.1. RFC 2616, IETF.

Fishwick, P. A. (2004). SimPackJ: Version 1.0. University of Florida. Disponível em http://www. cise.ufl.edu/ ${ }^{\sim}$ ishwick/simpackj.

IBM (2003). IBM hard disk drives. Disponível em http://www.storage.ibm.com.

Jain, R. (1991). The Art of Computer Systems Performance Analysis - Techniques for Experimental Design, Measurement, Simulation and Modeling. Wiley - Interscience, New York, NY.

Kanodia, V.; Knightly, E. W. (2000). Multi-class latency-bounded web services. Proceedings of the 8th IEEE International Workshop on Quality of Service (IWQoS '00), p. 231-239.

Kristol, D.; Montulli, L. (1997). HTTP State Management Mechanism. RFC 2109, IETF.

Kurose, J. F.; Ross, K. W. (2000). Computer Networking: A top down approach featuring the Internet. Addison Wesley Longman.

Kurose, J. F.; Ross, K. W. (2003). Rede de Computadores e a Internet: Uma Nova Abordagem. Addison Wesley, São Paulo.

Kurose, J. F.; Ross, K. W. (2006). Rede de Computadores e a Internet: uma abordagem top-down. Addison Wesley, São Paulo.

Lee, S. C. M.; Lui, J. C. S.; Yau, D. K. Y. (2002). Admission control and dynamic adaptation for a proportional-delay diffserv-enabled web server. SIGMETRICS '02: Proceedings of the 2002 ACM SIGMETRICS international conference on Measurement and modeling of computer systems, p. 172-182. ACM Press.

Mourão, H. C. B.; Santana, M. J.; Santana, R. H. C.; Barbato, A. K. (2007). Reconhecimento de sessões em um modelo para servidor web com diferenciação de serviços. $V I$ Workshop em Desempenho de Sistemas Computacionais e de Comunicação (WPerformance), p. 1-10. Anais do XXVII Congresso da SBC.

Presti, F. L. (2005). Joint congestion control: routing and media access control optimization via dual decomposition for ad hoc wireless networks. MSWiM '05: Proceedings of the 8th ACM international symposium on Modeling, analysis and simulation of wireless and mobile systems, p. 298-306, New York, NY, USA. ACM. 
Serra, A.; Cardoso, K.; Barroso, G.; Ramos, R. (2005). Controle de Admissão e Diferenciação de Serviços em Clusters de Servidores Web. XXIII Simpósio Brasileiro de Redes de Computadores (SBRC), Fortaleza, CE.

Shenker, S.; Partridge, C.; Guerin, R. (1997). Specification of Guaranteed Quality of Service. RFC 2212, IETF.

Sit, Y.-F.; Wang, C.-L.; Lau, F. (2004). Cyclone: A high-performance cluster-based web server with socket cloning. Cluster Computing, v.7, n.1, p.21-37.

Stardust (1999a). White Paper - QoS protocols \& architectures. Disponível em http: //www. qosforum. com.

Stardust (1999b). White Paper — The need for QoS. Disponível em http: //www . qosforum . com.

Tanenbaum, A. S. (2002). Computer Networks. Prentice Hall, 4. edição.

Teixeira, M. A. M. (2004). Suporte a Serviços Diferenciados em Servidores Web: Modelos e Algoritmos. Tese de doutorado, Instituto de Ciências Matemáticas e de Computação - Universidade de São Paulo.

Teixeira, M. A. M.; Santana, M. J.; Santana, R. H. C. (2005). Servidor Web com Diferenciação de Serviços: Fornecendo QoS para os Serviços da Internet. XXIII Simpósio Brasileiro de Redes de Computadores (SBRC), Fortaleza, CE.

Traldi, O. A.; Barbato, A. K.; Santana, R. H. C.; Santana, M. J.; Teixeira, M. A. M. (2006). Service differentiating algorithms for qos-enabled web servers. WebMedia '06: Proceedings of the 12th Brazilian symposium on Multimedia and the web, p. 263-272, New York, NY, USA. ACM Press.

Vasiliou, N.; Lutfiyya, H. (2000). Providing a differentiated quality of service in a World Wide Web server. ACM SIGMETRICS Performance Evaluation Review, v.28, n.2, p.22-28.

W3C (1999). HTML 4.01 specification. Disponível em http://www.w3c.org/TR/html4.

Wang, Q.; Makaroff, D. J.; Edwards, H. K. (2004). Characterizing customer groups for an e-commerce website. EC '04: Proceedings of the 5th ACM conference on Electronic commerce, p. 218-227, New York, NY, USA. ACM Press.

Welsh, M.; Culler, D. (2003). Adaptive overload control for busy internet servers. 4th USENIX Symposium on Internet Technologies and Systems (USITS '03).

Wroclawski, J. (1997). Specification of the Controlled-Load Network Element Service. RFC 2211, IETF.

Ye, N.; Gel, E. S.; Li, X.; Farley, T.; Lai, Y.-C. (2005). Web server qos models: applying scheduling rules from production planning. Comput. Oper. Res., v.32, n.5, p.1147-1164. 
Zhu, H.; Tang, H.; Yang, T. (2001). Demand-driven service differentiation in cluster-based network servers. Proceedings of IEEE INFOCOM, p. 679-688.

Zilber, J.; Amit, O.; Talby, D. (2005). What is worth learning from parallel workloads?: a user and session based analysis. ICS '05: Proceedings of the 19th annual international conference on Supercomputing, p. 377-386, New York, NY, USA. ACM Press. 